\title{
Cost Effective Manufacturing of the SEA 10X Concentrator Array
}

\section{Final Subcontract Report 9 January 1991 - April 1991}

N. Kaminar, J. McEntee, and D. Curchod Solar Engineering Application Corporation San Jose, California

NREL Technical Monitor: R. Mitchell

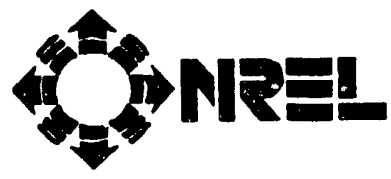

National Renewable Energy Laboratory (formerly the Solar Energy Research Institute) 1617 Cole Boulevard Golden, Colorado 80401-3393

A Division of Midwest Research Institute Operated for the U.S. Department of Energy under Contract No. DE-AC02-83CH10093

Prepared under S: bcontract No. XC-1-10057-21

November 1991

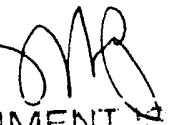




\section{On September 16, 1991, the Solar Energy Research Institute was designated a natlonal laboratory, and lis name was changed to the Natlonal Renewable Energy Laboratory.}

This publication was reproduced from the best available camera-ready copy submitted by the subcontractor and received no editorial review at NREL.

\section{NOTICE}

This report was prepared as an account of work sponsored by an agency of the United States government. Neither the United State!s government nor any agency thereof, nor any of their employees, makes any warranty, express or implied. or assumes any legal liability or responsibility for the accuracy, completeness, or usefulness of any information, apparatus, product, or process disclosed, or represents that its use would not infringe privately owned rights. Reference herein to any specific commercial product. process, or service by trade name, trademark. manufacturer, or otherwise does not necessarily constitute or imply its endorsement, recommendation, or favoring by the United States government or any agency thereof. The views and opinions of authors expressed herein do not necessarily state or reflect those of the United States government or any agency thereot.

\section{Printed in the United States of America \\ Available from:}

National Technical Information Service

U.S. Department of Commerce

5285 Port Royal Road

Springfield, VA 22161

Price: Microfiche A01 Printed Copy A06

Codes are used for pricing all publications. The code is determined by the number of pages in the publication. Information pertaining to the pricing codes can be found in the current issue of the following publications which are generally available in most libraries: Energy Research Abstracts (ERA); Government Reports Announcements and Index (GRA and I): Scientific and Technical Abstract Reports (STAR); and publication NTIS-PR-360 available from NTIS at the above address. 


\section{Table of Contents}

\begin{tabular}{|c|c|c|}
\hline 1 & Introduction & Page \\
\hline 2 & General Description of the SEA $10 \mathrm{X}$ Concentrator Array & \\
\hline 3 & Description of Manufacturing Procedure & \\
\hline 4 & Costs & \\
\hline 5 & Improvements in the Manufacturing Process & \\
\hline 6 & Impediments to Improvements & \\
\hline 7 & Solutions to Impediments & \\
\hline 8 & Time and Cost Estimates & \\
\hline & Summary/Conclusions/Recommendations & \\
\hline 10 & Appendices & \\
\hline
\end{tabular}




\section{$1 \quad$ Introduction}

This report describes changes to the present SEA 10X concentrator manufacturing techniques that will allow production at a selling price of seventy one cents per Watt output and that will produce $A_{2} C$ bus bar electricity at four cents per kilowatt-hour. This report describes the present production techniques, changes required to improve these techniques, impediments to the changes, and solutions to the impediments.

This report was written under subcontract XC-1-10057-21 for the Solar Energy Research Institute in Golden Colorado as part of the "Photovoltaic Manufacturing Technology - Phase I" program.

The SEA 10X concentrator system was conceived as a low cost, mass producible product. It differs from other PV systems in a number of important ways: It was designed from the inception as a commercial product using cost effective, currently available components and manufacturing processes. It uses standard, "one-sun" solar cells in conjunction with an inexpensive plastic lens to generate approximately eight times the amount of electricity that would normally be produced by these cells. Production costs have been minimized through the use of simple design with a minimum number of parts and manufacturing steps.

SEA is presently engaged in development of a $10 \mathrm{X}$ concentrator and has limited manufacturing capability. We plan to add more manufacturing capability, in stages, reaching a production rate of $100 \mathrm{MW} /$ year by the end of 1995 . 


\section{General Description of SEA 10X Concentrator Array}

The SEA 10X concentrator, shown in figure 1, consists of an extruded linear focus Fresnel lens which focuses on a string of one-sun cells. The cells are bonded to an aluminum heat sink with an electrically insulating adhesive. The anodization and adhesive provide the necessary electrical standoff. The module sides are planned to be extruded along with the lens. They are made reflective over their entire internal surface by a thin aluminum film which acts as a secondary optical element, providing improved on- and off-track performance. End caps with molded-in bearing shafts complete the module assembly. Tracking is along a single axis in the easi-west direction. Because of the wide acceptance angle, only a simple, low precision tracker drive is needed. The arrays are shipped completely assembled and require only setting on the ground, driving four stakes, and connecting the wires.

\section{One-Sun Cells}

The SEA 10X concentrator 'ses inexpensive and readily available one-sun cells which are more cost-effective than concentrator cells at the present time.

\section{Extruded Lens and Housing Sides}

The lens and housing sides are made by the least expensive manufacturing method: linear extrusion. The SEA extruded lens is about one third the cost of our nearest competitor. When the lens and sides are combined in a single extrusion, they will provide optics, structural support and environmental protection all in one part. The inside surfaces of the housing sides are made reflective to act as a secondary optical element to improve on- and off-axis performance at very little additional cost. The design-allowable tracking error of this optical system is $\pm 4^{\circ}$.

\section{Anodized Sheet Aluminum Heat Sink}

The heat sink is formed from inexpensive sheet stock and requires no separate fasteners for attachment to the acrylic housing. A heat sink made from sheet aluminum is less expensive than one made from extruded aluminum because less material is used and the material costs less per pound. The necessary electrical isulation is provided by the combination of the anodization and the adhesive used to bond the cells, leads and bypass diodes to the heat sink.

\section{Molded Plastic End Caps}

Injection molded plastic end caps are attached to the ends of the module. These parts include molded in tracker bearing shafts and venturi-type aspirators. They are adhesive bonded to the ends of the lens/housing extrusion to complete the module assembly. The end caps are designed to be made by an inexpensive, twopart, single-cavity mold. 
Figure 1, SEA 10X Concentrator Module

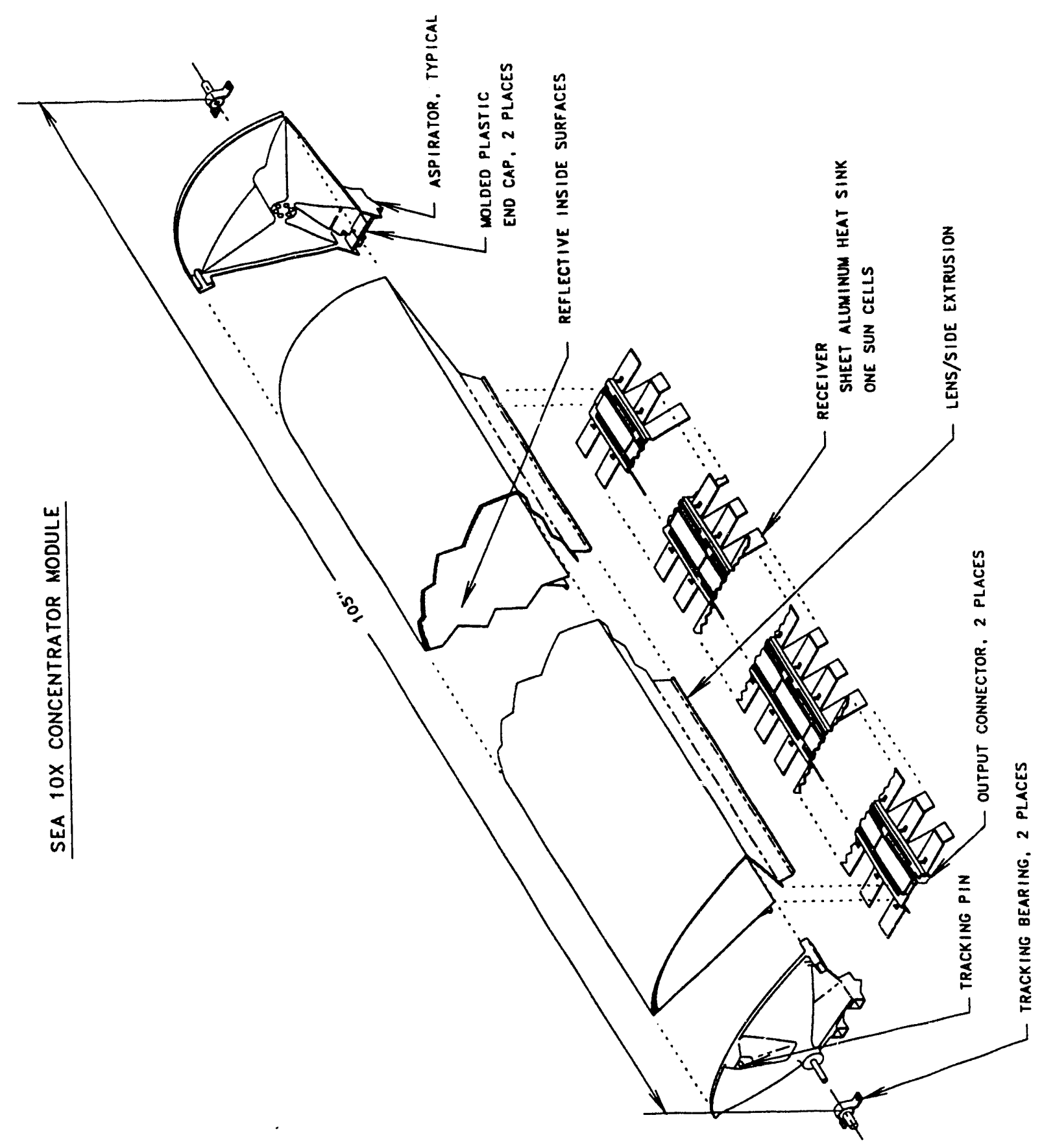


Receiver Assembly

Cell interconnection is provided by flexible stamped copper cell leads which are soldered to the cells and adhesive bonded to the heat sink along with the cells and bypass diodes. The diodes have similar flexible stamped copper leads. The waterproof output connectors snap assemble to the heat sink. All electrically active elements of the receiver are encapsulated for moisture protection. The receiver is a complete assembly which can be tested independently of the rest of the module.

\section{Single Axis Tracking Array}

Arrays of 10 modules are supported in a stationary rectangular steel frame as shown in figure 2. The array frame is inclined according to the local latitude and the modules track east to west. Simple, single axis tracking, and a wide acceptance angle, minimize tracking hardware and simply the support structure.

The $1 \mathrm{KW}$ SEA 10X concentrator array is designed for low cost installation. The arrays are anchored with four stakes. The arrays are designed to be linked in series end to end to produce the desired voltage. Features for electrical connection are provided so that separate power cables are not required. Up to four arrays can be driven by one common tracking drive.

Nominal Array Specifications:

$\begin{array}{lll}\text { DC Peak Power Output: } & 1 & \text { KW } \\ \text { Voltage : } & 16.0 & \text { Volts } \\ \text { Current: } & 62.5 & \text { Amps } \\ \text { Efficiency: } & 13 & \% \\ \text { Aperture Area: } & 7.74 & \mathrm{~m}^{2}(10 \text { foot modules })\end{array}$




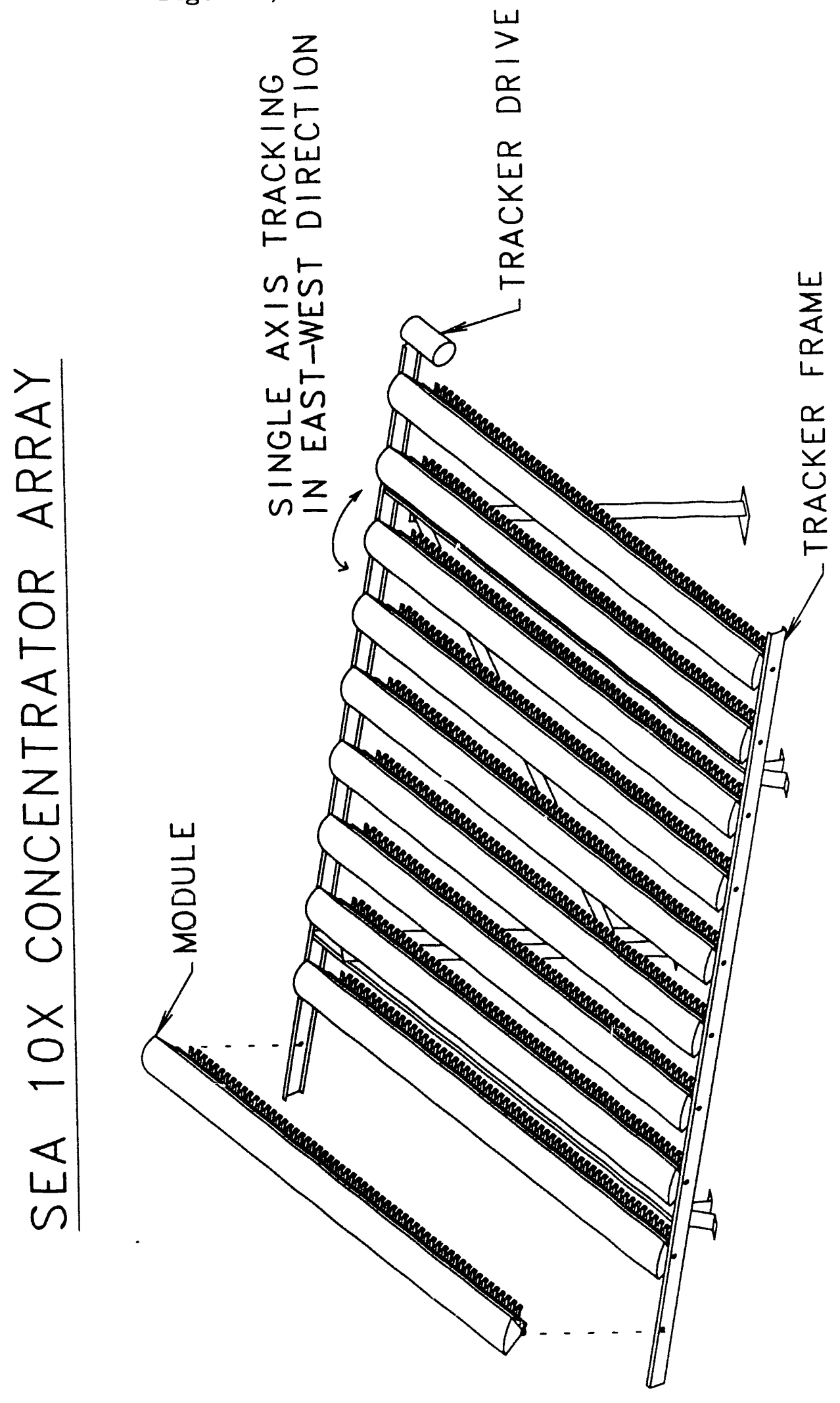

Figure 2, SEA 10X Concentrator Array 


\section{Description of Manufacturing Procedure}

This section describes the manufacturing process currently in place for the SEA 10X Concentrating Array. Chart 1, below, shows the "Bill of Materials Structure" for the module.

Modules consist of two basic sub-assemblies, a housing assembly and a receiver assembly, which are mechanically joined by crimping the tabs on the receiver heat sink. The housing assembly is assembled from the lens/side extrusion and the two end caps. The receiver assembly is electrically complete with cells, leads, bypass diodes and output connectors. The joining of the housing and receiver is the last step in the module assembly process. The modules are tested prior to array assembly.

An array is assembled from 10 concentrator modules and associated hardware in an environmentally protected, formed, steel frame. The modules are brought to the array assembly area, bearings are added and they are inserted by hand into the frame. Self tapping screws are used to secure the frame elements and module bearings. Adding the wiring completes the array. The arrays are tested and then stored, with legs folded, ready for shipment.

\subsection{Lens/ Side Extrusion}

The Lens/Side Extrusion is planned to be formed in one piece. It consists of the lens, the side pieces and the attachment flanges, see figure 3 . The extrusion is cut to length and then bonded to the end caps to form the Lens/Housing subassembly. Finally, it is mechanically fastened to the receiver.

The present fabrication technique is to form the lens and sides in separate pieces and then to bond them together, see figure 4 . The attachment flanges are presently extruded from polycarbonate for strength. The side pieces are formed from sheet acrylic. All the parts are held in position in a fixture and then bonded using a solvent adhesive.

The reflective film is added to the inside surface of the housing sides. The present manufacturing technique is to apply an aluminized polyester film to the inside surfaces using a pressure sensitive adhesive and a roller. 
Chart 1, SEA 10X Bill of Material Structure

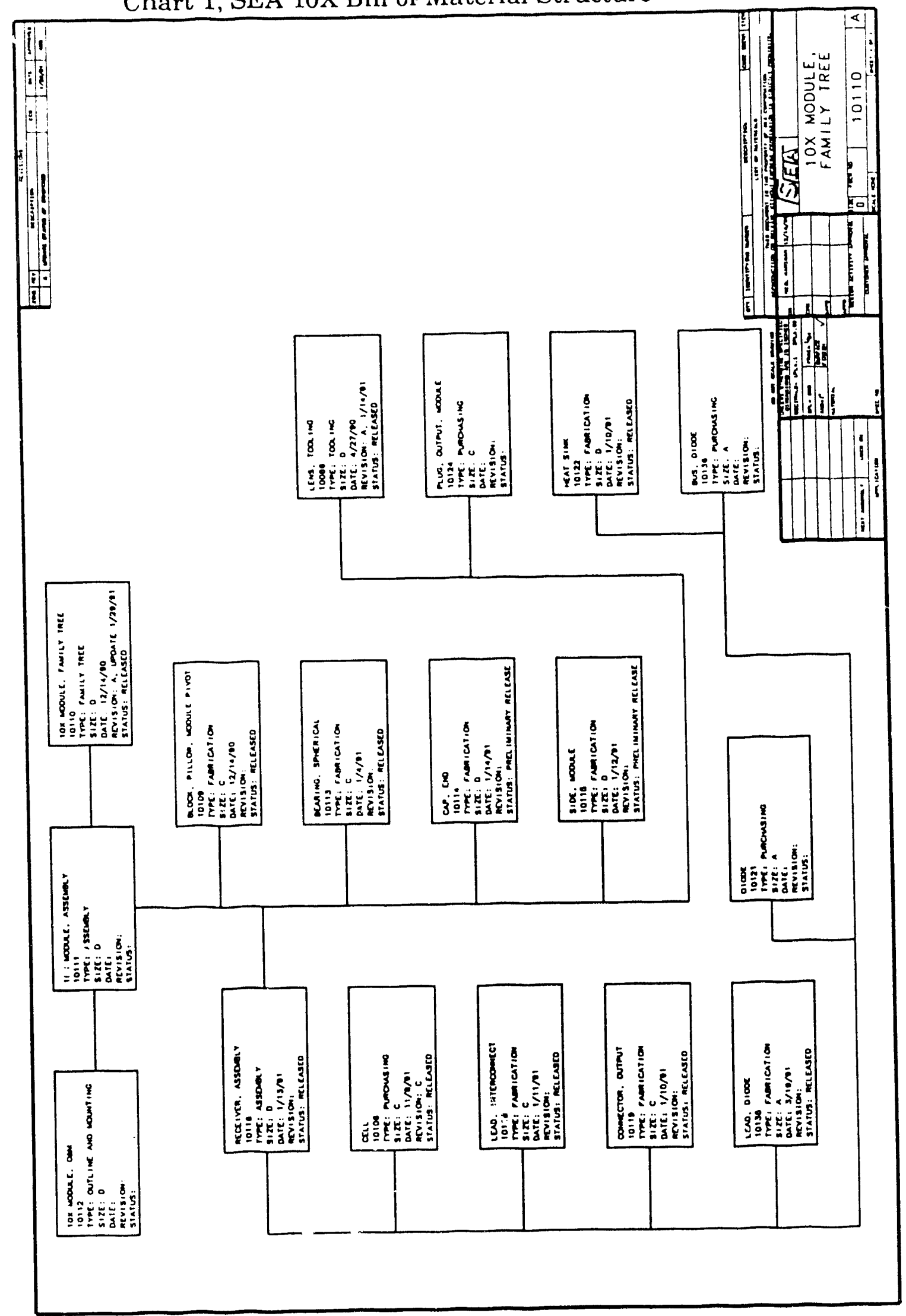

Page 9 
Figure 3, Lens/Side Extrusion

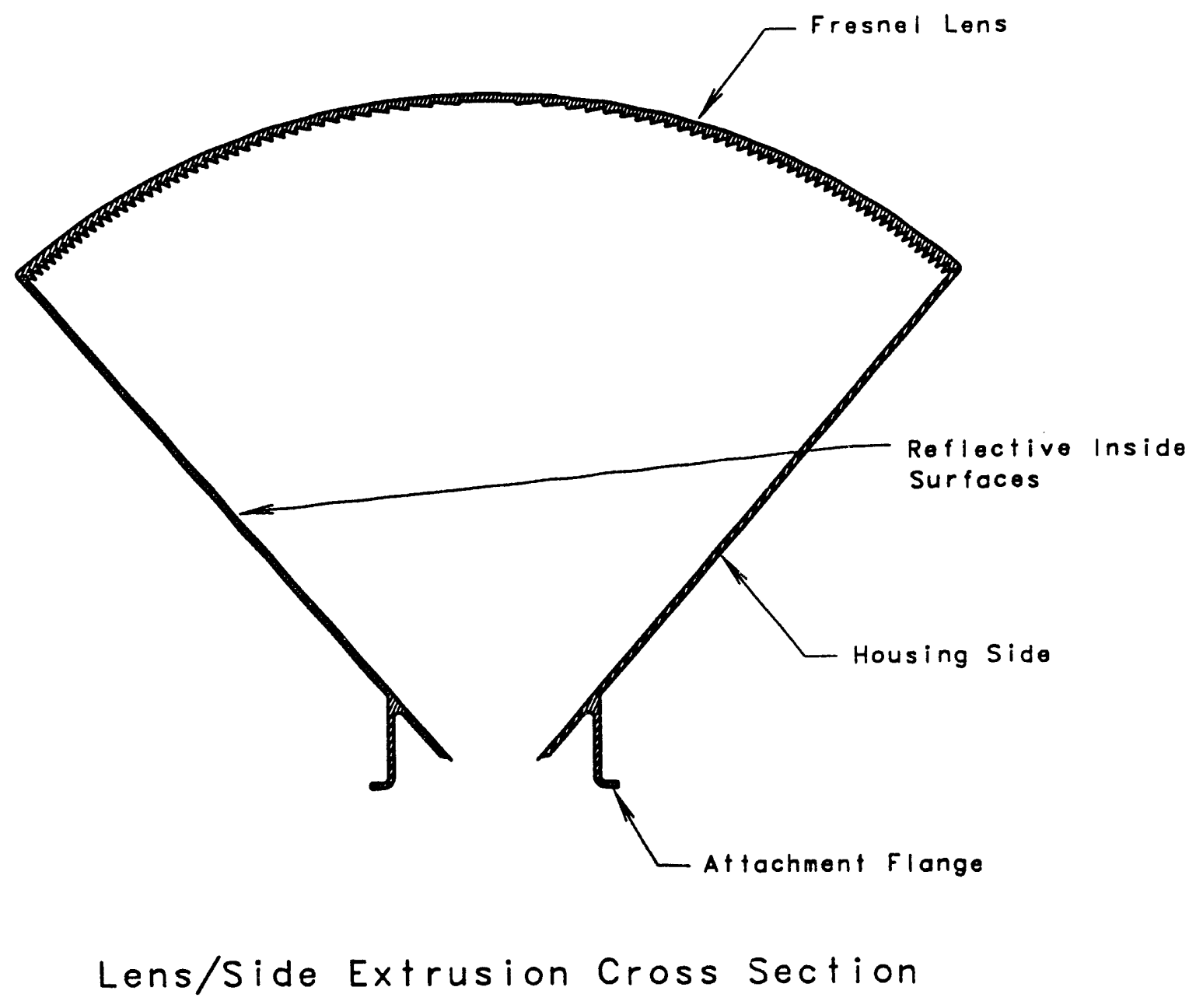

Page 10 
Figure 4, Prototype Lens/Side Assembly

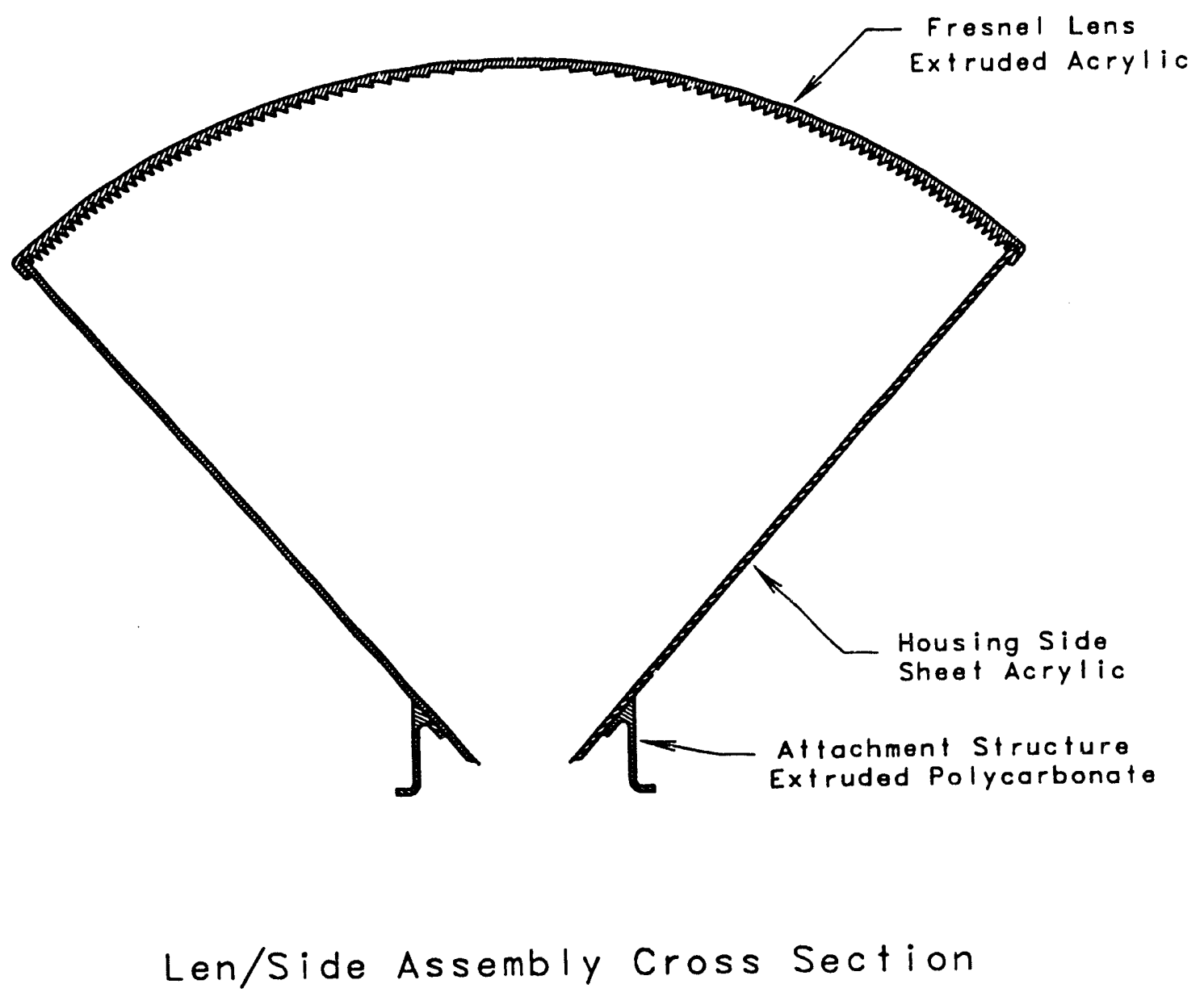

Page 11 


\subsubsection{Extruded Lens}

The lens extrusion has been in development at SEA corporation under DOE contract for several years. The efficiency of the lens has continually increased and now exceeds $78 \%$. An efficiency of $85 \%$ is expected by the end of 1991 .

SEA now has in place, through a sub-contractor, the tooling and the know-how necessary to produce prototype extruded Fresnel lenses for the 10X concentrator. These lenses are 10 inches across and prototype lenses are extruded at the rate of 34 linear inches a minute. (Higher extrusion rates are used in production.) Once the extrusion process is started, and all the process parameters are optimized, each machine is run 24 hours a day, 7 days a week. Within one week, approximately $3,500 \mathrm{~m}^{2}$ of lenses are produced per extrusion machine. At a production schedule of 50 weeks per year, over $175,000 \mathrm{~m}^{2}$ of lenses are produced per year, per machine. At an insolation of $850 \mathrm{~W} / \mathrm{m}^{2}$ and a module efficiency of $15 \%$, this equates to over $22 \mathrm{MW} / \mathrm{yr}$ capability from each machine. Additional capacity can be simply and inexpensively added by cutting additional dies and installing them on additional extrusion machines.

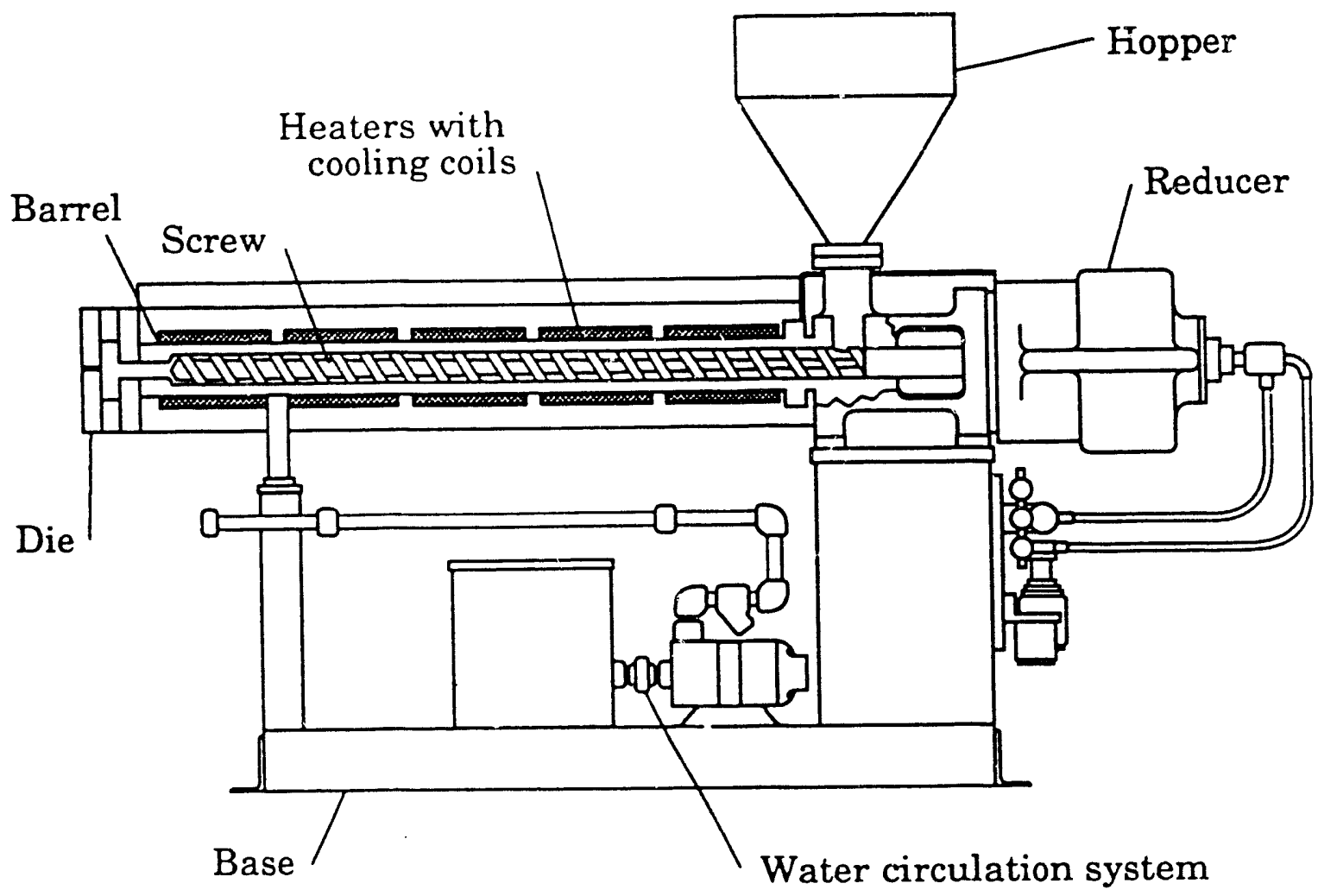

Figure 5, Extrusion Machine 


\section{Extrusion Process}

The extrusion process is simple in concept. Plastic pellets are fed from a hopper to a spiral steel screw similar in design to those used in food grinders, see figure 5. The screw is housed in a barrel which contains electrical heating units which assist in melting the plastic. The friction of the material going through the screw provides a significant portion of the heating. The screw mixes and pressurizes the plastic and forces it through a die to produce the desired shape. The extruded part comes off the machine where it is cooled by air or water and cut to length. The part is quite soft as it comes out of the die and plates or metal fingers are used to control the part shape as it cools and shrinks. A tractor-type drive or wheel-type drive is used to pull the part out of the die.

A number of parameters are controlled to maintain the correct part size and form. Raw material dryness is an important parameter for acrylic extrusions where clarity is desired. The plastic pellets are dried for hours before use by a regenerative-type desiccant bed drier. The screw rate, the temperature and the pressure are all controlled. Cooling rates are controlled by variable flow air jets. The rate of the tractor drive is also controlled. Once all the various parameters are optimized, the machine is left running 24 hours a day until the job is completed.

For the lenses now being manufactured, an extrusion machine with a 3.5 inch diameter screw and a screw length to diameter ratio, $L / D$, of $24: 1$ is used. The plastic pellets are dried for 8 hours before use. The correct lens radius is maintained during the cooling by a series $c$ ? plates.

$\underline{\text { Die }}$

The die is cut using wire electrical discharge machining, EDM. The shape of the die is different from the designed shape to account for shrinkage and distortion of the material as it exits the die. This is basically a cut and try process and many modifications to dies and new dies are needed before the required lens shape is obtained. Once the correct die shape is obtained, and the extrusion parameters are determined, the process is very stable and repeatable. The EDM program used to cut the die is saved, and once the final die configuration is determined, exact copies can be easily and inexpensively made, adding to production c $x$ pability.

\section{Material}

The acrylic used for extruded lenses must have several important properties: It must be an extrusion grade. It must have good optical transmission qualities over the desired spectrum. It must be weather resistant, especially maintaining clarity with long exposure to ultraviolet radiation. It must also have impact strength to withstand hail stones and stresses during handling. The material used for the lens is Rohm \& Haas VO-45 impact modified extrusion grade acrylic.

The present lens extrusion contains features designed to capture the side panels. These features will be removed for a one-piece Lens/Side extrusion. 


\subsubsection{Module Sides}

The mounting flange on the module sides are ultimately joined with the receiver by a series of crimped tabs formed with the receiver heat sink. This joining process puts stress on the mounting flange. Additional stress is applied to this joint during temperature extremes due to differential thermal expansion. To resist this stress, the flange are extruded from polycarbonate, which is less brittle than acrylic. The mounting flanges are bonded to the acrylic sides using a fixture as described previously.

\subsection{End Caps}

The End Caps are designed to be molded with a simple two piece injection mold. They are angled at $25^{\circ}$ to allow for the $\pm 23.44^{\circ}$ seasonal change in the sun's apparent declination angle. Venturi aspirators, a tracking pin locating hole, a pivot pin locating hole and stiffening features have been incorporated into the part to reduce the module cost. The end caps are designed to eliminate the tracking arm that was previousily required. The pivot pin and tracking pin are bonded into the locating holes on the End Cap molding prior to module assembly.

\subsection{Receiver}

The receiver contains a string of 32 one-sun PV cells mounted on the heat sink. The cells are provided with series interconnections and 3 bypass circuits. Cell attachment is accomplished by a thin layer of flexible adhesive. A series of heat fins on the heat sink provide cooling to the cell string.

Positive and negative connectors are provided on opposite ends of the receiver assembly. Because the receiver sub-assembly contains all electrical components and interconnection, a complete functional electrical test is possible at the receiver sub-assembly level, prior to final assembly of the module. This allows less irivestment in the testable assembly and reduces loss should the assembly fail.

\subsubsection{Aluminum Heat Sink}

The Heat Sink is a formed sheet metal structure which provides mechanical support and cooling for the cells, see figure 6. It incorporates fastening features for joining to the Lens/Housing sub-assembly. In addition, it completes the module structure to create a torsionally rigid assembly. 
Figure 6, Sheet Aluminum Heat Sink

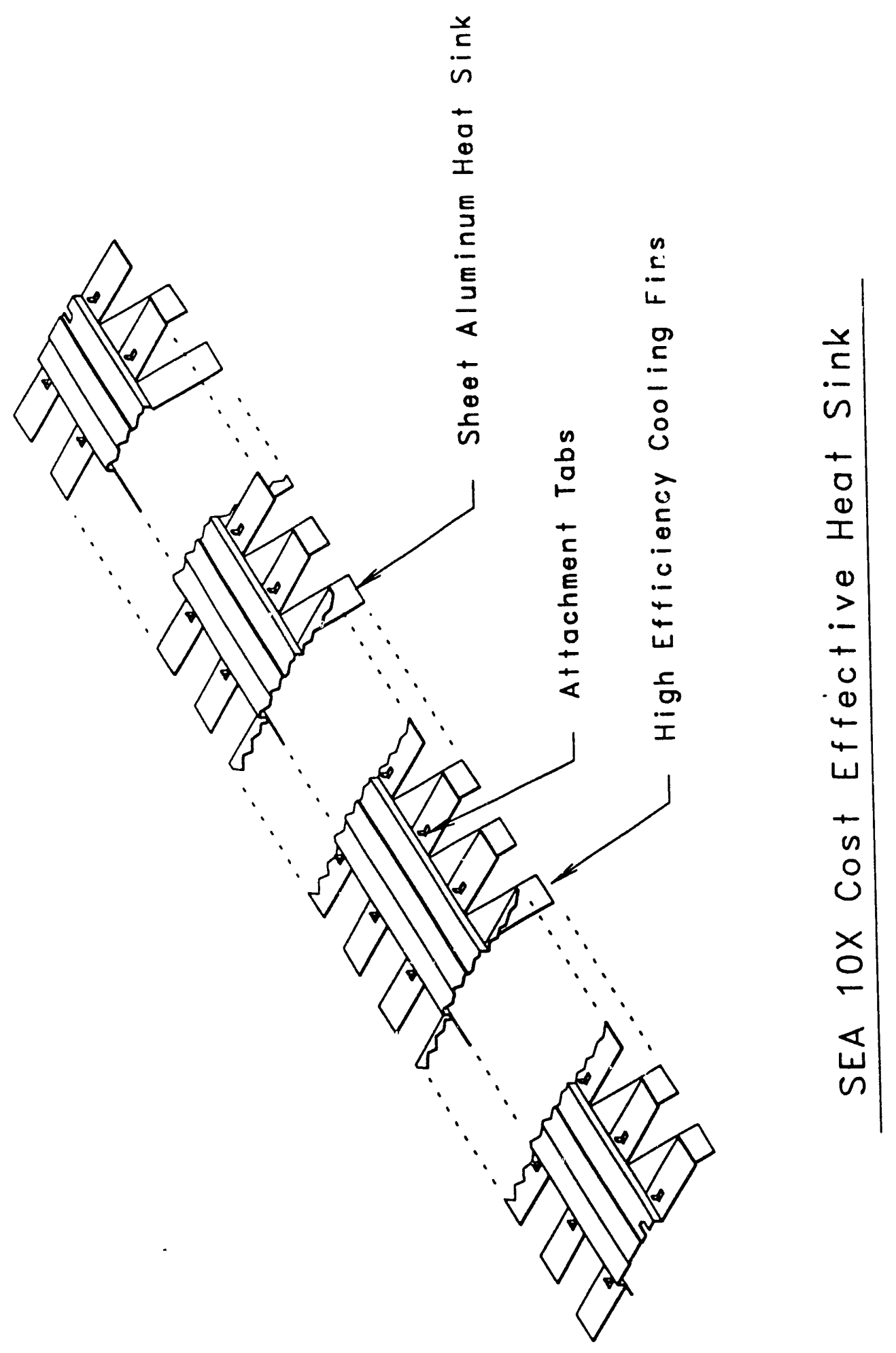

Page 15 
The heat sink fins are a series of one-inch wide tabs which are alternately bent to $45^{\circ}$ angle from the cell plane. This improves the heat transfer to the air by keeping the boundary layer thickness small. The heat sink design has been costoptimized using a finite element heat transfer computer program.

The heat sink is currently formed from aluminum sheet on a numerically controlled punch machine and break. It is then anodized (Type III) to a minimum thickness of .001 inches.

\subsubsection{Cells and Diodes}

\section{One-Sun Cells}

The SEA 10X concentrator is designed to use one-sun cells from a number of different manufacturers. At the present time, one-sun cells are more costeffective than concentrator cells. Recent tests at SEA and Sandia National Laboratories have shown that one-sun cell technology can be used at low concentration. SEA will benefit from efforts to improve one-sun cell technology but some additional research and development, specific to low concentration applications, is necessary.

One-sun cell production is relatively mature. It has developed over the years to obtain low cost manufacturing techniques. Different manufacturers employ different methods to obtain single or polycrystalline wafers. Most manufacturers use sawn Cycholski wafers but ribbon technology is possible. Sliced, cast poiycrystalline wafers are also used. Other sources show promise. AstroPower is developing a re-melted, crushed silicon on ceramic substrate process. A standard gaseous phosphorus diffusion is used to create the junction. All one-sun cells, now in commercial production, use a screen-printed grid line metalization on the front and solid screen-printed metalization on the back.

Concentrator cells now available are typically specialty items, requiring expensive material, expensive evaporated metalization and other expensive special processing. Prices range from 10 to 1000 times the per area cost of one-sun cells.

Recent tests have shown that screen-printed, one-sun cells can be used at low concentration. Figure 7 shows a polycrystalline silicon cell, manufactured by AstroPower, with a screen-printed grid line that was specifically designed for the SEA 10X concentrator. This cell was made using their standard one-sun manufacturing line techniques. A screen mask was used to generate a grid line pattern optimized for $600 \mathrm{~mW} / \mathrm{cm}^{2}$, AM 1.5, (6 suns). The best fill factor of these cells, measured at AstroPower under 4.7 suns illumination was $81.2 \%$, which is an excellent fill factor for a screen printed cell under concentration. The maximum measured efficiency for these cells to date is $14.74 \%$ at 4.95 suns. AstroPower has projected an efficiency of $17 \%$ for their one-sun cells by middecade. 
Figure 7, One-Sun Cell Used at 10X

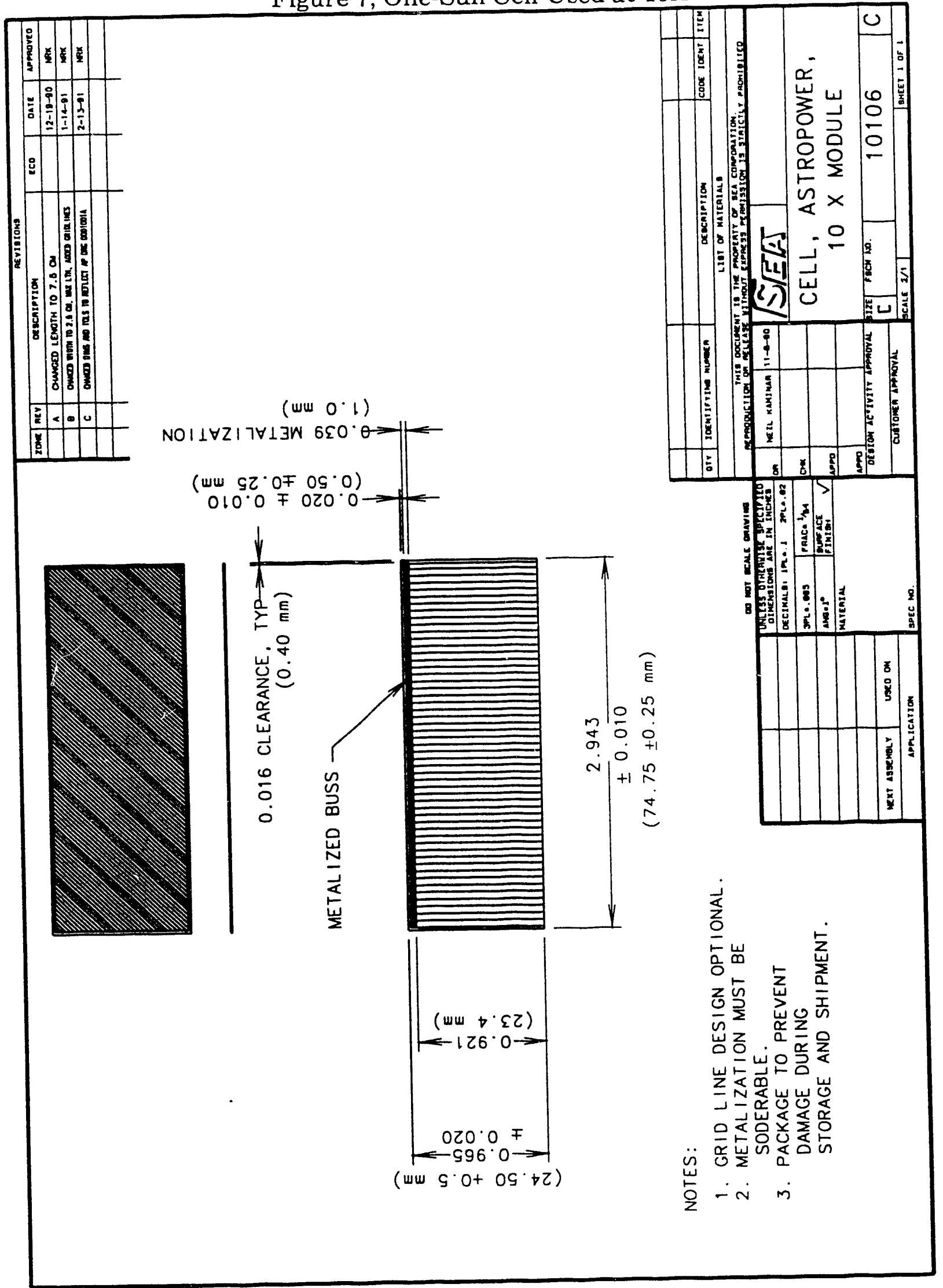


Laser-groove cells are being developed by Solarex and others as an alternative to screen-printed cells for use at low concentration. Vertical grooves are formed in the surface of the silicon using a laser. These grooves are electroless plated to form grid lines. The vertical walls of the grooves provides increased contact area to compensate for high contact resistance and to reduce grid line obscuration. It is not clear at this time whether laser-groove cells will be as cost effective as screen printed cells. Solarex is projecting an efficiency of $22 \%$ by mid-decade, but the cost projected by Solarex for these cells is several times higher than the cost projected by AstroPower and others for screen printed cells.

The SEA 10X concentrator design, and assembly processes, must remain flexible to cell suppliers to take advantage of competition and technical advancements. It must be easily adaptable to different cell sizes and concentration ratios. Flexibility of the manufaciuring process is discussed below in section 5.1, Improvements in the Manufacturing Process: Receiver Assembly.

Performance of screen printed, one-sun cells, at low concentration could benefit greatly by development efforts. SEA is able to piggy-back on one-sun cell development. However, any changes to one-sun cells for use at low concentration must not substantially change the basic one-sun manufacturing process. This is discussed further in section 5.3, Improvements in the Manufacturing Process: Cell and Diode Manufacturing.

\section{Diodes}

Packaged diodes, available commercially, are not cost effective. SEA is using unpackaged diode chips and soldering them to the cell leads which are bonded to the receiver heat sink, see figure 8 . This technique provides a thermal bridge to the heat sink while maintaining electrical isolation.

The small diode chips normally commercially available are not suitable for this application. These chips are designed to be soldered to carriers and wire bonded to make the top contact. The dimensions are small, less than one millimeter. The top metalization is aluminum and therefore not solderable. The cost is high because of high overhead, profit markup, and the high cost of the device grade silicon wafer material and processes. Changes in the metalization or the size cannot easily be done because of large investments in tooling by the manufacturers.

SEA is using large area diodes $(2.5 \mathrm{~mm}$ by $10 \mathrm{~mm}$ ) manufactured specifically for use in our concentrator. These diodes are made from solar grade silicon wafers and have inexpensive screen printed, solderable metalization top and bottom. The large area permits the use of multiple soldered connections for redundancy. It also provides a large area for heat transfer, necessary when current is flowing through the diode. 
Figure 8, Bypass Diode Assembly

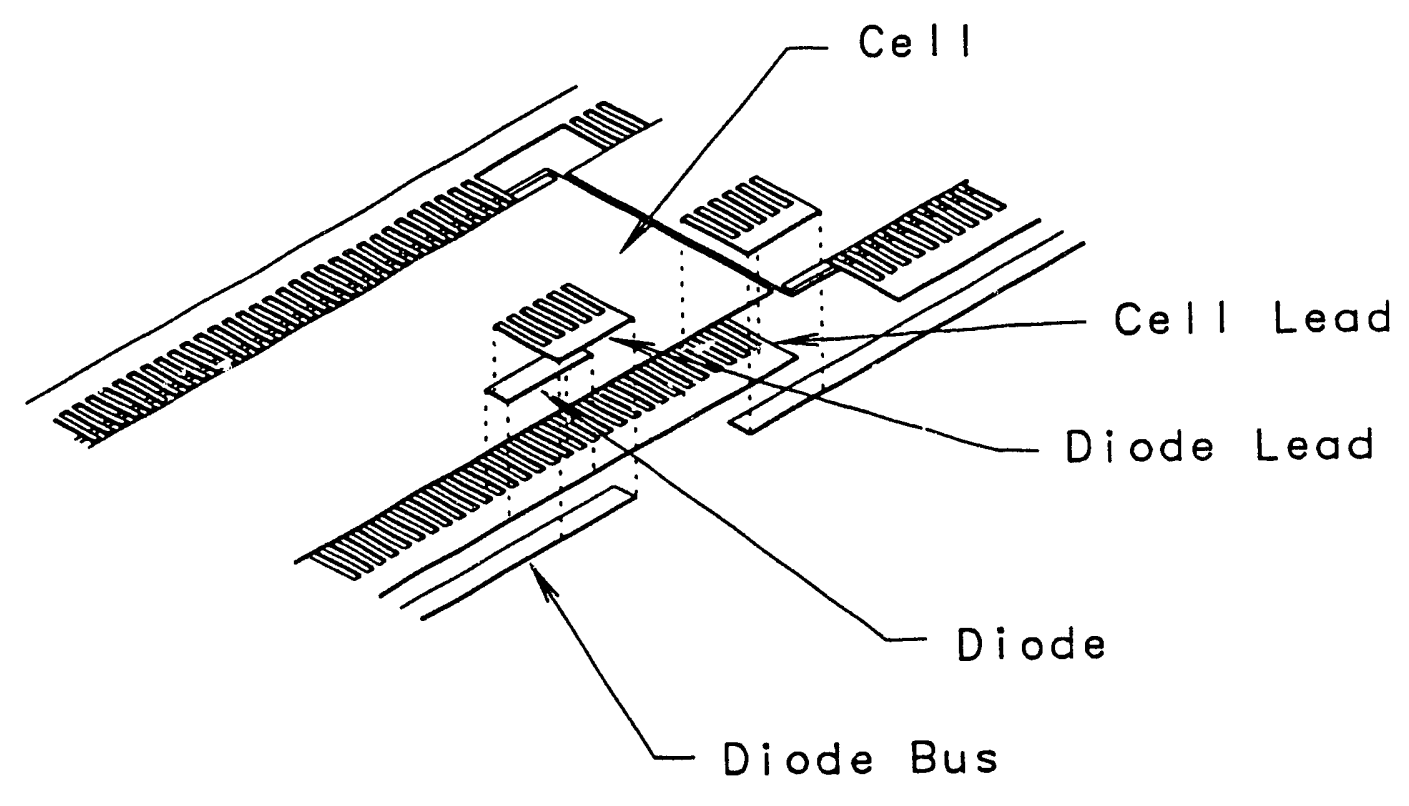

Bypass Diode Assembly 
Diodes made for the SEA concentrator are manufactured by the cell supplier using exactly the same materials and techniques used for making cells. The cost of these of diodes are low because low cost PV materials and processes are used rather than high cost device materials and processes. The wafers are metalized over the entire top and bottom and then cut into the final size. Improvements in the costs of manufacturing one-sun cells would lower the production costs of these diodes too. This is discussed further in section 5.3, Improvements in the Manufacturing Process: Cell and Diode Manufacturing.

\subsubsection{Leads}

Leads are made of $0.003^{\prime \prime}$ thick soft copper sheet. They are electroplated with SN-62 solder in order to provide a tinned surface of 0.001 inch minimum thickness. Two types of leads are used in the receiver assembly. These are cell leads and bypass leads (see figures 9 and 10). The cell leads are used in two orientations (right and left). A special case occurs at the first and last cell in the string, where a cell lead is cut into two halves.

The leads are received by SEA Corporation in sheets of multiple parts, held in place by thin webs, which are cut from the sheet as they are needed. They are presently manufactured using chemical etching.

\subsubsection{Receiver Assembly}

The receiver assembly process is detailed in flowchart 1 . The cell contact areas are abrasively cleaned and a no-clean flux is applied before soldering. A no-clean flux is applied to the leads also. The top cell bus contact is pre-soldered in a fixture. The Cell/Lead assemblies are then assembled with the bypass leads and diodes face down in a solder fixture that are the full length of the receivers. The parts are then manually soldered together using a temperature controlled solder iron.

An adhesive is then applied to the heat sink which is then positioned on the alignment pins of the fixture. Pressure is applied to the back of the heat sink and the adhesive is cured. Then the heat sink/cell string assembly is removed from the fixture. The output connectors slide into locating slots in the heat sink and snap into place. The connector leads are soldered to the cell string using a soldering iron. A conformal coating completes the assembly. The coating is applied with a brush.

The receiver is tested prior to module assembly. Testing includes performance tests and wet and dry hipot tests. 
Figure 9, Cell Lead

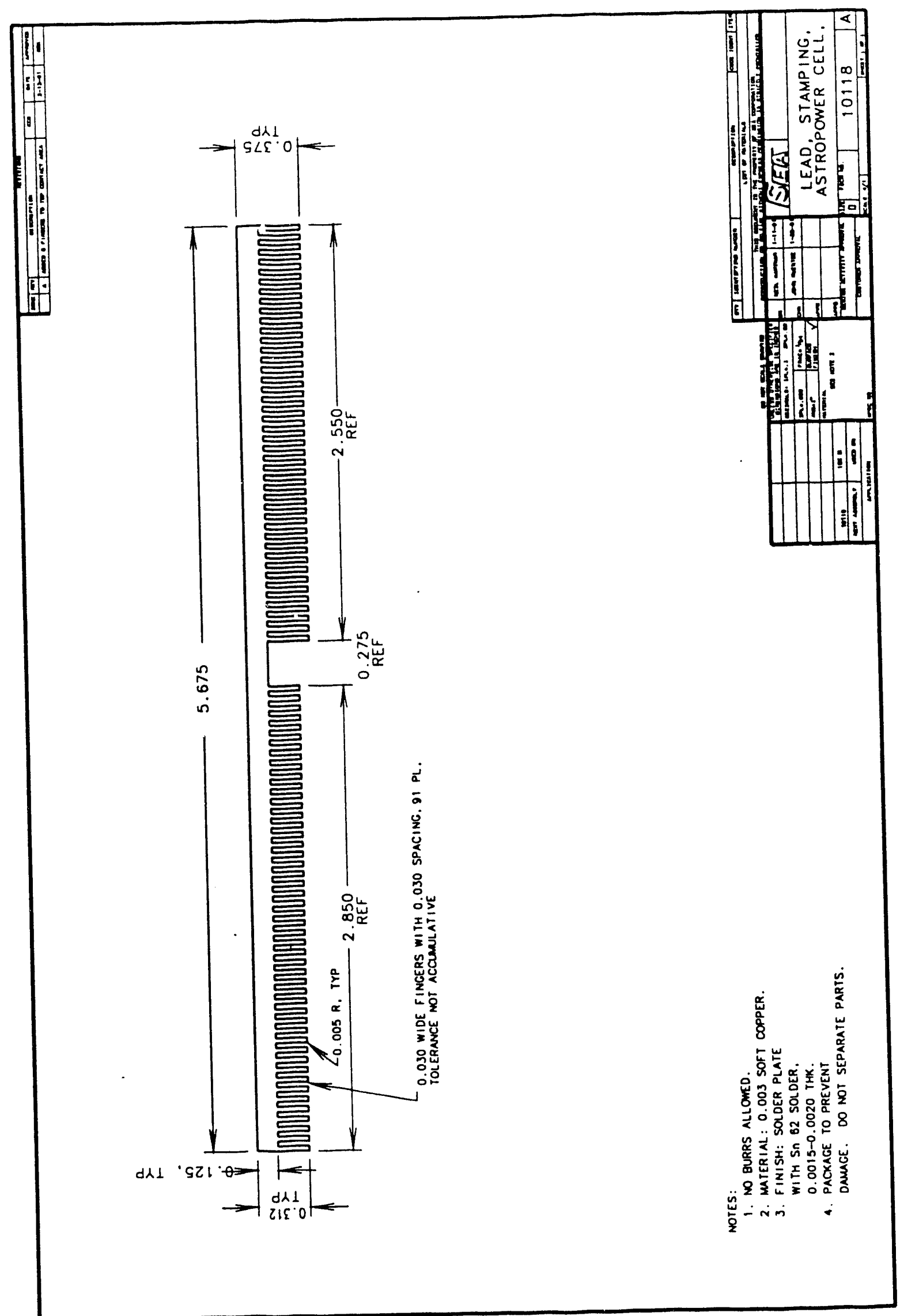


Figure 10, Diode Lead

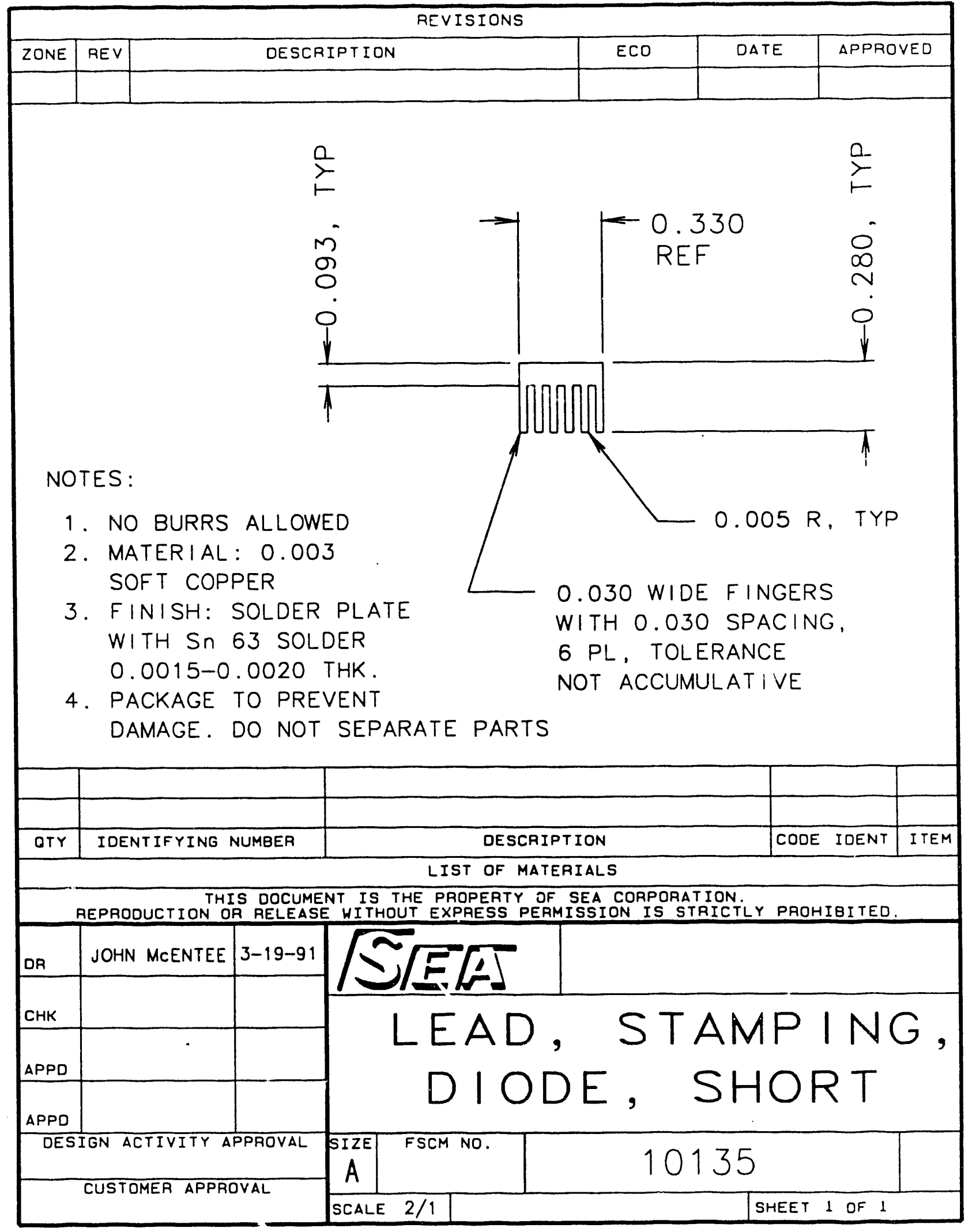


Flowchart 1, Current Receiver Assembly
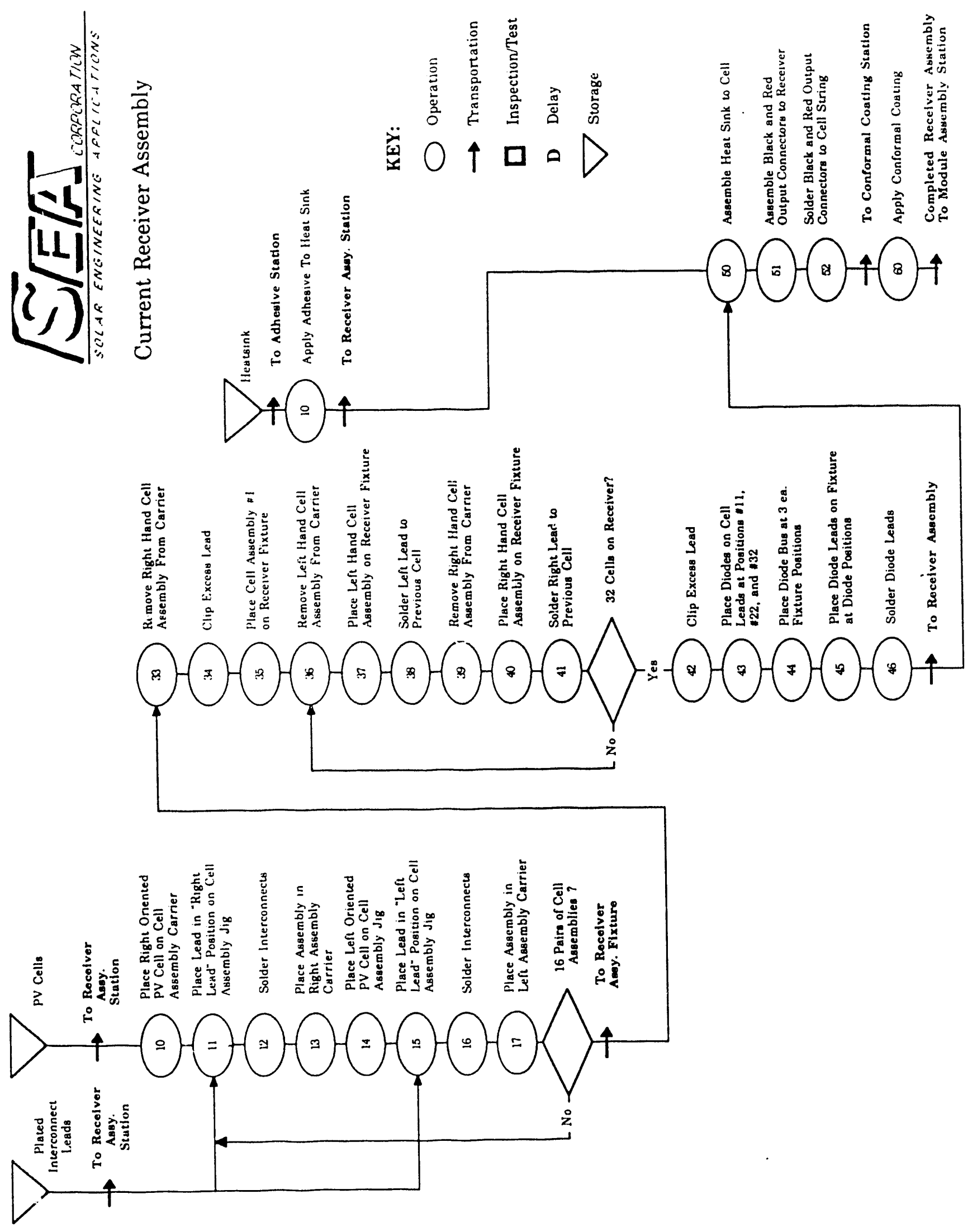


\subsection{Module Assembly}

The module is assembled from two sub-assembles, the receiver assembly and the lens/housing assembly.

\subsubsection{Assembly of Lens/Housing sub-assembly}

The extruded lens, sides, and end caps have mating features which allow them to self locate. The parts are placed by hand in a module assembly fixture which maintains proper alignment. A solvent type acrylic adhesive is injected into the mating features using a syringe. The assembly remains undisturbed until the joints gain sufficient strength for handling.

\subsubsection{Joining Receiver to Lens/Housing}

Joining of the receiver to the lens/housing is done while the lens/housing is still in the module assembly fixture. This maintains module alignment. The receiver is fit into the flange feature of the lens/housing sub-assembly and attached by crimping a series of tabs on the heat sink with a hand tool. This completes the module assembly.

\subsubsection{Module Testing}

Each module is performance tested. The testing is performed outdoors. Water spray tests are also done.

\subsection{Array Assembly}

An array consists of 10 modules mounted by self aligning pivot bearings to the array frame. The array frame components are formed from environmentally protected steel sheet on a numerically controlled punch machine and break. The assembly requires 20 pivot bearings which are formed from UV resistant, selflubricating plastic and an environmentally protected stamped steel housing. The plastic pivot bearing are now made from bar stock on a screw machine but are designed to be molded.

The frame is bolted together on a flat fixture. The pivot bearings are slipped over the pivot pins. The modules are then positioned over the array frame, and the bearings are screwed into place using self tapping screws. A tracking drag link is next attached to the modules. This connects all the modules together and to the tracker drive. One of four arrays will contain a drive unless the arrays are to be used for stand alone operation. The elevation supports are left in their folded position until field assembly. 


\subsection{Shipping, Field Setup}

Ten arrays are shipped in a special shipping frame, one frame per truck-trailer. They are stacked with the elevation supports unfolded. Upon arrival, the elevation supports are unfolded and the arrays are placed end to end on a relatively flat surface. They attach to each other to form long strings of arrays. No additional wire or hardware is required to form these array strings, they simply plug into each other. Four arrays share a common tracker drive. These drives are independent and completely self sufficient. In the unlikely event that one drive fails, the whole field does not go down, only four arrays.

The arrays weigh approximately 150 pounds and can be carried by two people. For erection of a large field, the use of placement equipment speeds the process and reduces the chance of accidents. The arrays are secured by four steel stakes driven into the ground. These stakes are sized for th.e local soil conditions to resist over 100 miles per hour wind speed and expected seismic loads. Arrays can also easily be bolted to roof tops.

The arrays are self aligning, requiring only to be placed facing south and at the proper angle for the specific latitude. They acquire the sun in the morning and track through the day using a simple, active feedback system. 
4 Costs

The costs are made up of three basic components, material costs, manufacturing costs and overhead. Costing is based on conservative estimates from reliable sources. If errors are present, they are on the high side. Contingencies are added at each stage of the costing. SEA Corp. is constantly updating the costing to reflect new information.

Manufacturing costs are very high now due to the startup nature of the product. As the production rate is increased, the material costs will decrease due to economies of scale. Manufacturing costs will not decrease with increased production without changing the techniques as described in this report.

Most of the cost of a given product is determined durring the inception phase. The SEA 10X concentrator system was designed from its inception as a commercial, cost-effective product. It was designed for production. All the basic components are readily available. No special products or manufacturing processes are required. A minimum number of parts are used which can be assembled easily. This makes the SEA $10 \mathrm{X}$ the most cost-effective concentrator design available today.

Costs are kept in a data base and updated as required. In this way, different options can be tried and their effect on cost can be determined.

\subsection{Material Costs}

Material costs are presented below at three different levels of production: 1,10 and $100 \mathrm{MW} / \mathrm{yr}$. These costs are based on quotes from vendors and are conservative. The costs are really prices because they include overhead and markup appropriate for each level of production, (120\% for $1 \mathrm{MW} / \mathrm{yr}, 95 \%$ for $10 \mathrm{MW} / \mathrm{yr}$ and $65 \%$ for $100 \mathrm{MW} / \mathrm{yr}$ ). Costs are listed per array. The aperture area of each array is $7.74 \mathrm{~m}^{2}$.

\section{Material Costs per One Array, (with Overhead and Profit)}

\begin{tabular}{lrrr} 
& \multicolumn{3}{c}{ Production Rate, MW/yr } \\
Item & 1 & \multicolumn{1}{c}{10} & \multicolumn{1}{c}{100} \\
\hline Cells & $\$ 626.12$ & $\$ 346.84$ & $\$ 211.36$ \\
Cell Interconnects & 11.07 & 8.30 & 6.00 \\
Diodes & 2.04 & 1.51 & 1.15 \\
Lens/Side Extrusion & 344.47 & 235.90 & 176.11 \\
Reflective Film & 17.88 & 6.95 & 3.06 \\
End Caps, Heat Sink, Adhesive & 349.07 & 187.15 & 145.71 \\
Array Structure & 129.25 & 105.50 & 77.52 \\
Drive & 100.12 & 61.13 & 51.72 \\
Total Parts Cost & $\$ 1580.02$ & $\$ 953.28$ & $\$ 672.63$
\end{tabular}




\subsection{Manufacturing Costs}

Manufacturing costs are very high now because of the prototypical, handassembly nature of existing production. We have calculated manufacturing costs at three levels of production, 1,10 and $100 \mathrm{MW} / \mathrm{yr}$. The $1 \mathrm{MW} / \mathrm{yr}$ rate assumes production methods similar to those now employed and the $10 \mathrm{MW} / \mathrm{yr}$ assumes a mix of manual and automated production. (We plan to move to automated production very early to avoid developing manual techniques that would eventually have to be scrapped when automation is finally introduced.) The 100 $\mathrm{MW} / \mathrm{yr}$ production rate assumes all the improvements to production discussed in this report. As in the material cost, manufacturing costs are more appropriately called price as they assume overhead and profit appropriate for each production rate as detailed above.

\section{Manufacturing Costs per One Array, (with Overhead and Profit)}

\begin{tabular}{|c|c|c|c|}
\hline \multirow[b]{2}{*}{ Iter } & \multicolumn{3}{|c|}{ Production Rate, MW/yr } \\
\hline & 1 & 10 & 100 \\
\hline Module Assembly & $\$ 164.46$ & $\$ 63.80$ & $\$ 52.99$ \\
\hline Array Assembly & 75.49 & 42.54 & 23.51 \\
\hline Field Installation & $\underline{15.02}$ & 6.56 & $\underline{3.28}$ \\
\hline $\begin{array}{l}\text { Total Manufacturing Cost } \\
\text { Electricity costs }\end{array}$ & $\$ 254.97$ & $\$ 112.90$ & $\$ 7 \overline{9.78}$ \\
\hline
\end{tabular}

Total costs, including overhead and profit, for the three production rates are as follows:

Total Costs per One Array, (with Overhead and Profit)

$\begin{array}{cc}\text { Production Rate, MW/yr } & \text { Total Costs per array } \\ 1 & \$ 1834.99 \\ 10 & 1066.18 \\ 100 & 752.41\end{array}$

With $7.74 \mathrm{~m}^{2}$ of aperture are per array, these figures translate to the following costs per $\mathrm{m}^{2}$ of aperture area:

Total Costs per $\mathbf{m}^{2}$, (with Overhead and Profit)

\begin{tabular}{cc} 
Production Rate. MW/yr & Total Costs per m \\
\hline 1 & $\$ 237.08$ \\
10 & 137.75 \\
100 & 97.21
\end{tabular}

Cost per Watt can be calculated assuming an insolation of $850 \mathrm{~W} / \mathrm{m}^{2}$ and an array efficiency. The efficiency for 1 and $10 \mathrm{MW} / \mathrm{yr}$ production rates was assumed to be $11 \%$. For the $100 \mathrm{MW} / \mathrm{yr}$ production rate, the improvements described in this report were assumed which gives an array efficiency of $16 \%$. 


\section{Total Costs per Watt, (with Overhead and Profit)}

\begin{tabular}{cc} 
Production Rate. MW/yr & Total Costs. $\$ / \mathrm{W}$ \\
\hline 1 & 2.54 \\
10 & 1.47 \\
100 & 0.71
\end{tabular}

Electricity costs can be calculated using the following formula:

$\mathrm{EC}=\left(\mathrm{FCR}(1+\mathrm{ID})((\mathrm{AC})+\mathrm{PC} * \mathrm{IN} * \mathrm{ASE})+\left(\mathrm{G}^{*} \mathrm{CRF}^{*} \mathrm{OM}\right)\right) /\left(\mathrm{S}^{*} \mathrm{ASE}\right)$

Where:

$\begin{array}{llcl}\mathrm{FCR}= & \text { Fixed Charge Rate= } & 9.10 & \text { percent per year } \\ \mathrm{CRF}= & \text { Capital Recovery Factor }= & 7.30 & \text { percent } \\ \mathrm{G}= & \text { Present Worth Factor }= & 13.7 & \\ \mathrm{ID}= & \text { Indirect Cost Factor }= & 0.5 & \\ \mathrm{~S}= & \text { Annual Solar Availability } & 2600 & \mathrm{KW}-\mathrm{hr} / \mathrm{m}^{2}-\mathrm{yr} \\ \mathrm{IN}= & \text { Average Peak Insolation }= & 0.85 & \mathrm{KW} / \mathrm{m}^{2} \\ \mathrm{OM}= & \text { Operation and Maintenance Cost }= & 1.40 & \$ / \mathrm{yr} / \mathrm{m}^{2} \\ \mathrm{AC}= & \text { Area Related Cost }= & \mathrm{AC} & \$ / \mathrm{m}^{2} \\ \mathrm{PC}= & \text { Power Related Cost= } & 100 & \$ / \mathrm{KW} \\ \mathrm{ASE} & \text { Annual System Efficiency= } & \mathrm{ASE} & \text { percent }\end{array}$

ASE is calculated from the product of the array efficiency and the combined wiring and inverter efficiency. For 1 and $10 \mathrm{MW} / \mathrm{yr}$ production, $\mathrm{ASE}=11 \% * 90 \%=9.9 \%$. For $100 \mathrm{MW} / \mathrm{yr}$ production, $\mathrm{ASE}=16 \% * 95 \%=15.2 \%$. AC is the area related costs calculated above.

Using this formula to calculate electrical costs yields the following table:

AC Bus Bar Electrical Cost, (with Overhead and Profit)

\begin{tabular}{cc} 
Production Rate, MW/yr & Electrical Cost. $₫ / \mathrm{KW}$-hr \\
\hline 1 & 13.56 \\
10 & 8.30 \\
100 & 4.16
\end{tabular}

These costs are conservative. One may argue with specific values, but the fact remains that the SEA $10 \mathrm{X}$ module uses a minimum number of inexpensive parts that can be assembled easily. This will lead, once in production, to a cost-effective PV system. 


\section{Improvements in the Manufacturing Process}

\section{General Evaluation Criteria}

The manufacturing process for the SEA 10X Concentrator described here is based on a production rate of $100 \mathrm{MW}$ per year. To produce high reliability solar products at the lowest possible price, a careful evaluation of the manufacturing processes must go beyond the assurance that the product conforms to its specification. The evaluation must also consider the efficient use of capital in the design and operation of the factory. SEA Corporation recognizes that there are many manufacturing scenarios which are capable of producing quality products. The advantage of one approach over another is in how cost effective the process is from an overall system perspective. Inefficient use of capital will be reflected in the cost of the product.

In order to best evaluate the manufacturing approach for the SEA 10X Concentrator at the anticipated level of production, SEA Corporation will take the following factors into consideration:

\section{Production Ramp-up factors}

Ramping up to $100 \mathrm{MW}$ per year production will require a stepped investment strategy. How efficiently this is done depends on the cost of continually meeting the immediate capacity requirements, without making a large investment in unneeded capacity. For example, investment in small modular work cells that can be added in parallel as needed is usually a more efficient ramp up strategy than the purchase of faster more costly equipment, which although capital efficient at higher production rate, will not be utilized at that capacity for some timie.

\section{Cost of capital equipment}

The cost of capital equipment and its maintenance over its useful lifetime, and the cost of the invested capital itself, must be reflected in the price of the product. The level of difficulty of a given task is a good indicator of how expensive it will be. In order to keep the product cost low, processes must be designed so that they require minimum sophistication. Changing the order of process steps, for example, can often reduce the precision required at any one step. If tight tolerances are necessary only to assure that mating parts fit together, a design change on the part may eliminate the need for an expensive process step. 


\section{Manufacturing Flexibility}

In any evolving technology, the success of a given manufacturing operation, to a large extent, is a result of manufacturing flexibility. Large investments in highly specialized machinery often fall victim to obsolescence as the product needs change, long before the machine has reached the end of its mechanical lifetime. Worse still, a large investment may cause stagnation of the technology. Flexibility, however, can be designed into the manufacturing floor by maintaining a modular "work cell" environment. If the product design changes, rearrangement of the factory floor, or addition or modification of work cells can bring the new product on line with a minimum of time and expense. Manufacturing flexibility can be designed into tooling as well. For example, tooling to accurately position cells for soldering would become obsolete if the size of the cells or the interconnect geometry changed. However, using a different strategy, a flat vacuum chuck base plate and a simple $x, y, z$ stage (robot) with vacuum pick can be programed to handle and position most PV cells and interconnects to the accuracy of the stage. In this case small modifications in program variables allow adaptation to a wide variety of part geometries.

\section{Time and WIP Factors}

The faster a set of purchased materials can be transformed to a product on the shipping dock, the less overhead burden the product accumulates. The amount of work in progress, or WIP level, is a common source of inefficient investment. Long queues for process bottlenecks, uncoordinated process cycles, unnecessary intermediate inventories, and the like can result in a significant capital losses due to the excessive inventory involved in the operation. Low WIP levels usually mean a smaller, more efficient factory. SEA corporation favors manufacturing strategies which encourage low WIP levels.

\section{Safety Factors}

Designing for safety is a vital part of any manufacturing operation. Neglected, it can become an enormous financial burden to a manufacturer. It is far easier and less expensive to design safety into machinery than to retrofit it later. For example, if vapor recovery is not required at a bonding station under anticipated production, but will be required when the work cell is operating at capacity, it is wise to design for vapor recovery from the start. This will probably have only a small effect on the cost of the equipment. Attempting to tackle the problem later when pruduction increases may require a new apparatus and/or production down time, not to mention legal expense and low worker morale. 


\subsection{Receiver Assembly}

Receiver assembly is the most complex operation in the manufacture of the module. Only automation offers the speed, reliability, and accuracy required to produce these assemblies cost effectively. SEA Corporation is concurrently investigating automation strategies while making changes to the receiver design which will make it more manufacturable. This effort is intended to lower the level of difficulty, and thus, the cost.

Wet processes such as the conformal coating and the adhesive bonding of cells and leads to the heat sink, offer special problems to the automation process. SEA Corporation has made a preliminary investigation of materials which may offer the receiver assembly process greater manufacturability. These are adhesive films which can be calendered to the desired thickness, slit to the required width and applied to the receiver or cells in a dry, continuous process. These films can be stored at room temperature for weeks, and can then be cured under elevated temperature in less than five minutes. The uncured surface of the film is tacky allowing cells and leads to be held in place on the surface prior to soldering and adhesive curing.

Preliminary tests have been performed with this material and it has demonstrated great promise. (Receivers assembled using this material are presently undergoing environmental testing at Sandia National Laboratories in Albuquerque, New Mexico.) Void free bonds have been made to demonstrate application feasibility. Cells and leads have been soldered while reliably held in place by the tack of the material. Because of the transparency of the base material (95\% light transmission) it can be used as a conformal coating, eliminating another wet process.

The cell leads and diode leads are fragile and, thus, present special handling problems. The desired strategy is to stamp them in continuous strips and store them in rolls. They are then fed into the receiver assembly process and automatically cut from the strip as required.

SEA corporation has identified three automation scenarios which offer improvements in the manufacturability of the the receiver. These scenarios will be investigated using the perspective outlined above in the General Evaluation Criteria. 


\subsubsection{Scenario 1, Group Assembly in Fixture}

This scenario is an automated version of the current manual production method. Using this strategy, cells and cell leads would be assembled face down in a soldering fixture which would maintain the correct orientation of the parts. The fixture would traverse along one axis while an inexpensive $x, y, z$ robot placed the paıtc. Cells and leads are placed in a alternating "left" and "right" orientation. A special case occurs at the receiver ends where only half the lead is used. Bypass strips are continually fed from a roll and positioned at three locations. Diode leads must be added in six locations, and diodes at three locations corresponding with the ends of the bypass strips. The assembly order is shown in figure 11. Hot bars access the assembly from the top of the fixture to hold the mating parts together and reflow the pre-tinned contact areas. The fixture is then moved to a different station where a heat sink, with adhesive previously applied, is lowered onto the fixture, put under pressure and cured. A heat cure adhesive is favored for this speration to speed the process. This process is outlined in Flowchart 2.

\subsubsection{Scenario 2, Separate Cell Assemblies}

Scenario 2 is an attempt to make the receiver assembly a fixed repeatable pattern. In this case the cell, leads, and a diode are pre-assembled in a separate station as a separate unit, see figure 12 . These units are then assembled in a secondary operation in a fixture. Finally, the receiver is bonded to them. In a modification of this procedure, the units are applied to the tacky surface of a partially cured adhesive coated receiver. The assembly operations would be done using inexpensive $\mathrm{x}, \mathrm{y}, \mathrm{z}$ robots. This assembly process is detailed in Flowchart 3 . Using this strategy may simplify the assembly process due to the elimination of the three long diode leads required for bypass. This, of course, must be traded off against an extra operation to create the cell/diode unit as well as the additional costs associated with the 29 extra diodes required for each receiver.

\subsubsection{Scenario 3, In Situ Assembly (ISA)}

This scenario, which SEA Corporation calls "In Situ Assembly" (ISA) may offer the greatest flexibility and simplicity of the strategies considered so far. In this case a dry adhesive film is first applied to the heat sink. The heat sink is manufactured with reference features which allow it to be accurately positioned on a traversing mechanism. In this strategy, the receiver itself becomes the assembly fixture, using the tacky surface of the adhesive to reliably fix the components in the proper orientation. Components are applied in the order shown in figure 13. The receiver is indexed in one dimension while cells, leads and diodes are placed directly to the tacky surface in a linear process with an inexpensive $x, y, z$ robot. A second $x, y, z$ robot solders the components with a hot bar. A conformal coating is then applied to the assembly. This can be done using a wet or dry process. This assembly procedure is shown in flowchart 4 . 
Figure 11, Assembly Order of Receiver Parts Assembled in Fixture

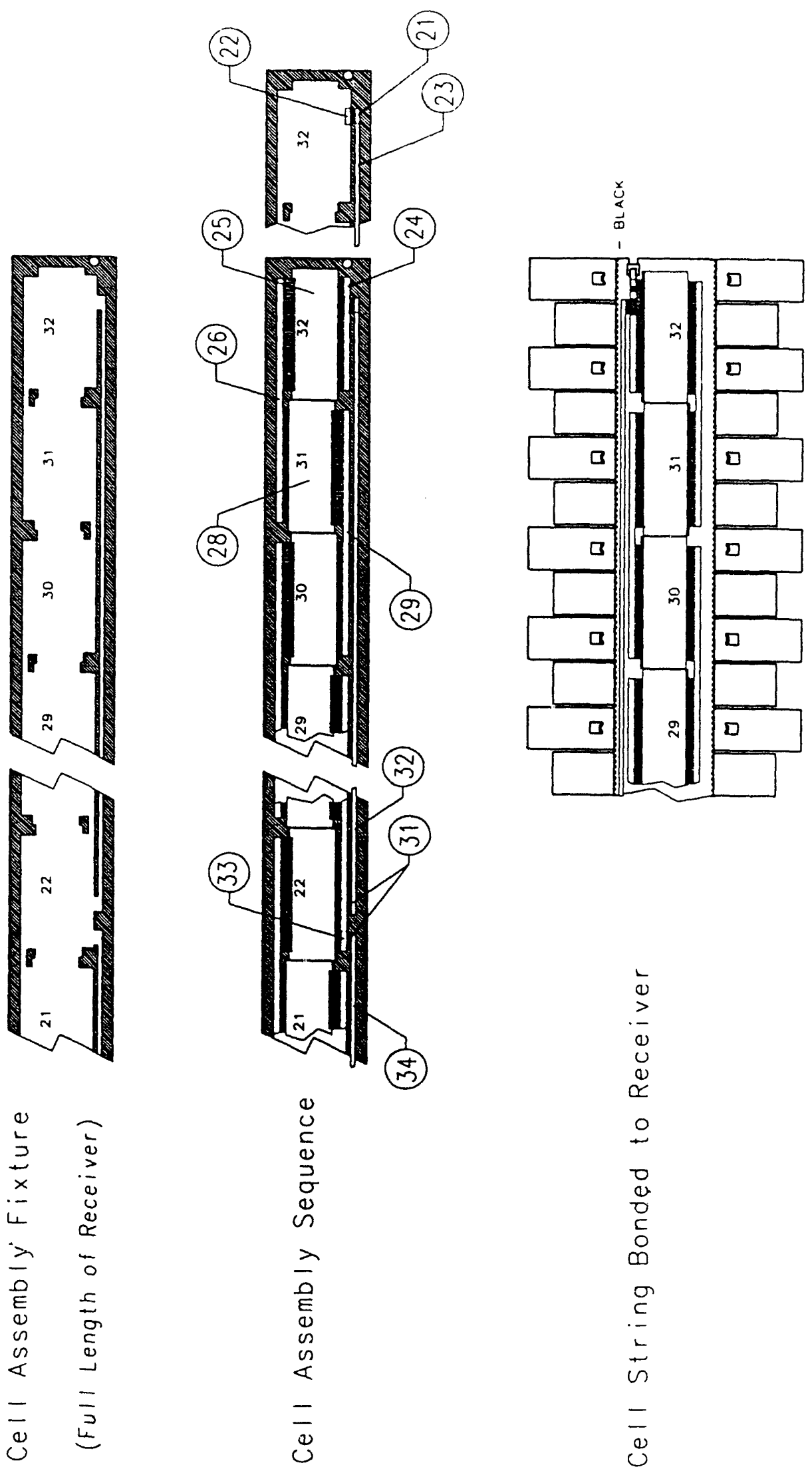




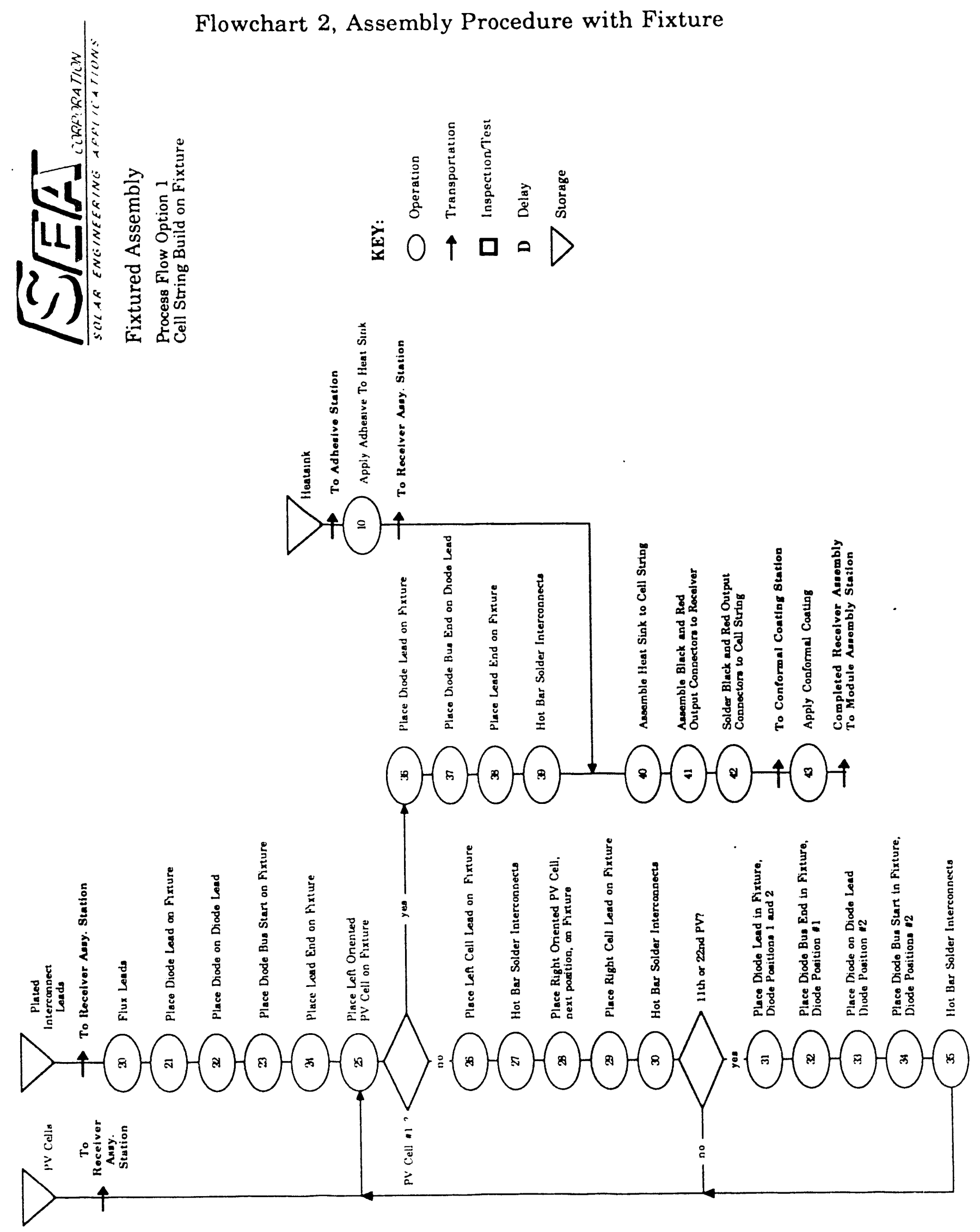


Figure 12, Separate Cell and Diode Assembly

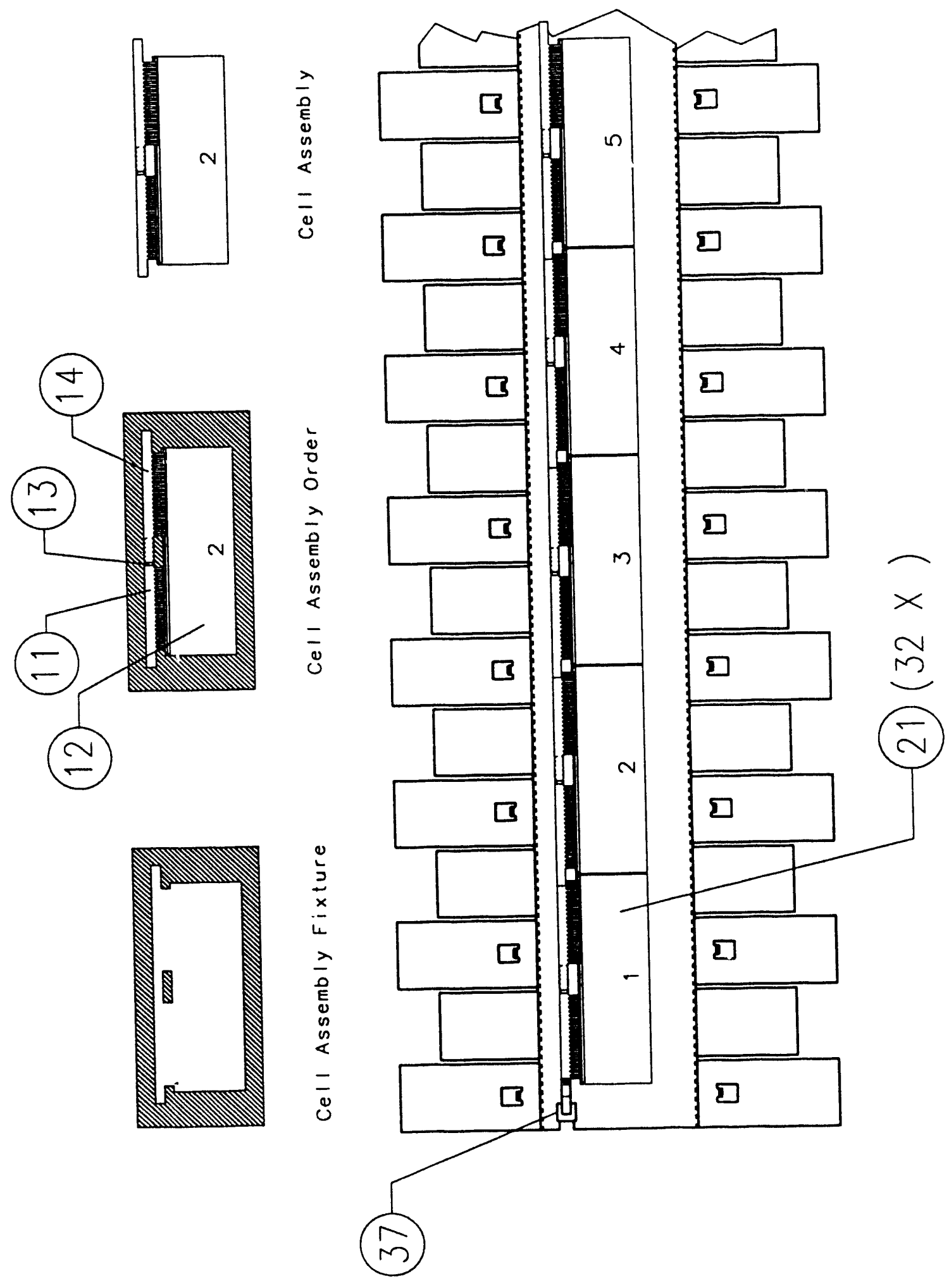




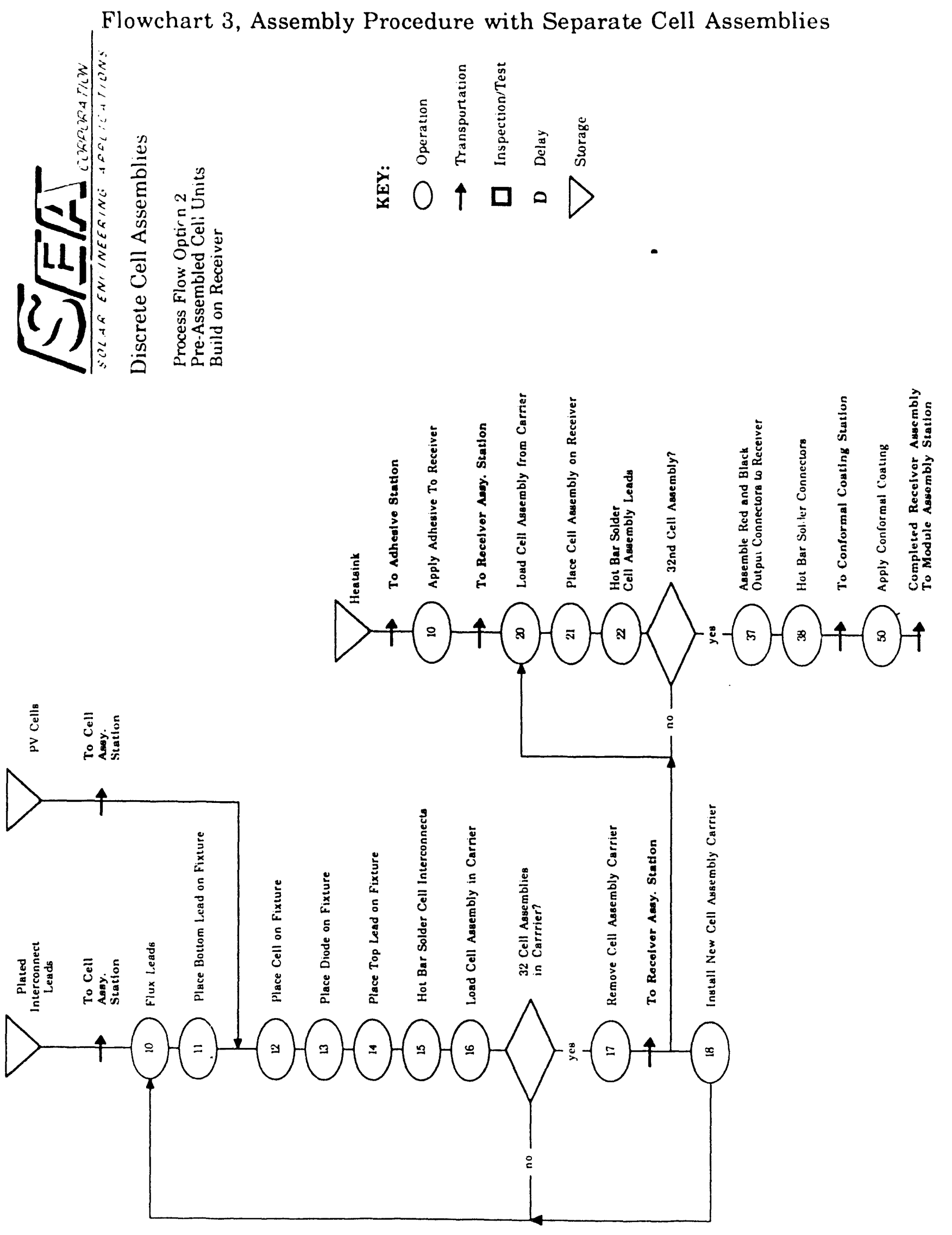

Page 36 
Figure 13, Assembly Order with ISA Technique

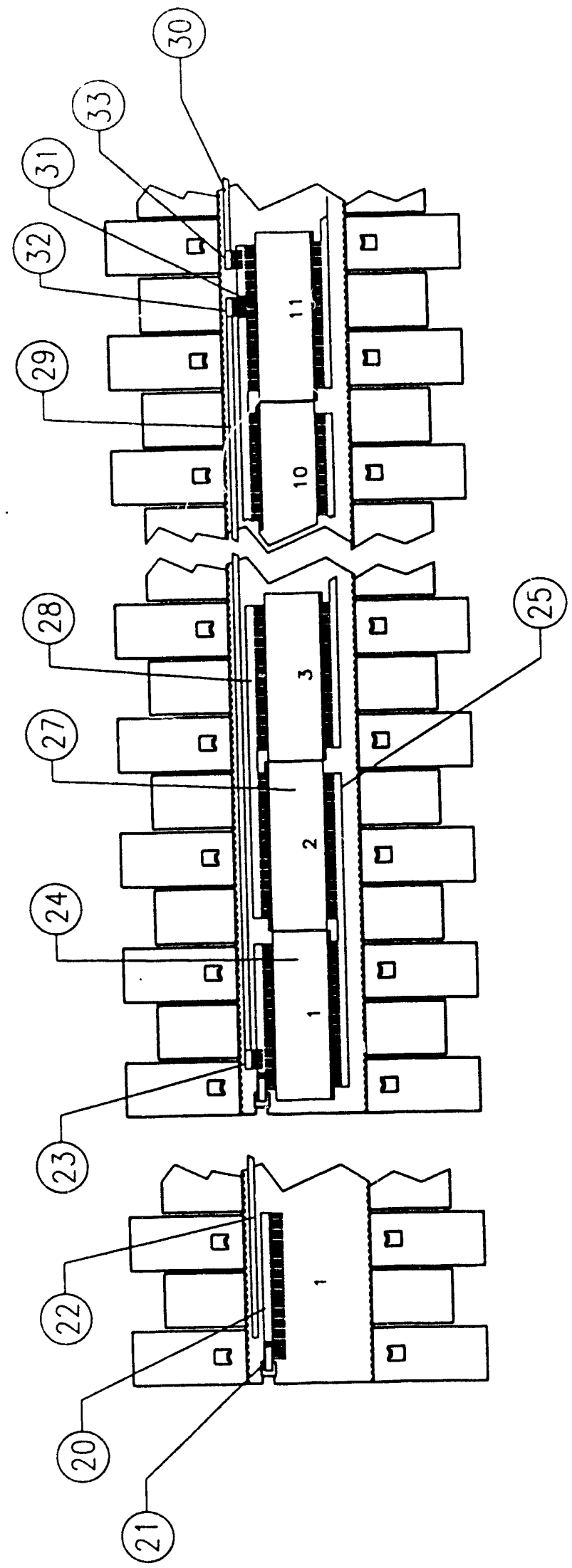

Page 37 


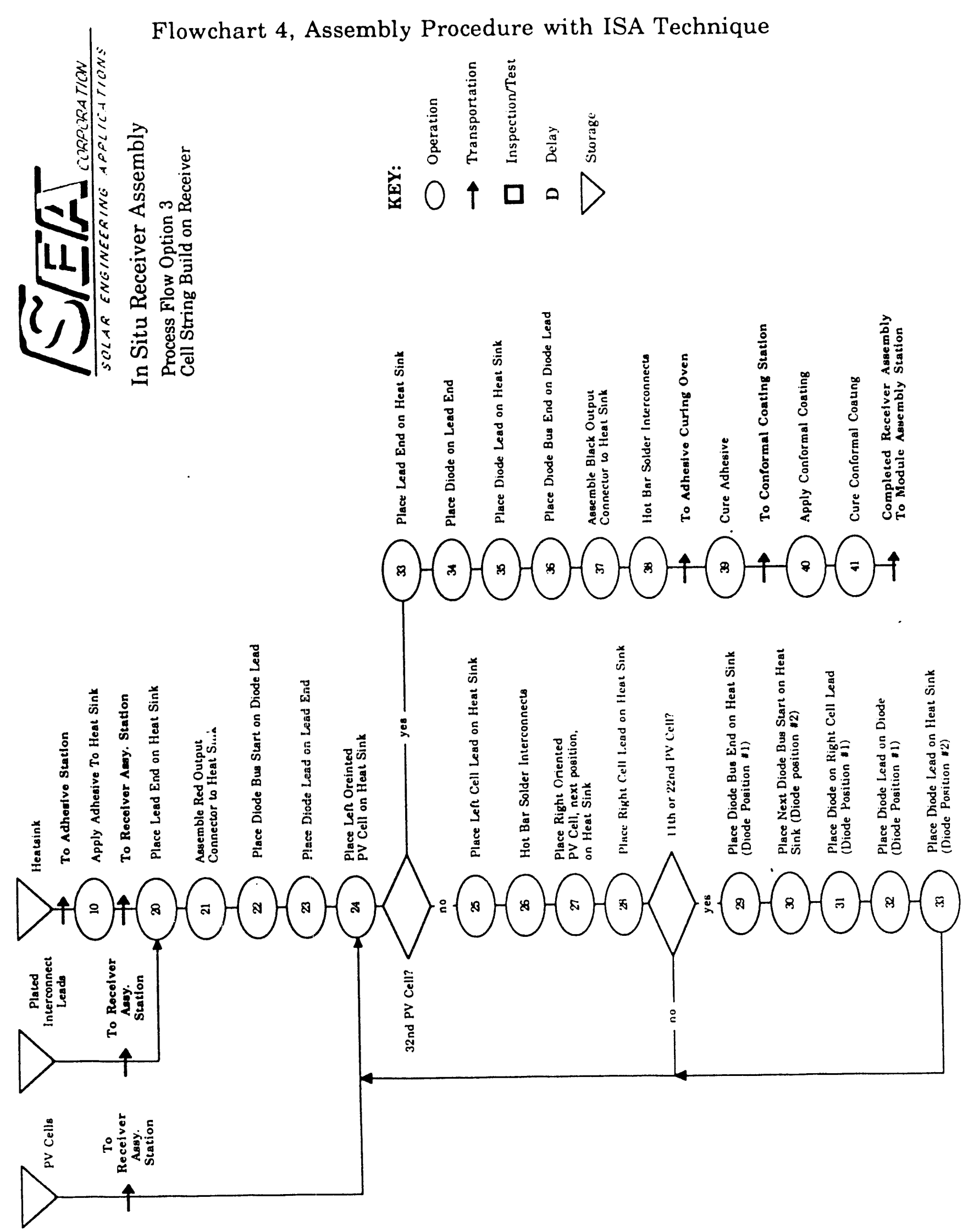

Page 38 
SEA Corporation has performed these operations in the laboratory and believes that ISA will produce a highly reliable process. Because hard fixturing is not required for the cell assembly, this process has a high level of flexibility. Due to the fact that positioning is done only by the robot, reference interference between robot and positioning fixture is not a problem, thus lowering the required sophistication of the process. SEA Corporation expects these advantages to make a significant cost savings.

\subsection{Heat Sink Manufacturing}

The heat sink is a formed sheet metal structure which is coated for electrical isolation and environmental protection. SEA corporation intends to investigate both the forming process and the coating process in order to improve the manufacturability and the reliability of the processes.

SEA Corporation has made a prelirninary investigation into the forming of the receiver. A line of standard equipment has been defined for the process which takes aluminum coil stock at one end and delivers formed heat sinks on the other end. This line includes the following equipment:

1. Roll Straightener

2. Ultrasonic Loop control (2 ea.)

3. Pre-notch press w/programmable feeder

4. Shear Tab Die

5. Roll Former and Roller Die Tooling

6. Post Punching Press and Edge Punching Slotting Die

7. Cut-Off and Form Press

8. Run-Out Conveyor

This tooling can be purchased and set up as a turn-key system at a cost of about $\$ 380,000$ and has a production rate of 60 feet/minute, fast enough for greater than $100 \mathrm{MW} / \mathrm{yr}$ production from a two shift operation.

After the receiver is formed, it must be coated for electrical isolation and environmental protection. Currently this is done with Type III hard anodize. Anodic coatings offer the advantage of a long history. The process has been refined over many years and is well understood.

Other coatings are, nevertheless, candidates as well. For example Sandia National Laboratories has been investigating electrophoretically applied dielectric coatings, (EP coatings) which may be used with an anodic coating or by themselves. EP coatings may be a cost effective alternative or addition to anodizing. An investigation of these materials is planned. 


\subsection{Ciell and Diode Manufacturing Improvements}

Since the SEA 10X concentrator uses one-sun cells at low concentration, it can piggy-back on any improvement in efficiency or reduction in the cost of one-sun cells. This includes certain thin film cells such a copper-indium-diselenide or new one-sun technology such as the new Texas Instruments' cell. The one aspect of one-sun cell development not covered is the adaptability of these cells to concentration.

The advantage of using one-sun cells is cost. All commercially available one-sun cells use screen printed contacts. The cost of this process is approximately 0.3 $\varnothing / \mathrm{cm}^{2}$. One-sun cells use low cost wafers, approximately $1.5 \phi / \mathrm{cm}^{2}$. Concentrator cells use evaporated metalization which alone costs approximately $3 \mathrm{q} / \mathrm{cm}^{2}$. The wafers are more expensive too. One-sun cells are in production now and considered commodity items, while concentrator cells are considered speciality items. The present cost of concentrator cells are many times the present cost of one-sun cells.

What ever is done to one-sun cells to adapt them to low concentration use must not add to the manufacturing or material cost or deviate significantly from the standard one-sun production line. Such changes as using a different screen mask or a different screen ink or a different diffusion schedule will not change significantly the standard manufacturing process. For instance, the different screen mask could be substituted for the one-sun mask for a month of production without effecting processing.

Recent tests have shown that screened metalization technology can be used at low concentration. Fill factors measured in these tests were a maximum of $81.2 \%$ at $471 \mathrm{~mW} / \mathrm{cm}^{2}$. Maximum measured efficiency was $14.74 \%$ at $495 \mathrm{~mW} / \mathrm{cm}^{2}$. This is the first time, to our knowledge, that cells with screened gridlines have been successful at concentration.

Higher concentration might benefit cost. The optimum concentration ratio depends on many factors, such as the lens transmission at different concentrations, the concentration limit of one-axis tracking, the cell efficiency at different concentrations, etc. Optimum concentration calcuiations are planned.

\subsection{Lens/Side Extrusion}

Reduction in cost of the lens/side extrusion is focused on two aspects: combining the lens and the housing sides into one extrusion and improvement in optical efficiency. Figure 3, on page 10, shows the lens/side extrusion.

\section{Cornbining Lens and Sides}

Assembly cost is saved by combining the lens and module housing sides into one extrusion. We have been concentrating on the lens development because this was the most technically risky. It was felt that the sides could be added to the lens 
relatively easily. Combination of these elements will eliminate the joint at the top of the module which is a potential source of failure and water leakage.

The attachment flange at the bottom of the lens/side extrusion is presently extruded separately using polycarbonate plastic. Polycarbonate is stronger than acrylic, and is used because the local stress are high at the crimped tabs, due to the crimping forces and the differential thermal expansion. Assembly costs can be saved by combining this attachment flange to the extrusion. This will also eliminate a joint which is a potential source of failure and water leakage.

Two possible scenarios are being considered for extruding the attachment flange with the lens and sides. One involves extruding the entire part from acrylic and the other involves co-extrusion of two different plastics: acrylic and polycarbonate. We favor the first option because the cost will be lower: only one extrusion screw is needed and the relatively expensive polycarbonate plastic is not used. However, tests will be necessary to determine if acrylic can be used in this high stress area. Minor changes in the design may be necessary.

By combining the lens and sides (including attachment flanges) into one extrusion, approximately 15 minutes assembly time can be saved per module. In addition, approximately $\$ 50,000$ in tooling per module assembly line can be saved. This translates to a savings of approximately $8 \notin$ per peak watt or approximately $1 / 2 \varnothing$ per KW-hr.

\section{Improvements in Optical Transmission}

Improvements in optical transmission will have a direct effect on material costs. Less acrylic, in the lens and housing sides, will be needed to generate the same amount of solar flux on the cells. (This line of reasoning is different than what is normally used in concentrator design. The lens area is normally held constant and changes in optical efficiency show up in the denominator in the dollars-perWatt calculation.) In addition, there is some small savings in shadowing losses and small reductions in the amount of structure needed to support less weight and wind loading due to slightly smaller lenses.

Small changes in optical transmission results in linear changes in lens width, which results in approximately linear changes in acrylic material used. Moving from a $77 \%$ optical transmission to a $85 \%$ optical transmission, (10.4\% improvement in optical transmission), will result in an approximate $10 \%$ savings in lens material. The cost of the extrusion is a large proportion of the module cost. The $10.4 \%$ improvement in optical transmission will result in a savings, after adding overhead and profit, of approximately $13 \varnothing$ per peak Watt or approximately $0.8 \varnothing$ per $\mathrm{KW}-\mathrm{hr}$. This does not include incidental savings such as structural material cost savings.

The optical efficiency is steadily improving. Our first lenses achieved less than $60 \%$ transmission. The latest lenses are over $78 \%$ transmission and we expect significant improvement by the end of 1991 . 
Our ray-trace computer program calculates $90 \%$ transmission for a lens that has facets formed as designed. The major cause of low transmission remains the form of the lens facets. Figure 14 shows a sequence of three lens cross sections. Lens Mod 1 is from the original 10 inch die. Lens Mod 2 results from changes to the die to improve the top surface. The bumps have been removed in the top surface but the facet faces are more convex. Lens Mod 3 is the result of modifying the die to reduce the convex shape of the facet faces. The die changes have gone too far, resulting in concave facet faces. We are in the process of making a new die that will incorporate the experience gained on these three die changes. We expect $85 \%$ transmission on this new die.

After the correct lens facet form is obtained, the die can be polished and hardened. This will result in improved transmission due to improved surface quality.

\subsection{Module Assembly}

At a production rate of $100 \mathrm{MW}$ per year, a factory must produce approximately $1,000,000$ modules each year. Running two 8 hour shifts five days/week requires the assembly of 312 modules/hour or 5.2 modules/minute. Efficiently meeting this production rate will require automation. Inexpensive robotic mechanisms will offer the manufacturing flexibility required to keep the procedure economical. Significant effort has been made to make the assembly of the module simple. However, adapting this operation to full automation requires consideration of the following design parameters:

\section{Loading and Unloading Components}

The module is assembled from the following components:
1. Receiver Assembly
2. End Caps (2 ea.)
3. Lens/Side Extrusion

The speed of an assembly operation can never be faster than the speed at which parts can be loaded into the assembly operation and finished assemblies unloaded from the process. For an automation strategy to be efficient, parts must be loaded in an orientation where they can be handled and positioned reliably. This usually means that parts are handled in a bulk form that maintains orientation between processes. Magazines or carriers of "nested" parts are a typical way of doing this.

The receiver assembly has been designed to be nested. Nested receivers self-align and can be stacked as many as forty high without danger of damage to fragile areas such as the cells.

The End Cap is inherently nestable and SEA Corpore tion intends to add design features to improve the stacking density. Gripping/Indexing features will also be added to the End Cap as the automation tooling for the Module Assembly is defined. 


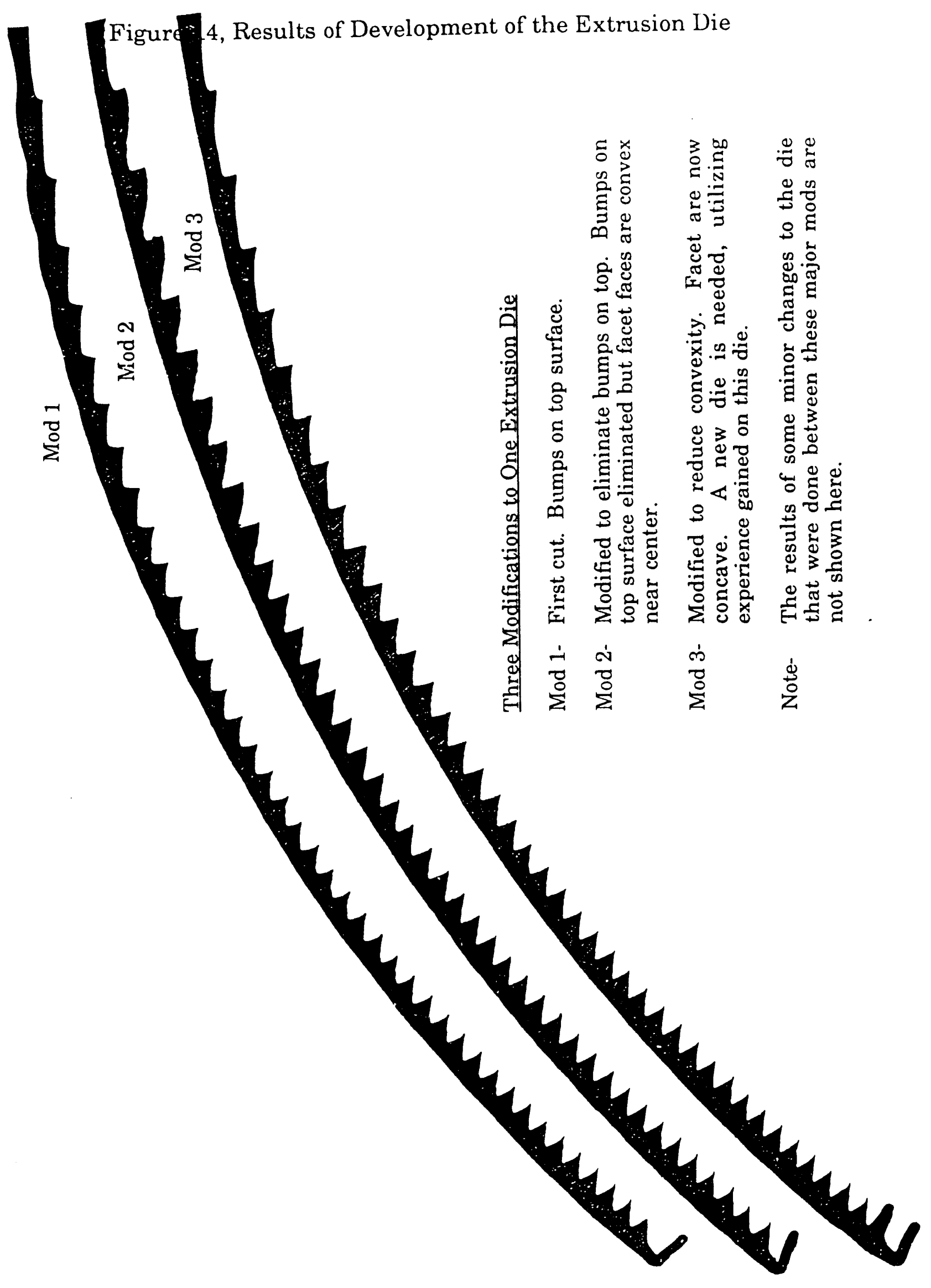

Page 43 
The Lens/Housing Extrusion, because of its geometry, cannot be stacked with a high density. It can, however, be loaded directly into the assembly station as it is unloaded from the extrusion line. Other queuing strategies will also be investigated during the design of the factory.

\section{Self-Locating Assembly}

The Lens/Housing is a relatively large assembly which requires close registration of interlocking features before bonding can take place. In assemblies requiring close registration of parts, self-locating assemblies have lower process complexity than assemblies requiring external registration of parts. Self-locating minimizes the tolerance stack-up of mating features, complicated by the tolerance of component grip points and robot precision by creating a geometry on the mating features which lead the parts into the correct registration. Tooling designed for this strategy must first position the components within the tolerance required by the lead-in, then allow flexibility as the parts are mated so that they can lead each other into the correct registration. The assembly operation planned for the Lens/Housing is outlined below:

1. End Cap to the Lens/Side Extrusion

a. The end cap will contain lead-in features to guide the extrusion edges into its mating groove.

b. The lens/side extrusion will be fixed in the lens-down position by vacuum chuck. This is a flexible part, but will be held by the vacuum chuck in its desired shape. Vacuum gripping the extrusion near the mating edges will minimize tolerance stack-up because the actual mating surface is registered directly.

c. The fixture gripping the end cap will be referenced on the pivot pin and fixed in rotation by the tracking pin. This gripping fixture can be designed in such a way to allow lateral displacement of the end cap when displacement along the axis is resisted. This will allow the parts to self-locate.

d. Solvent adhesive will be injected into the mating joints. The assembly remains undisturbed while bonding occurs.

e. The gripping fixture will be locked as the vacuum chuck is released. This completes the assembly of the lens/housing.

2. Receiver to the Lens/Housing Assembly

a. The lens/housing remains referenced from the previous operation.

b. The receiver will be positioned by robot over the mating cavity of the lens/housing and moved into the mating cavity. The lens/housing 
assembly contains lead-in features for the receiver causing it to be selfaligning.

c. The receiver is fixed by crimping of heat sink tabs.

3. Insertion of Bearings

a. The pivot pin contains a lead in for the bearings.

b. The module assembly remains referenced on the pivot pin and fixed in rotation by the tracking pin. The gripping fixture on the bearings allows lateral displacement of the bearing when displacement along the axis of insertion is resisted. The parts self-locate.

c. The bearing shaft is released. The module is now referenced by the bearings and keyed in rotation by the tracking pin.

\subsection{Array Assembly}

With a factory running two shifts at a production rate of $100 \mathrm{MW} /$ year, arrays must be produced at a rate of one array every 1.9 minutes. Array assembly is a very simple task with few operations.

Using manual assembly and a properly designed work cells, two unskilled persons could keep up with the anticipated production rate. This however does not make manual assembly cost effective. Highly repetitive unskilled tasks are usually have high error rates when performed manually. These tasks are best left to automation when possible.

SEA Corporation plans to automate this process. Array Frame struts will be roll formed and nested in stacks for transfer to the assembly process. Top and bottom ${ }^{~} \mathrm{C}$ " sections will be captured end to end on a linear traversing mechanism such as a conveyor. Nested struts will be fed into a positioning fixture on the line and fastened on the " $\mathrm{C}$ " sections as it is indexed to the appropriate position. The frame can be fastened by spot welding or clinching.

Modules will be fed into the Array assembly station, referenced by the bearings. Module are lowered onto the Array frame and fastened. To improve the manufacturability of the array, the frame and bearing strap can contain mating snap-together features which require only insertion to retain and rigidly fix bearing mounts. The gripping fixture is designed to allow the parts to self-locate.

The array can be off loaded onto special skids designed to be inserted in standard shipping containers. The array assembly procedure is shown in flowchart 5. 
Flowchart 5, Array Assembly Procedure

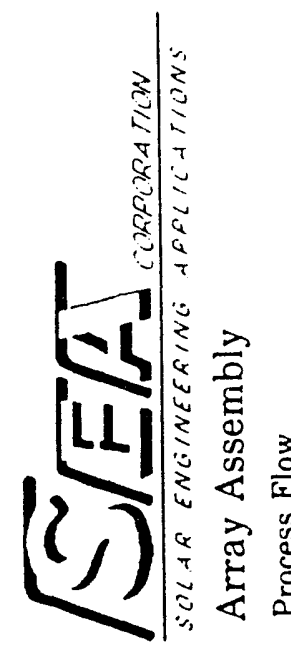

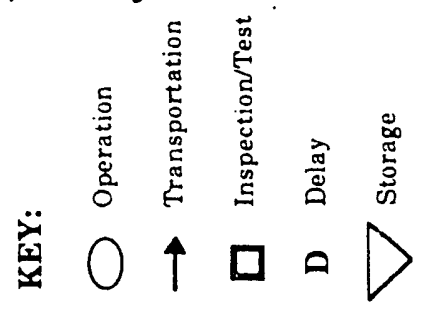
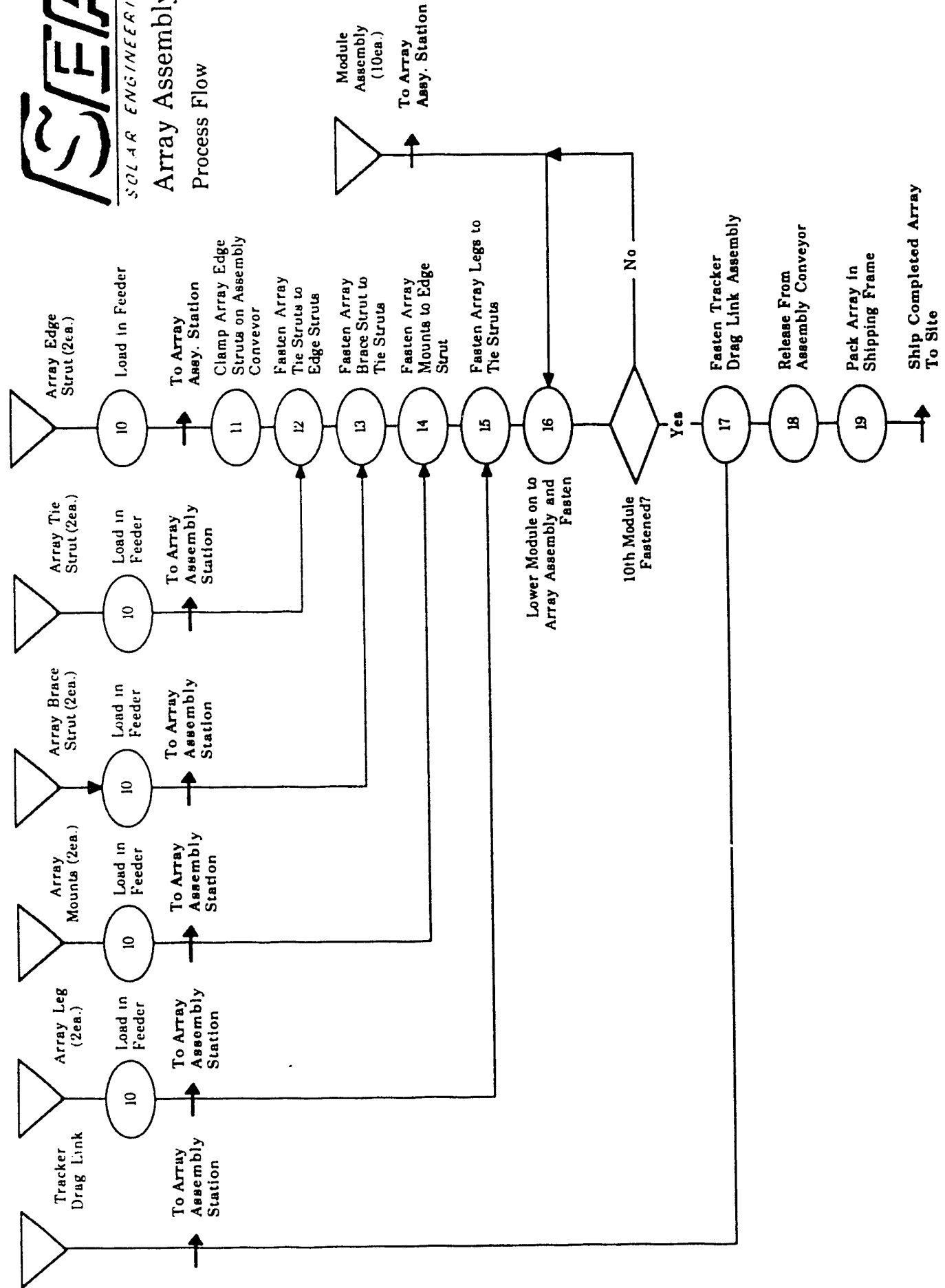


\subsection{Shipping, Field Setup}

The SEA $10 \mathrm{X}$ concentrator array is designed to lay flat during shipping. There is a cost saving in using standard shipping containers. Arrays could be nested in self supporting stacks to be packed in modified shipping containers.

The SEA 10X Concentrator Array is designed for simple installation. For large installations, there is a cost advantage in using specially designed equipment that will move them into position and drive the four ground stakes. 


\section{$6 \quad$ Impediments to Improvements}

Most of the required improvements are straight forward and do not include any major breakthroughs for their success. Material and process development and some research is needed to carry them out. The optimum procedures and materials are as yet not defined. The basic concepts are known but not the details. For example, three scenarios have been identified for the automation of the receiver assembly, and we believe that the ISA method is most cost-effective, but exact procedures and materials have not been quantified to the point where a final decision can be made and capital committed.

\subsection{Receiver Assembly}

There are a number of problems to be resolved before automation of the receiver assembly can be accomplished.

\section{Cell Orientation}

The cells must be bonded to the heat sink in alternating left hand and right hand orientation. Of four possible orientations, only one is correct. The cells are geometrically symmetrical making if difficult to mechanically assure that they are oriented correctly. Visual inspection by a worker during the loading of cell magazines is an unreliable method. A cost effective solution must be found.

\section{Leads Manufacture}

The leads are made of 0.003 inch thick soft copper and are easily bent. The tiny fingers on each lead makes the parts difficult to stack in magazines without the danger of the fingers in adjacent leads becoming interlocked making them difficult to separate.

The combination of soft material and 0.003 inch thickness makes the leads more difficult to stamp without damage or burrs. Few manufacturers have experience or have designed tooling for material with these properties.

\section{Receiver Assembly Scenarios}

We believe that the ISA assembly method is the most cost-effective, but this is not certain at this time. Each scenario needs to be further studied before committing to one. There are also questions pertaining to each individual scenario. 


\subsubsection{Scenario 1, Group Assembly in Fixture}

This scenario is an automated version of the current manual assembly technique. Although the technique works well in the manual version, automating the process requires addressing several potential problems.

1. The precision of the parts placement must be adequate to prevent part interference with the reference edges of the fixture.

2. Detection apparatus is required to assure that cell or lead is not cocked in its cavity.

3. The tooling required for this scenario creates process inflexibility.

\subsubsection{Scenario 2, Separate Cell Assemblies}

As a general rule, reducing a process to a repeatable pattern is desirable. Whether this applies to this particular case requires consideration of the following:

1. Additional tooling will be required to create the separate cell assembly.

2. An additional cell/lead handling step is required to move the separate cell assemblies to the receiver. This step has an associated cost and failure rate.

3. The diode cost is a critical factor in the economy of this scenario. Can the diodes cost be lowered?

4. The number of electrical connections is increased with an associated failure rate.

\subsubsection{Scenario 3, In Situ Assembly (ISA)}

SEA Corporation believes that ISA has the greatest potential of the three scenarios for cost-effective receiver assembly. The following issues, however, need to be addressed:

1. The dry adhesive film used in this scenario is new to this application and needs to be tested and qualified.

2. Testing must be done to assure that an automated process can utilize the dry adhesive film effectively. Void free bonds are required.

3. Additional tests need to be performed to assure that parts fixed on the film's tacky surface can be soldered reliably. Solder joints on the back face of the cell cannot be easily inspected. 
4. The adhesive film probably cannot be cleaned after the soldering process. Tests need to be performed to assure that the conformal coating can be applied over the soldered assembly when using a no-clean flux.

\subsection{Heat Sink Manufacturing}

\section{Aluminum Forming}

Although a preliminary investigation has been made into the tooling required to form the heat sink, a significant effort is still required to determine which combination of tooling is most cost-effective, while providing the maximum flexibility to design changes. The forming tooling is expensive and must be reliable. The line must incorporate manufacturing flexibility to respond quickly to design changes at a minimum cost.

\section{Coating}

The coating on the heat sink provides both environmental protection for the aluminum and electrical isolation for the cells. Three processes are under consideration at SEA Corporation. These are: anodic coating (hard anodize), electrophoretically applied dielectric coatings (EP coating), and anodic coating plus EP coating. Questions remain as to which process provides the most costeffective solution to assuring a 30 year life for the receiver assembly. EP coatings are new and may require additional process and material development while an anodic coating is a new use for an estaiblished process. There are environmental and safety issues to consider. The EP coating process is more benign than the anodizing process.

\subsection{Cell and Diode Manufacturing}

\section{Cells}

The SEA 10X concentrator uses one-sun cells at low concentration. These cells use screened metalization.

Screened metalization has the disadvantage of high contact resistance and high series resistance. High contact and series resistance is not much of a problem at the current densities associated with one-sun operation, but can contribute to low fill factors at concentration. Testing shows that, at 5 suns, the fill factor can be greater than $80 \%$. with present screened metalization technology, which should give cells of greater than $15 \%$ efficiency.

The contact and series resistance of one-sun cells with screened contacts needs to be improved. If they can be made with fill factors approaching those of evaporated contacts, then there will be a significant performance/cost improvement. 
The solderability of the screened metalization will have to be improved. The metal includes a glass frit which acts as a binder during firing. It also includes other additives which makes it hard to wet with solder.

As new one-sun cell technologies come along, they need to be evaluated for use at low concentration in the SEA $10 \mathrm{X}$ concentrator. New cell technologies, which cut the cost of flat panels, could also cut the cost of the SEA 10X concentrator, if they can be adapted for use at low concentration with no added cost.

\section{Diodes}

The manufacture of the diodes is relatively straight forward and no major impediments have been identified. The solderability of the metalization, as discussed above, pertains to the diode as well. Optimization of the size and material properties are necessary.

\subsection{Lens/Side Extrusion}

\section{Combining Lens and Sides}

Combining the lens and the housing side (including the attachment flange) is untried and may present a number of difficulties. Combining the parts may introduce a process control interaction where control of the side geometry affects control of the lens geometry. Since the lens geometry is critical to the function of the product, unstable process control may increase the reject rate and, thus, increase the ultimate cost of the product. Also, the extrusion rate may be slowed to the point where the savings gained in less process steps may be lost in longer production time.

The stress levels in the attachment flange may require the use of polycarbonate plastic in this area. This would require co-extruding with two different materials which would raise production costs.

\section{Improvements in Optical Transmission}

It may not be possible to achieve lens transmissions as high as theory predicts, (90\%), using the extrusion process. Since the extruded lens is approximately one third the cost of the lens of our nearest competitor, it is still cost-effective even at the present optical transmission level of $78 \%$. Improvements in lens transmission will only improve the cost-effectiveness.

The major impediment to improving lens transmission is the time and expense. The lens manufacturer is reluctant to stop his production line, which is making a cash product, and experiment with lens dies. The production line must be stopped and the lens tooling mounted and tested. It is not uncommon to disassemble the setup and make several minor changes to the die several times in one session. Also, changes to the die and new dies cost money. There has been significant cost sharing by the lens molder in past efforts. 
An improvement in the geometry and surface quality of the lens has been demonstrated with post extrusion forming, where precision rolling dies re-form the lens facets. Outside of laboratory tests, however, this technique is untried.

\subsection{Module Assembly}

Automated assembly of the module parts is untried and needs to be demonstrated. The optimum assembly process needs to be defined with a minimum outlay of time and money. Concurrently, the parts should be evaluated and modified where necessary for automated assembly by adding such items as gripping features and improving the stackability of the parts.

Most of the present module parts have lead in features and are self locating. Some parts, like the Lens/Side Extrusion, can be handled directly and immediately as they are passed from one process to the next and therefore do not require stackability.

\subsection{Array Assembly}

The impediments to automated array assembly are basically the same as those for automated module assembly: The optimum process needs to be defined with a minimum outlay of time and money. The parts should be evaluated and possibly modified for automated assembly.

In addition, the size of the array is a problem. Commercial robots are usually designed to handle small items.

\section{Fastening}

The best means of fastening the steel Array Frame has not been determined. Spot welding is simple and commonly used in similar situations but spot welds have the disadvantage of being difficult to inspect. Bad welds may not be detected until they fail. If something is wrong with the welding station, delayed knowledge of the problem can be very costly.

Clinching is a fastening technique which "staples" two sheet metal components together. A special tool is used which cuts and distorts a small area interlocking the two sheets in the process. It creates strong joints which can be easily inspected. The geometry of clinching tools, however, puts more limitations on part geometry than the more adaptable spot welding apparatus.

Both spot-welding and clinching have the disadvantage of disturbing the original metal surface. This means that parts must be environmentally coated after joining. A process that coats components just prior to assembly may have logistical advantages in the manufacturing process. 


\section{Environmental Coating}

The optimum coating process is unknown. Galvanizing has the advantage of being well developed and is self-healing for small scratches. However, discontinuities in the galvanizing may be introduce during assembly which are too big to be healed. It is impractical to galvanize the array after assembly. Also, the galvanizing process requires a separate environment from the other manufacturing processes. The cost-effectiveness and durability of alternate coatings, such as aluminizing, have not yet been investigated.

\section{The Array Support Legs}

The array support legs are manufactured at different lengths according to the latitude of the installation site. The tooling used to assemble the arrays must, therefore, adapt to the different leg lengths.

\section{Flexibility}

It is likely that the array design will change. The automation tooling must be flexible to these changes. For this reason, re-programable assembly robots may be preferable to hard tooling. 


\subsection{Shipping, Field Setup}

There is a cost advantage to shipping stacked arrays in reusable containers. A standard shipping container may have additional cost advantages due to the specialized equipment already in existence to manufacture and transport these containers. Preliminary investigations have indicated that non-standard containers may limit the available carriers and increase shipping costs. However, the array size will have to be adjusted to fit into a standard shipping container.

Standard pre-loaded containers are shipped at a "box rate" rather than by weight. This means that an increase in the packing density of arrays will have a direct effect on the shipping cost. In order to gain the cost advantage of container shipping, the packing density of the stacked arrays needs to be improved. 
The Solutions to Impediments section is framed in terms of a number of specific tasks which are designed to solve the problems described in Section 6 above. These tasks, listed below, will be described in detail.

- Automation of the receiver assembly

- Automation of the module assembly

- Automation of the array assembly

- Development of a one piece lens and module holising sides extrusion

- Improvement of extruded lens optical transmission

- Automation of the heat sink manufacturing

- Research and development of cell adhesive and encapsulation

- Development of soldering process

- Development of an optimized factory layout

- Development of one-sun cells for use at low concentration

\subsection{Automation of the Receiver Assembly}

An optimized automation process for assembling the receiver needs to be developed using the cost effectives techniques of prototyping and computer modeling. All three automation scenarios should be subjected to a preliminary investigation. The one scenario that shows the most promise should be subjected to a complete investigation. This effort needs to be carried on concurrently with the continued development of the receiver desig... The receiver parts must interface easily with the automation equipment. The process must be robust and adaptable.

Related to automation of the receiver assembly are investigations of adhesive systems to bond the cells to the heat sink, investigations of soldering operations and heat sink manufacturing automation. These subjects are presented as separate tasks below but really should be carried out concurrently with the automation of the receiver assembly. Continued environmental and performance testing of the finished receivers is necessary to assure continued quality.

The automation of the receiver assembly effort can be broken down into the following specific areas:

- Assembly process development

- Cell handling optimization

- Lead manufacture and handling optimization

- Process characterization 


\section{Assembly Process Optimization}

In automated assembly of the receivers, the reduction of the time required for different operations is critical to reduce costs. (Assuming a two shift, $100 \mathrm{MW} / \mathrm{yr}$ production, one receiver must be produced every 11.5 seconds.) The assembly procedures need to be analyzed and refined, using prototyping and computer simulation, to produce the most time efficient process.

Time and motion studies are necessary part of an efficient process design. More expensive equipment is often faster then less expensive equipment, but the cycle time of a given operation has more to do with manufacturing strategy than the speed of the equipment. For example, the maximum speed obtainable in the placement of a component is limited by many factors including the distance traveled, the mass that must be accelerated and decelerated to perform the operation, and the number of sequence dependent motions. For this reason, reduction of both the mass and motion invested in the placement of a part, is a critical factor in increasing the crocle rate of the operation without increasing the capitol invested in the equipment.

Consider Assembly Scenario \#3 outlined in Section 5.1.3. An automation plan for (1) tinning a cell lead and (2) assembling it to the receiver may require 20 seconds under the following plan:

1. Position vacuum pick over lead

2. Lower vacuum pick to lead

3. Lift the lead from the magazine

4. Rotate the lead sideways (fingers down)

5. position lead over flux bath

6. Lower lead into solder flux

7. Raise lead

8. Move lead to solder pot

9. Lower lead into solder (tinning)

10. Raise lead

11. Position lead over flux bath

12. Lower lead into solder flux

13. Raise lead.

14. Rotate leads to original "flat" position

15. Lay lead in carrier on conveyor

16. Release lead and raise pick

17. Return pick to first position

18. Move lead in carrier to second station

19. Position second vacuum pick over lead

20 . Lower vacuum pick to lead

21. Raise lead from carrier

22. Receiver is indexed to the required " $\mathrm{X}$ " position

23. Move lead over the required " $Y$ " position on the receiver

24. Lower lead into position on receiver

25. Release lead and raise pick

26. Return pick to first pôsition 
Faster equipment would probably have a small effect on the cycle rate. However, using a strategy of mass and motion reduction and limiting the number of sequence dependent motions, the cycle time can be reduced without the purchase of faster machinery. In the example below, the cycle time has been reduced to four seconds.

1. In a continuous process, leads are fed from a coil over a series of rollers through a fluxing bath, a solder pot (tinning), and another fluxing bath.

2. The end of the lead strip is fed through a registration slot and across a vacuum pick where it is stopped momentarily with a friction break as the end touches a detector. As the end of the strip is stopped, the strip ahead of the break continues to feed and the slack is taken up by a short loop.

3. The lead is captured by vacuum and sheared from the strip with a cutter.

4. The pick is rotated down $180^{\circ}$ so that the lead is held at the required "Y" position, just above the receiver (pick pivot has been positioned so that no " $\mathrm{Y}$ " motion is required).

5. Receiver is indexed to the required " $\mathrm{X}$ " position.

6. The lead is lowered onto the receiver.

7. The vacuum is released and the pick is raised

8. The pick is returned to the first position.

\section{Cell Handling Optimization}

Proper cell arrangement is necessary to assemble a receiver. Cell arrangement involves current matching cells in groups for receiver assemblies, and orientating the cells in magazines or cartridges to assure they are placed correctly on the receiver. Candidate cell arrangement strategies need to be analyzed to determine the most cost-effective system for accomplishing this. Process recovery from factors such a cell breakage or cell mis-orientation must be considered in the analysis.

Incorporating the cell arrangement with the cell IV testing, may be the most appropriate cell arrangement strategy. The cells must be oriented when they are tested and testing provides the information needed to current match the cells. Automatic handling at this point is very economical and unlikely to introduce errors. Automated cell testing is currently being developed at various cell manufacturers. Coordinated effort with potential cell vendors is necessary to develop appropriate processes and equipment.

Automated cell handling equipment must be prototyped. The equipment must be designed to precisely handle the cells rapidly without breaking them. To be cost effective, the system must accommodate the normal dimensional tolerance of the cells of \pm 0.02 . Vacuum pick apparatus has proven effective for cell handling and $\mathrm{SEA}$ plans to incorporate this technology in their equipment. 
If cell breakage occurs undetected, the receiver assembly will fail in testing and be scrapped. The breakage rate of the cells will determine how the manufacturing process must respond to the problem. If cell breakage is unusual, scrapping an occasional receiver may be more cost-effective then detecting and correcting the problem during assembly.

\section{Lead Manufacture and Handling Optimization}

Lead manufacturing and handling are special problems because the leads are made of 0.003 inch thick soft copper. Development of cost-effective, special tooling and handling equipment is needed. Prototyping and analysis of the projected manufacturing and handling processes are required.

Common tooling is inadequate to cut this thin, soft material. A precision die with close clearance is required to prevent burrs at the stamped edges. Although this soft material requires a special die design, it will cause less wear to the die giving the tooling a longer life.

The current production strategy is to stamp the leads in continuous strips and store them in coils. A paper strip separator is wound between the wraps to prevent the "fingers" from interlocking and bending each other. The lead strip can then be handled by pulling the strip from the coil into the process with a drive roller. During the tinning operation for example, the strip can be pulled across a series of rollers to draw it in and out of flux and pre-tinning solder vessels. Once at the final assembly station, the leads can be separated from the strip with a shear while held in a vacuum pick and then placed.

\section{Process Characterization}

Process characterization is needed to determine the optimum parameters for the assembly procedure. It is also needed to determine the robustness of the process: how far the parameters can be changed before quality is reduced beyond acceptable limits. Robustness is needed for cost-effectiveness.

Statistical experimental designs need to be generated and performed on the processes. This information would be used to assure product quality at the minimum cost in the following ways:

1. Setting process variables to optimum levels- Strategic test results will identify parameters which will make the process insensitive to variations in factors that are expensive to control, such as normal variation in component geometry, materials properties, environmental factors, etc.

2. Identifying key process parameters- Key process parameters will be monitored and used to control the process upstream, thus, minimizing variation in the product. 
3. Developing QA strategy- A statistical model will aid in understanding the process reliability. This will identify where testing is required to assure product quality.

\subsection{Automation of the Module Assembly}

An optimized automation process for assembling the plastic parts of the module needs to be developed using prototyping and computer modeling. This effort needs to be carried on concurrently with the continued development of the end-caps, lens/side extrusion and the receiver. As with the automation of the receiver assembly, the parts must interface with the automation equipment and the process must be robust and adaptable.

Related to the automation of the module assembly is the automation of the receiver assembly and automation of the array assembly. Each process feeds another. These tasks, along with layout of the factory, should be done concurrently.

The automation of the module assembly can be broken down into the following areas.

- Assembly process development

- Design for automation

- Process characterization

\section{Assembly Process Development}

An effort, similar to the development of the automated assembly of the module, is needed for the automated assembly of the receiver. The assembly procedures need to be analyzed and refined, using prototyping and computer simulation, to produce the most time efficient process. Time and motion studies are necessary. Refinement of assembly motions is needed to simplify the required assembly motions, shorten handling distances and reduce the number of assembly steps. Manufacturing strategies need to be tested using both hardware and computer simulation. (Computer simulation software is available through the Automation and Robotics Research Institute in Forth Worth, Texas.)

\section{Design for Automation}

An effort to design the module components for automation, concurrently with the design of the automation process will be required. The design task should include the following:

1. Simplification of component design to reduce manufacturing complexity. Stackable parts are desired.

2. Investigation of most cost effective reference surfaces and grip/transfer points evaluated from a manufacturing "system" perspective. 
Process Characterization

Process characterization is needed to determine the optimum parameters for the assembly procedure and to maximize the robustness of the process. This effort is similar to the effort needed for the automation of the receiver assembly.

\subsection{Automation of the Array Assembly}

As in the receiver assembly and the module assembly, an optimized automation process for assembling the array needs to be developed using prototyping and computer modeling. This effort must be closely integrated with the module assembly.

Process development is necessary. Time and motion studies must be done to determine the most time-efficient process. (Assuming a three shift, $100 \mathrm{MW} / \mathrm{yr}$ production, one array must be produced every 2.86 minutes.) Computer simulation can be used in conjunction with prototype hardware.

The module and array assembly stations must be designed as a combined process so that assembled modules can be lowered directly onto the arrays as they are assembled. This will keep WIP levels low and reduce the required factory floor space.

An investigation will also be necessary to optimize the fastening technique used to join the sheet metal array parts. The most manufacturable process will be chosen on the basis of reliability and cost. Continued development of the array parts will have to be done concurrently with the assembly process.

Storage and shipping considerations will have to be considered. Use of a standard shipping containers has many cost advantages. Preliminary investigations indicate that the array can be modified slightly to fit into a standard container and that, by nesting, the array stackability can be improved to nearly double the present packing density. For overseas shipments, it may be more cost effective to ship the separate parts, which can nest, and assemble the modules and arrays on site.

\subsection{Development of a One Piece Lens/Sides Extrusion}

Combining the lens and sides into one extrusion must be tried as soon as possible. The effect on lens transmission can then be measured. Also, the effect on extrusion rate and process control interaction can then be measured. This will require a new die where the lens portion is made exactly as the existing lens die to isolate the effect of adding the side walls.

If the extrusion rate is too slow, then a larger extrusion screw may be tried. It may not be possible to push the extrusion rate with a larger screw due to flow factors in the die, cooling rate factors or other factors. This question of whether the lens and sides can be extruded as one piece must be answered as soon as 
possible because it effects the design of the rest of the factory equipment and procedures.

\subsection{Improvement of Extruded Lens Optical Transmission}

Development of the extrusion die should be pushed as far as possible. This will involve an exhausting series of die modifications and new dies. Polishing of the dies should be tried. Also, the effect of extrusion parameters on optical transmission should be determined. Different materials should be tried. There are some plastics which give a clearer part but cost more.

An improvement in the surface quality and geometry of the lens has been demonstrated with post extrusion forming, where precision rolling dies re-form the lens facets to more closely conform to the desired geometry. ${ }^{1}$ The concept involves adding a set of rolling dies after the extrusion die to re-form the acrylic while it is still hot enough to be plastic. SEA has designed a proprietary system that allows for fluxuations in the geometry of the lens as it exits the extrusion die. Outside of laboratory tests, however, this technique is untried.

A post extrusion forming machine should be built for the entire lens using our proprietary design. This device can be tested separate from the lens extrusion line using an oven to re-heat the lens to a plastic state. In that way, the problems of extrusion and post forming can be separated and the extrusion production line need not be interrupted. Transmission before and after post forming should be measured.

Any improvement in transmission by post forming will have to be carefully weighed against the added cost. If the transmission is only slightly improved, then the added cost and complexity may not be worth it. If it is determined that the post forming concept is cost-effective, then it will have to be tried on the extrusion line. This will be a costly test and should only be attempted after the benefit of post forming has been clearly demonstrated.

\subsection{Automation of the Heat Sink Manufacturing}

There are two aspects of the heat sink manufacturing which need to be addressed. One is the automation of the forming operation and the other is the automation of the coating used for electrical isolation, presently anodizing.

\section{Heat Sink Forming Automation}

An investigation needs to be done to determine the most cost-effective manufacturing process and equipment. The forming of aluminum products similar to the heat sink is a mature process and off-the-shelf equipment can be used. A number of vendors should be consulted. Turn-key setups are available. The design of off-loading and stacking equipment is also required.

1 The Design. Testing and Fabrication of an Extruded, Linear Focus Fresnel Lens, Neil Kaminar and Don Curchod, Sandia National Laboratories, Albuquerque, NM, Aug 1990, SAND90-7032. 


\section{Electrical Isolation Coating R\&D}

It is critical to the safety and efficiency of the SEA 10X concentrator that electricai isulation is reliable. Electrical isulation is provided in three places: the heat sink dielectric to isolate cells and leads, the conformal coating over the receiver assembly to protect the cells and interconnect from moisture, and the output connector which must seal the connector contacts from the environment. Tasks have been identified in each case to address possible problems, lower the cost, and improve the product reliability.

There are presently two options for electrical isolation between the heat sink and cells and leads. Anodizing, along with the adhesive system, is presently used. However, electrophoretically deposited coatings of styrene acrylate, (EP coating), have been shown to be an effective promoter of electrical stand off when applied to anodized and bare aluminum. The cost of the EP coating could be very low, (5 $\varnothing$ per square foot).

Material research is needed to determine if the EP coating can be used as an effective electrical barrier in a PV concentrator module. The questions that need to be answered are: What is the expected lifetime of EP coating in a PV concentrator environment? What is the effectiveness of EP coating for electrical isolation in a PV concentrator environment? And, how robust is the EP coating process? The EP coating must be compared to the anodizing process, which is mature and well defined.

Cost-effectiveness should be based on automated processes. Once the acceptability of the EP coating is determined, its cost must be determined. An automated process must be defined and compared to an automated process for anodizing.

Process development for the most cost effective coating should include the use of prototype hardware and computer simulation. Environmental aspects will have to be considered. The chemicals used in the EP coating are relatively benign compared to the chemicals used for anodizing. Human contact with the hazardous materials must be minimized. This can be accomplished with a proper design of the automated process.

The robustness of the process must also be considered. Predictably uniform coatings are necessary.

\subsection{Research and Development of Cell Adhesive and Encapsulation}

The adhesive system used to bond the cell, leads and diodes to the heat sink and the encapsulation system used to prevent shorts, leakage current and damage caused by moisture are related by the similarity of the materials and processes. Both systems presently use a wet silicone process. 
Development of adhesive and encapsulation materials and processes are generic to receiver assembly to a degree. The SEA $10 \mathrm{X}$ system is unique in that the concentration is low enough, and the aperture area is small enough, that materials with low thermal conductivity can be used without the cell junction temperature becoming too high. Also, the adhesive is used to hold the parts in place in the In Situ Assembly, (ISA), which requires the adhesive to remain tacky and survive the soldering of the leads to the cells and diodes.

\section{Adhesives}

SEA Corporation must continue to improve and refine the techniques used to adhesively bond the cells, leads and diodes to the receiver. Both "wet" and "dry" processes are currently being developed. The dry technique is preferred because it allows a more cost effective receiver assembly technique, but the wet technique is being pursued as a backup process. Material research is needed along with process development.

The wet process involves the use of a thixothropic Room-TemperatureVulcanizing, (RTV), heat-conductive silicone rubber. The RTV can be applied with a spray, paint, screen or roller printing process. Experiments continue to be performed to improve the application techniques. New tooling must be developed to provide a uniform adhesive thickness and reliable void free bonds. Airless mixing techniques and experiments with accelerated cure are also important.

The dry process, pioneered by SEA, is a cell bonding technique using a propitiatory adhesive which can be calendered to the desired thickness, and saved as a film until needed. After application, it is cured to form a permanent but flexible bond. Preliminary tests with this material have provided good void free bonds of cells to the heat sink. Apparatus must now be developed to allow this process to be performed automatically. Using this apparatus as a test bed, the appropriateness of this process to automation can be determined.

Material studies of the adhesive film material are needed which should include an investigation of material compounds, fillers and thicknesses. Test receivers, assembled with different adhesives, should be subjected to performance and environmental tests.

The dry process is used to hold the cells, leads and diodes in place during the ISA receiver assembly technique. It must provide a tacky surface to hold the parts in place and must withstand the heat of soldering. Preliminary tests indicate that the material can perform these duties. Further testing is required, especially with prototype automation. This adhesive system must be concurrently developed with the soldering process and the receiver assembly automation.

Adapting the dry process to automation will require process development. The cost-effectiveness must be addressed along with quality control and robustness of the process. Integration of the dry process to the automated receiver assembly must be accomplished. It is important that the process be developed concurrently with continued development of the cells, leads, diodes, connectors and heat sink. 


\section{Encapsulating}

There are also two systems for encapsulating the receiver: a wet and a dry process. The encapsulant must provide protection from moisture and provide electrical isolation in wet conditions.

The wet system is presently employed by SEA and other PV module manufacturers. It is a silicone RTV conformal coating which is applied by brush or dip or spray processes. The spray process is more adaptable to automation. Existing spray machines, or new design spray machines, could be adapted to the SEA 10X concentrator manufacturing line. A uniform coating of bubble free and pinhole free coating is desired but sometimes hard to achieve with the wet process.

The dry encapsulating system is similar to the dry adhesive system. A propitiatory film is produced, which can be calendered to the desired thickness, and saved until needed. After application, it is cured to form a tack-free surface. The film can be rolled down to form a void free, pinhole free covering. Preliminary tests with this material to provide reliable dielectric protection, but more development is required, especially using automated application machinery.

\subsection{Development of Soldering Process}

The soldering process needs to be developed using prototype automatic machinery. The hot bar process is the most promising. Complete process characterization is necessary because testing of each solder joint is impractical. Soldering process development is generic to receiver assembly but the SEA 10X module has some unique features. Continued development of the leads and cell metalization need to be done concurrently with the solder process development.

Automatic machinery should be used for process development. Although manual implementation of the proposed soldering techniques has provided good results, it may not accurately model the same techniques performed with automation equipment. Experienced gained using a manual method is generally not transferable to an automated processes. Testing of the soldering process using automatic equipment is required to assure reliability of the receiver solder joints in production.

The hot bar soldering process should be developed. There are several processes that are usable, but the hot bar soldering is the most promising. It is adaptable to the ISA technique. It has proven to produce reliable solder bonds at the Automation and Robotics Research Institute. 
Complete process characterization is necessary. Testing or inspection of each solder joint is impractical. Once the correct parameters are determined for a good solder joint, then process monitoring is only necessary to produce the desired quality control. A statistical experiment needs to be designed to determine such factors as: the sensitivity of the process to parameter changes, the key process parameters and the process robustness. Parameters such as temperature cycle, time, and pressure should be tested. Techniques must be developed to detect solder station malfunction.

Soldering process development is somewhat generic to receiver assembly but the SEA 10X module has some unique features. Most receivers use soldering to join leads to the cells. The screened metalization used for the cells in the SEA 10X module is unique in that it has a glass frit binder and other additives which reduces the solderability. Wetting is reduced. Also, the ISA technique is unique to the SEA $10 \mathrm{X}$ module. Soldering of the cell bottom leads must be accomplished by heat conduction through the cell while the cell is mounted on the heat sink. There are many small redundant fingers on the leads that have to be attached.

Continued development of the leads and cell metalization need to be done concurrently with the solder process development. The design of the leads, the solder formulation, the cell metalization, as well as the adhesive system will all effect the soldering process.

\subsection{Development of an Optimized Factory Layout}

An optimized factory layout must be developed using computer simulation. Each process must feed into the other without unnecessary movement or intermediate inventory. All aspects of the factory: inventory, storage, shipping and management functions, must be considered. The factory layout must be flexible to allow changes to the concentrator design. Rapid and cost-effective capacity scaleup must be possible.

For the most cost-effective manufacturing, an optimized overall factory layout must be developed. Computer simulation is an ideal tool for this effort. The layout can be studied without a great expenditure of money. Manufacturing timing must be studied and refined to assure that sub-assemblies are fabricated and delivered to higher assemblies as required. Factory planning should incorporate a strategy of minimum intermediate inventories.

Each process, receiver assembly, module assembly, etc. all feed another process. These processes must be coordinated so that minimum transportation or intermediate inventory is required. An excess of running conveyer belts throughout a factory are often a sign of poor planing. The factory must be designed with each process efficiently handing off parts to the next process. Parallel paths are necessary for minimum down time should one process station be temporally out of order. Parallel paths also promote easy and cost-effective capacity scale-up. 
All aspects of the factory layout must be considered. It should be well coordinated. Inventory needs to be readily accessed by receiving and the first process in line. Shipping should be located to easily accept the finished arrays. Management requires access to all parts so that it can monitor the processes. The factory also needs to be ergonomic: it must be designed for human interaction.

Maintaining factory flexibility is necessary to efficiently respond to changes in the concentrator design. To remain competitive, the concentrator design must be receptive to change. There may be breakthroughs in cells or other components. The factory must be designed so that it can accommodate these changes. Smaller working units, that can be changed easily, are preferable to a large investment in a specialized piece of machinery that could become obsolete, or worse still, force the design to stagnate.

The factory must also accommodate rapid capacity scale-up with minimum cost. There must be room to grow. Smaller working units, that can be added in parallel to existing units, are preferable. This will also allow minimum down time, as discussed above. Because parallel stations are duplicates of existing equipment, they do not require the learning curve commonly associated with scale-up. SEA is planning rapid growth and the factory layout must be done with this in mind. A plan for upgrading factory capacity at stepped levels of production must be produced.

\subsection{Development of One-Sun Cells for use at Low Concentration}

Research and development of one-sun cells for use at low concentration is needed. Some effort is being expended now, but parallel paths need to be perused. Changes to the cells must not add cost, or deviate from the standard one-sun manufacturing procedures. Screened metalization may be the most cost-effective, and should be refined for use at low concentration.

An $R$ \& $D$ effort is needed to adapt one-sun cells for use at low concentration. The SEA 10X concentrator is able to capitalize on any efforts to improvement the overall efficiency of one-sun cells, but the adaptability of these cells to low concentration is not being considered by these efforts. A separate effort is needed.

Some efforts to develop low concentration cells are being done, but parallel efforts are needed. Laser-groove cells are being developed by Solarex and others, but it is not clear at this time if these cells are going to be as cost-effective as one-sun cells with screened metalization, especially considering recent tests showing that screened metalization is usable at low concentration. There may be other one-sun cell technologies that are adaptable for use at low concentration, for instance, the new Texas Instruments' cell that uses small spheres of silicon or a thin film technology. By focusing all effort on the laser-groove cells, these other possibilities, which could be more cost-effective, are ignored. 
Whatever is done to one-sun cells to adapt them to low concentration must rot add cost or cause the manufacturing process to deviate from standard one-sun techniques. One-sun cells are viewed as commodity products. The manufacturing facilities are in place. Large investments have been made in these facilities and for that reason there is reluctance to change, especially for a cell order that is viewed as a specialty item. The changes necessary to adapt the one-sun cell to low concentration must fit into the existing manufacturing line. For instance, changes in the screening mask would be acceptable while changing to an evaporated contact would not. Concentrator cells will always be a specialty order because much less cell area is needed. A one-sun cell manufacturer could supply enough cells for an equal electrical output of SEA 10X concentrators by adding just $10 \%$ more capacity.

Screened metalization may be the most cost-effective technique and should be investigated. All one-sun cells now commercially available use screened metalization. Contact resistance and series resistance have traditionally been thought of as too high with screened contacts for use at concentration, but recent tests at. SEA and Sandia have shown that it is possible to use screened cells at low concentration. This is really the very first attempt to use screened metalization. AstroPower is now working on a second batch of cells which are expected to be much improved in efficiency. Further optimization of the doping, gridline design and screen ink could produce cells with efficiencies approaching the efficiencies of cells with evaporated contacts at a fraction of the cost. At the same time, the solderability of these cells could be much improved by modification of the screen ink. 


\section{$8 \quad$ Time and Cost Estimates}

Presented here are estimates of the time and cost necessary to carry out the efforts described in Section 7. These estimates are presented separately, but the efforts must really be carried out concurrently: automated assembly techniques must be developed concurrently with the materials employed and with the overall factory layout. There is cost savings in concurrent development too, due to the efficiency of effort and equipment. The estimates presented here are assuming concurrency. They include some capital equipment such as robots that would be used in prototyping a process and could also be used in the final production.

\section{Estimated time and costs}

\begin{tabular}{|l|r|r|r|}
\hline Task & Duration & Labor costs & Other costs \\
\hline \hline Automation of Receiver Assembly & 3 years & $\$ 450,000$ & $\$ 150,000$ \\
\hline Automation of Module Assembly & 3 years & $\$ 350,000$ & $\$ 150,000$ \\
\hline Automation of Array Assembly & 2 years & $\$ 350,000$ & $\$ 200,000$ \\
\hline Development of One Piece Lens/Sides & 2 years & $\$ 150,000$ & $\$ 300,000$ \\
\hline Improvement of Lens Transmission & 2 years & $\$ 150,000$ & $\$ 300,000$ \\
\hline Automation of Heat Sink Manuf. & 1 year & $\$ 150,000$ & $\$ 500,000$ \\
\hline R\&D of Cell Adhesive \& Encapsulation & 2 years & $\$ 350,000$ & $\$ 150,000$ \\
\hline Development of Soldering Process & 2 years & $\$ 150,000$ & $\$ 150,000$ \\
\hline Development of Factory Layout & 1 year & $\$ 150,000$ & $\$ 50,000$ \\
\hline Development of One-Sun Cells & 3 years & $\$ 500,000$ & $\$ 100,000$ \\
\hline
\end{tabular}




\section{Summary/Conclusions/Recommendations}

The SEA 10X concentrator system was conceived as a low cost, mass producible product. With the improvements in manufacturing techniques described in this report, it could be produced at a selling price of $71 c$ per Watt and would generate electricity at $4 \varnothing$ per KW-hr.

No major impediments to these improvements exist. What is needed is a coordinated development effort. 
10 Appendices 


\section{Problems and Solution for Automated Manufacturing of a Photovoltaic Receiver}

An analysis and recommendations for the automation of Solar Energy Applications Corporations' photovoltaic receiver

By David G. Vanecek and Mick Fitzgerald

Automation \& Robotics Research Institute

\subsection{Introduction}

This report addresses the needs, problems and approaches related to automated manufacturing of the receiver assembly of the Solar Energy Application Corporation (SEA) $10 \mathrm{X}$ concentrating photovoltaic collector module. The receiver is assembled from: a 10 foot long heat sink formed from 0.032 inch thick anodized aluminum sheet, with PV cells attached, interconnected, and encapsulated, and includes bypass diode circuits and end connectors. Diagram 1 (attached) is a bill of znaterials stucture with the receiver components shown in shaded boxes a:d the other module components in unshaded boxes.

\subsection{Description of Receiver Assembly Process}

\subsection{General}

\section{Receiver Manufacturing Philosophy}

From its inception, the SEA receiver has been designed and developed for high quality, high volume production for a market which is expected to expand rapidly to include remote, peaking and bulk power generation. Maximum value must be added at the lowest possible cost. There will be increasing competitive pressures driving the need for continuous improvement of the product, and its production processes and methods Automation will be a means of improving quality and reducing cost of the receiver. SEA will be a world class PV system manufacturer.

\section{Qverall Procedure for Manufacturing of SEA Receiver}

There are four basic processes required to complete the assembly of the receiver once the heat sink has been fabricated, they are; assembly, interconnection, encapsulation, and material handling. Several other processes are closely coupled to receiver manufacturing automation but will not be directly addressed here. Interconnect plating, forming and feeding will effect assembly and soldering. Likewise, heat sink forming and finishing will effect assembly and bonding. There may be some processes that could be done in the receiver assembly area to facilitate module assembly such as sealant dispensing or hardware assembly. Common material handling and data requirements will probably exist.

\section{Receiver Assembly Flow Options}

Based on the development of the SEA receiver and its manufacturing processes thus far, three receiver process flow scenarios have been developed. These scenarios are a starting point which allow for the identification of potential automation equipment. As more specific information is available for these processes, the flow diagrams will be used to predict throughput and to aid in designing the automated receiver assembly systems. A description of each option is given below. 
(Option numbers here are different than the options numbers as described in the main text.)

\subsection{Option 1, In Situ Receiver Assembly}

A heat sink, with partially cured adhesive applied as a dielectric barrier and thermal bridge, is mounted on a holding/transfer device. Cell, interconnects, and diode strings are then assembled onto the receiver heat sink using a robot. The cell string is then soldered using a robot manipulated hot bar soldering end effector. A top layer of transparent encapsulant coating is applied over the cells and interconnects.

A flow diagram of Option 1 can be found in Appendix B along with preliminary estimates of cost and performance for each Option 1 workstation. The preliminary estimates of throughput for the Option 1 baseline configuration is 3.90 receivers per hour and an equipment/tooling cost of $\$ 325 \mathrm{k}$. Option 1 has the best baseline cost efficiency.

\subsection{Option 2, Cell String Build on Fixture}

In this case, the cells, interconnects and diode strings are all assembled, upsidedown, onto an assembly fixture using a robot. The cell string is then soldered using a robot with a hot bar end effector. The heat sink, with adhesive applied, is then lowered onto the cell string and cured. (A number of adhesives are being considered: wet adhesive, partially cured adhesive ribbon and others.) A top layer of transparent encapsulant is then applied over the cells and interconnects.

A flow diagram of Option 2 can be found in Appendix B along with preliminary estimates of cost and performance for each Option 2 workstation. The preliminary estimates of throughput for the Option 2 baseline configuration is 3.86 receivers per hour and an equipment/tooling cost of $\$ 578 \mathrm{k}$. Option 1 has the best baseline cost efficiency. Option 2 has the second worst baseline and apparently the worst ramping cost efficiency.

\subsection{Option 3, Discrete Cell Assembly Build}

In this scenario, cells, interconnects, and diodes are all first assembled and soldered in a single cell fixture yielding discrete sub-assembles (cell assemblies). The cell assemblies are then placed on the receiver heat sink and the interconnects are then joined by welding or soldering using a robot. A top layer of transparent encapsulant is applied over the cells and interconnects.

A flow diagram of Option 3 can be found in Appendix B along with preliminary estimates of cost and performance for each Option 3 workstation. The preliminary estimates of throughput for the Option 3 baseline configuration is 1.72 receivers per hour and an equipment/tooling cost of $\$ 308 \mathrm{k}$. This option has the worst baseline cost efficiency, however when capacity is ramped to $2.46 \mathrm{MW}$, it has the best cost efficiency.

\subsection{Long Range Potential Benefits of Automation of the Receiver Assembly}

\subsection{General}

\section{Manufacturing Automation Potential}

Manufacturing costs will be minimized by the use of automation in three principal ways. First, labor content will be minimized. Tile SEA module cannot be produced at high volume and with low enough cost if the receiver is manufactured manually. Second, the rate of assembly(throughput) will be increased, reducing the overhead cost per module. Third, overall material yields will be highcr than with manual means. Specifically, 
manufacturing errors will be kept to a level much lower than error levels associated with manual methods. Cell treakage alone which would be expected to reach up to $3 \%$ in manual assembly shop conditions would cost as much as $\$ 1.5 \mathrm{M} / \mathrm{yr}$ at $100 \mathrm{MW} / \mathrm{yr}$ production rates. With automation of assembly and material handling, cell breakage in production could approach zero.

Because automation of the SEA receiver assembly processes will result in a very consistent product, the potential to have improved performance over manually produced receivers should not be underestimated. Automated processes under stable control will yield a better product because of reduced variation. Although one may make the distinction between an absolute performance improvement and one that is relative to a performance degraded by less consistent manufacturing, the effect is the same. Modules produced by automatic means are expected perform better than those manufactured by hand.

\section{Assembly and Soldering}

SEA intends to use robots for assembly of the receiver. The assembly time available is favorable for the use of robots at least up to the tens of $\mathrm{MW} / \mathrm{yr}$ production levels. For example if one robot were used to place each cell individually upon the receiver, 5.4 seconds could be allotted for each placement at a rate of $10 \mathrm{MW} / \mathrm{yr}$ on a standard three shift operation with $80 \%$ availability. The SEA receiver has been designed to be assembled using simple straight line motions *actuatable by low cost, modular rectilinear axis robots.

Many highly reliable, automatable soldering processes are available which could be transformed for application to the SEA cell interconnect soldering. Focused IR, IR oven, wave, and hot bar are primary process candidates. Careful selection of fluxing regimes will minimize flux residue effects. No-clean, water soluble, and other less active fluxes are being tested for use. Controlled atmosphere soldering environments can be employed. The capability to automatically solder in N2 or inert gasses could yield major quality and process control improvements.

\section{Encapsulation}

Partially cured adhesive films have been developed as a laminate for high performance jet aircraft transparencies. Consistent high quality partially cured films are available for encapsulation of the receiver in place of the materials now used. These unique films have been successful in initial tests at meeting the unusual requirements for a thin, void free, insulating layer between the cell and the heat sink. Further process development and testing will be required to discover assembly methods and to optimize the formulation for dielectric vs. heat transfer characteristics.

\section{Material Handling}

SEA intends to work with cell manufacturers to have SEA cells pre-sorted into matched groups and then loaded into magazines. The design of this material handling step can capture cell orientation at the cell suppliers IV test station and preserve the orientation in a manner compatible with SEA equipment. A material handling benefit that will reduce cost. 


\section{Process Monitoring}

Process monitoring is preferred over product inspection. A process monitoring and control strategy will focus on measuring and monitoring critical process parameters before and during process execution to insure product conformance. In those instances where post process inspection is required, it will be necessary to reduce the time to feedback information to the process to prevent a proliferation of manufacturing process errors.

Robust processes are desirable. Processes that are insensitive to rormally anticipated variations in cell, solder, encapsulant, and other input materials will be given careful consideration. Processes that can be easily controlled to adapt to material and environmental variations will also be considered even though implementation efforts might be greater.

\section{Long Range Benefits of Receiver Automation}

The most important long term benefit of receiver manufacturing automation is consistent conformance to design. Automation can provide a product that has maximum durability. Manual production methods are much more likely to introduce non conforming variation. Design for automation will be a key to capturing this benefit.

Automation can also provide the long term benefit of achieving the lowest possible cost of production at high volume.

A major strategic benefit arises from implementation of automation at the earliest possible time. If automatic methods are used early, in prototype and pilot production, then ramp-up can be can be adapted to the needs of SEA's customers in a highly responsive manner. Capacity can be stepped up one module at a time or by the rapid replication of modular workstations. This flexible market response capability could give SEA an important competitive edge.

\subsection{Option 1 Benefits, In Situ Receiver Assembly}

Robotic assembly and soldering can be done with low cost 3 axis modular robots. One or more robots could be configured in each assembly/solder workstation. It would be possible to increase assembly capacity in both robot sized and workstation sized increments. If identical robot models are used they would be completely interchangeable. Programs, tooling, and the robots could be arranged as needed so that throughput could be kept at near optimal levels.

The hot bar is fundamentally capable of a reliable and robust operation. The use of the hot bar in a manufacturing process provides several advantages; 1) is the relatively low cost of the system, 2) the flexibility of the heater bar itself requiring only a new heater bar be made when changes in the product design are changed, and 3) a weld head providing a controlled and uniformed pressure to the lead/cell contact area insuring lead coplanarity during soldering. .

Correct design and use of automatic material handling can improve flow, increase material yields, and reduce labor. The use of the heat sink as a platform for material transfer is being considered. Precision locating features could be designed into the heat sink to allow for direct mechanical interface with assembly and soldering equipment and for material transfer devices. The need for expensive handling and locating fixtures could be minimized. 


\subsection{Option 2 Benefits, Cell String Build on Receiver}

The two most prominent benefits of this option are first, that the cell assemblies can be readily accessible to solder, assembly and test equipment. Second, the cell string fixture concept is much more likely to be compatible with oven soldering, a benefit that could be critical if temperature tolerances become critical.

Another benefit is the potential to function test the entire cell string prior to placement onto the heat sink. This only becomes a benefit if quality problems and poor yields occur in assembly.

\subsection{Option 3 Benefits, Discrete Cell Assemblies Build}

Soldering of the cell interconnects prior to adhesion to the backside dielectric may allow for the sublimation of the flux and therefore prevent encapsulation of flux residue with the cell assembly. This may or may not be an important benefit.

Discrete cell assemblies can be tested for current matching purposes after the interconnects have been soldered. If yields through the soldering process are less than $100 \%$, damaged cells can be prevented from being assembled into receivers.

\subsection{Problems Associated with Receiver Assembly Process}

\subsection{General}

\section{Automation Start Up and Capacity Increase Problems}

SEA faces a fundamental problem associated with the implementation of automation for a new product. Automation start up is typically expensive and cápital intensive. Engineering and equipment costs can occur much faster with the introduction of automation than with the introduction of manual processing. Automation will ultimately be required to achieve profitability at the high rates of production necessary for profitability. Yet a high volume plant cannot be built as a first manufacturing facility without great technical risk. There is great financial risk associated with making a large capital investment in a new industry with a new product, particularly when recovery rates are uncertain. Because of the start up nature of SEA Corporation, cash will be difficult to manage and capital investment liabilities will be at risk. The technical problem of automation is inseparable from the financial problem of automation.

It is very undesirable to run prototype production using manual means. If the product and the manufacturing processes used are developed using manually controlled processes then the effort required to automate will become very large. The reason is that the processes used to manufacture the receiver by hand would be very different from automated processes. Human adaptability and knowledge will inevitably be employed to control manual processes. As the product develops with the application of human skill and adaptive processing, the transition to automation which must ultimately take place, is at best delayed, and more likely hindered by the need for major design changes and process changes at a time when the product is more mature. An appreciable portion of the large non-recurring engineering effort expended to develop the module as a product would actually occur again before automation is put in place. Manual pilot production can result in a competitive disadvantage. 
The SEA module is a new product and design changes are likely to occur during the introduction of the product. The need for continuous improvement of the product brought on by competition will motivate changes. Other forces at work to change the SEA product are the PVMaT and Concentrator Initiative programs. Changes in cell geometry and metalization could have a major impact on process requirements. Part specific tooling will be at risk. Valuable process equipment could be rendered useless. These are manufacturing problems that can be prevented, minimized, and solved by design.

\section{Receiver Manufacturing Automation Development Problems}

The fundamental technical problem associated with introduction of automation is the development of products and processes that are compatible with each other and automatable at low cost. Fortunately a wealth of process automation technology has been developed by the electronics industry that is compatible with the manufacturing of SEA receivers. Unfortunately, the SEA concentrating collector receiver is unique. The specific application of processes to new products with new physical characteristics introduces risk and requires new engineering effort. Soldering of solar cell joints is a unique soldering problem. There is no well understood general methodology for automatic soldering of solar cells. Other new processes will require the discovery and development of processing methods. Application of B-stage.film could be very difficult to handle and control. Specific receiver process automation problems are listed below. Generic automation problems are also discussed in section 4.5 below.

\section{Cell Interconnect Leads}

The SEA interconnect may be difficult to handle. It is thin and subject to plastic deformation by very small forces. Lead forming or bending may be required in the assembly and soldering area.

\section{Material Handling}

No major material handling problems are anticipated.

\section{Process Monitoring}

There are two general process development problems that will be encountered. Empirical process models will be needed for control and monitoring and sensors will be required for process observation. The soldering and encapsulation processes are the most complicated, the most critical to performance, and will require the greatest effort.

\subsection{Option 1 Problems, In Situ Receiver Assembly}

Assembly on the receiver offers flexibility in design changes because the use of part specific tooling is either eliminated or limited to very small and simple gripping devices. Different cells and /or leads are accommodated by changing the programming of the assembly robots. A properly designed hot bar soldering system would be widely adaptable to a variety of cell dependant thermal profiles. 


\subsection{Option 2 Problems, Cell String Build on Fixture}

The method of assembling the entire string of cells using an assembly fixture introduces significant risk and cost because of the extensive use of specialized tooling that would be required. Design changes are anticipated. Particularly, flexibility to use any of a number of cells now in development is needed. Minor changes in cell design can result in changes in all of the receiver manufacturing processes. A dependency on part specific tooling and fixturing should be limited until the production has proceeded beyond the pilot plant stage and until the module receiver design is foreseen to be stable enough to justify the anticipated tooling expense.

\subsection{Option 3 Problems, Discrete Cell Assembly Build}

One problem in achieving the Option 3 process flow is the integration of the diode into each cell assembly. Although the effort needed to achieve the diode integration or even the additional material costs associated with this integration may appear to be substantial, the total cost may be minimal compared to the manufacturing costs of assembling a diode string in production. The trade-offs between individual cell assemblies with diodes integrated, and separate diode strings will be clarified as process flow and workstation concepts develop.

\subsection{Generic Problems}

Soldering, bonding, process monitoring, encapsulation, etc., all of the problems mentioned above are problems that have generic forms that the entire PV industry will experience.

\section{Assembly and Soldering}

Soldering can be a very reliable and robust method of interconnection. Solder joints must be made consistently and reliably because of the requirement for durability. A soldering method which can be controlled to achieve the best possible joint should be used. Large expensive ovens which require all product to pass through serially can become bottlenecks. Downtime at such a station is essentially downtime for the entire line. If the soldering is done after the cells are attached to the heat sink, processing capability could be very limited. Cooling rates will be much slower than those with reflow methods.

\section{Encapsulation}

Because of the heat transfer requirements and electrical isolation, the encapsulation needed for the backside of the cell is unusual. This is a problem generic to a number of concentrator modules. Introducing the use of preformed adhesive films could improve quality because the film properties can be controlled very precisely at low cost. However, this is risky in that methods must be developed and automated to place and bond the film in a void free manner. The automatic application of sticky tape may present problems in material control and process control. Structured experimentation should be used to determine the important process control parameter setting. Off the shelf taping equipment might be adaptable. 


\subsection{Solution Approaches for Receiver Manufacturing Problems}

A concurrent engineering approach will be followed to discover and implement highly effective means of receiver manufacturing automation that are compatible with the financial environment at SEA, while also achieving major automation goals which support near term production requirements and provide a strategy for rapid production ramp-up. This approach will be much more effective than the traditional serial product development approach. Automation integration issues such as process monitoring, process control, assemblability, and material handling will be addressed while product and manufacturing equipment designs are most flexible - before production ramp up commences. By comparison, the concurrent integration effort required is expected to be much less costly and much more effective than the traditional integration effort.

The receiver, its manufacturing processes, process equipment, and the receiver production facility will be designed and developed concurrently. These efforts will take place in parallel and the developments will be interactive. The product design, processes selection, and manufacturing development are interdependent, therefore, success will require highly effective communication and teamwork among all of the manufacturing enterprise functions.

\section{Manufacturability Review}

Manufacturability reviews will be conducted frequently throughout the development of the module. The review provides a structure foum for the identifiction of potential design improvements to the reciever and its manufacturing methods and equipment.

As processes are selected, the receiver design will be continuously revewed to improve its compatibility with the selected processes. Design changes will be sought to improve all processes including material handling, inspection, flux applications and other secondary processes. Reduction in the number of parts required and the number of processing steps is expected.

\section{Process Development}

Every possible means of soldering, encapsulating, and assembling the receiver should be given some consideration. These potential processes will then be evaluated for use. Processes which survive the initial analytical screening will be tested further using experimental methods which will confirm the processes qualification for application to SEA's receivers.

Intial process screening will proceed with an emphasis on developing decision making information to be used in selecting a single primary process flow, rather than several options, as the basis for automation equipment development. Option 1 solder tests should be conducted as soon as possible to determine ther viability of soldering the backside solder joints while they are in intimate contact with the adhesive film. Backside film placement and bonding are equally critical. The fundamental viability of these processes must be established first.

Once the critical processes are selected, process equipment development can proceed through the use of parametric experimentation. Tape laminator, adhesive cure, soldering, and cell placement will probably require parameterization to determine the specific processing requirements of the SEA application. Process control and monitoring must be designed into the automation equipment. Process flexibility and adaptability will be more important considerations because the need to have the capability to incorporate 
product changes and other improvements. Quantified process requirements will be used to specify equipment performance requirements.

\section{Receiver Automation Conceptual Design Development}

\section{Simulation}

Simulation will be used to design the receiver assembly and soldering workstations. It is not anticipated that the tape laminating equipment and material handling equipment, including the specialized reciever indexing tables will require simulation. Modelling of the individual workstation components will begin as process decisions are made. Simulation will begin using preliminary estimates of process cycles and space requirements. As the processes are developed, the more accurate process cycle information will be incorporated in the simulation. All three of the current flow options appear to be restricted by the speed of he assembly robots. Graphic workstation simulations will be used to test the interactions of multiple robots operating each of the assembly work stations. Robot placement, motion control sequences, and cycle times can be analyzed and improved. The simulation and flow analysis can then be used in conjunction with economic models as an aid to designing and planning the factory.

The simulation effort will proceed concurrently with process development and prototyping efforts. When decisions are made to prototype any component of the receiver workstation, models will be developed to verify the prototype designs. As information is generated from process experimentations and prototype testing, the models will be changed accordingly. Equipment modularity will be simulated. Each modular equipment increment will be simulated to develop quantified estimates of throughput increments.

Robot motion optimization is expected to be of major importance in achieving cost/performance goals. Several different robots will be considered. Commercially available robots, as well as any promising custom designed robots will be modelled and simulated as needed to develop the best comceptual design of the receiver assembly workstation.

\section{Prototype Testing}

When no other suitable analytical or experimental means are available to verify process performance capability, prototype equipment will be required. Prototype testing of an automated robotic receiver workstation using the ARAWC system at ARRI (see attached capabilities document) along with vendor supplied demonstration equipment is an option. This capability allows for the development and debugging, or a complete major workstaion system/basic workstation controller development.

\section{Automated Receiver Line Implementation}

Automation of the most critical receiver manufactuing processes will be implemented as soon as possible. Modular, low cost robots, and modular process equipment, will be used in the less critical processes. This method of introducing automantion: to the most critical and difficult processes first, is directly contradictory to the typical approach used to introduce automation to an existing manufacturing plant. This unique approach is necessary because the long term survival of SEA is known to be dependant on sucessful automation.

The modular approach metntioned above will provide the most cost effective means of incremental capacity increase. The overall approach described above will prepare SEA 
with the cap. bility to respond quickly to market demand increses, and to respond quickly with receiver design and production improvement.

\subsection{Estimation of Cost and Duration of Receiver Automation Development Effort}

This estimate is for the effort required by outside organizations (ARRI) to work with SEA Corporation to develop the processes and conceptual design for automation required to assemble, solder and encapsulate the SEA receiver.

\subsubsection{Summary of Assumptions for Estimates}

\section{Manufacturability Review \\ -160 man hours \\ -no travel \\ -no other cost \\ -3 , eight hour review sessions}

Process development

-1820 man hours (2000 student)

-no equipment purchase costs included

-no travel

-some tooling/fixturing

-use of existing ARRI equipment as applicable

-SEA supplies materials

Automation Development - Simulation

-1170 man hours (500 student)

Automation Development - Prototype Workstation

-1180 man hours (500 student)

\section{General}

-total estimated cost $\$ 132,431.95$

-not an official quote - budgetary only

-duration six to nine months 
APPENDIX A

Page 11 


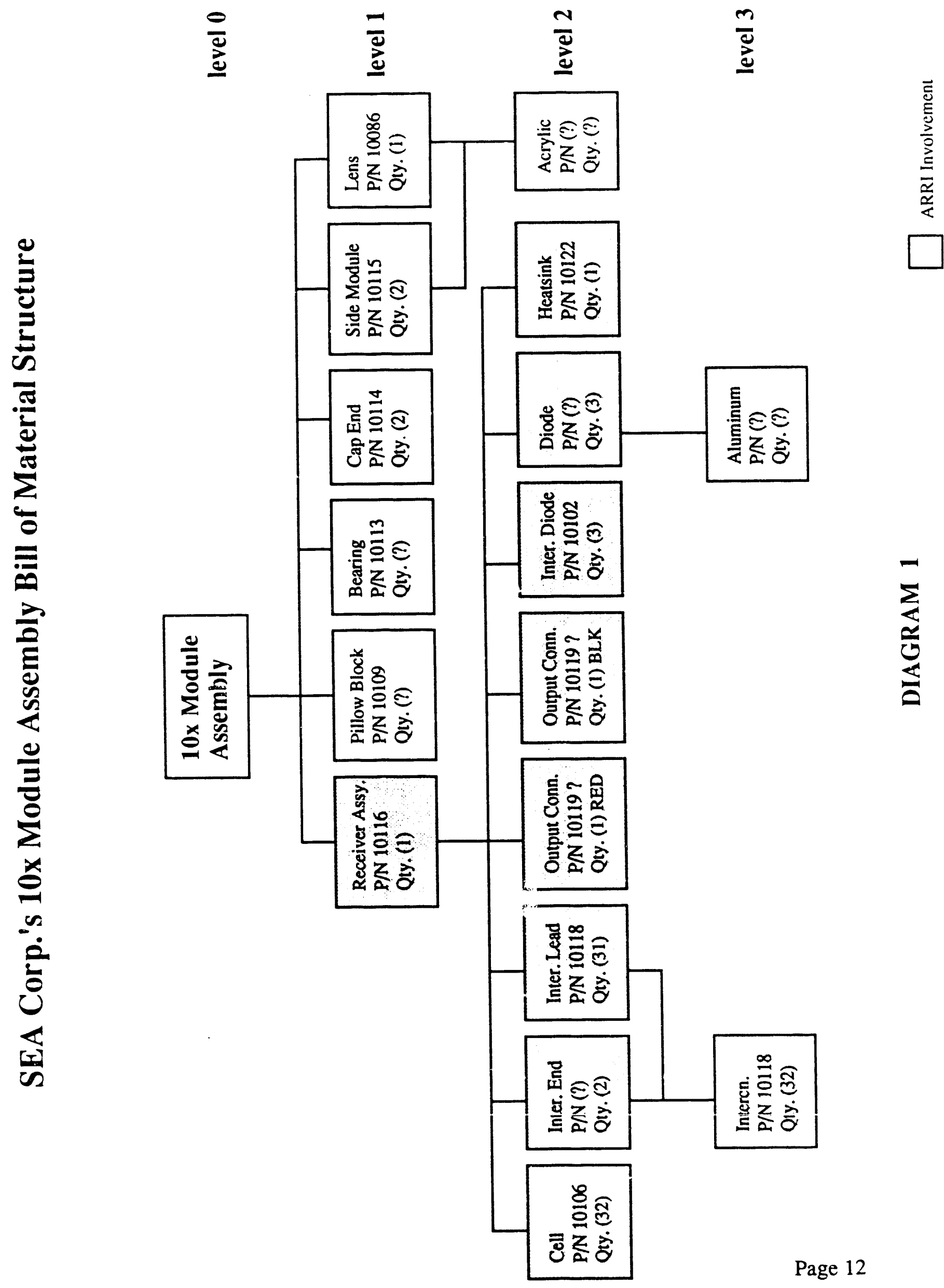


APPENDIX B

\section{Diagrams and Workstations for Three Flow Options}

For each option equipment and tooling costs are estimated. Additional integration and implementation costs could range from 1.5 to 2.0 times the equipment costs. The accuracy of these estimates is uncertain. Vendor quotes and workstation conceptual designs will provide a much more accurate estimation of cost and throughput relationships. 


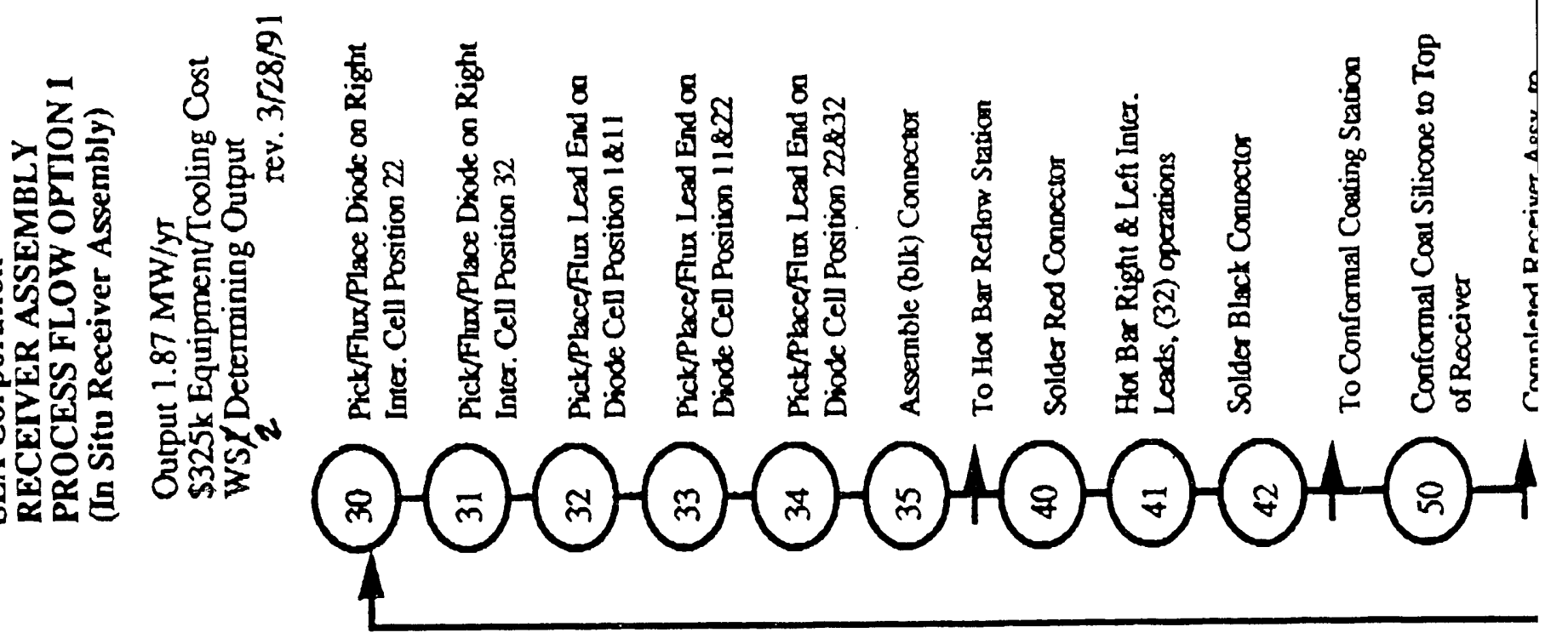

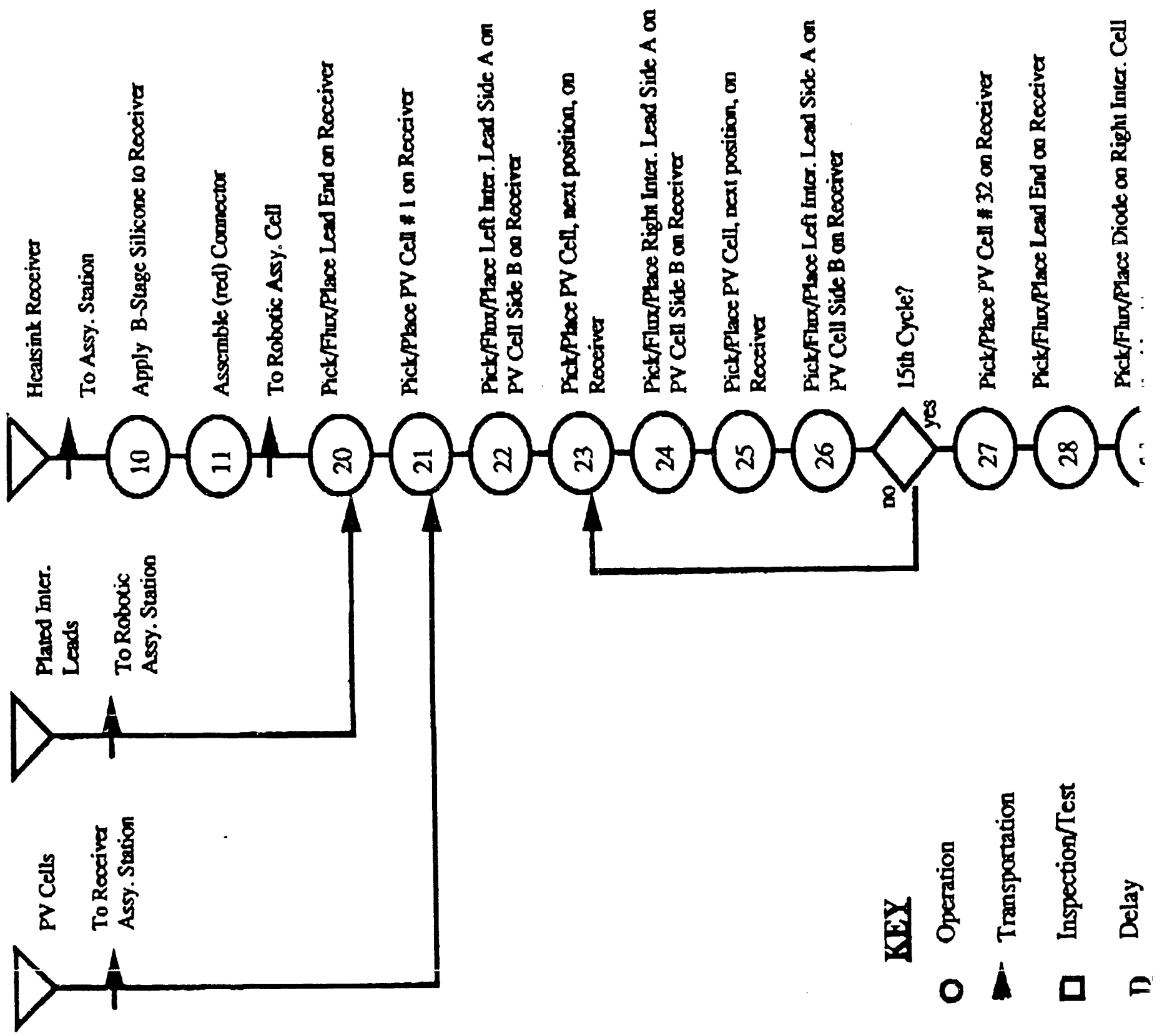




\section{Workstation Designs for Option 1 \\ In Situ Receiver Assembly}

Operation:Apply B-Stage Silicone to Receiver

\begin{tabular}{lllllr} 
Workstation No:1 & & & \\
Oper.\# & Operation & Machine & Aux. Equip. & $\mathrm{Hr} / \mathrm{Pc}$. & $\mathrm{Pc} / \mathrm{Hr}$ \\
10 & Apply B-Stage & Laminator & n/a & 0.0167 & 60 \\
11 & Assemble Rd Conn & n/a & n/a & 0.0042 & 240 \\
& \multicolumn{2}{r}{ Process time of WS1 to build (1) receiver $=$} & 0.0209 & 47.85
\end{tabular}

Equipment Cost:

a) Laminator- $\$ 50 \mathrm{k}$

b) Workstation Controller- $\$ 3 \mathrm{k}$

Total WS 1 equipment cost $=\$ 53 \mathrm{k}$

Labor:

a) (1) operator

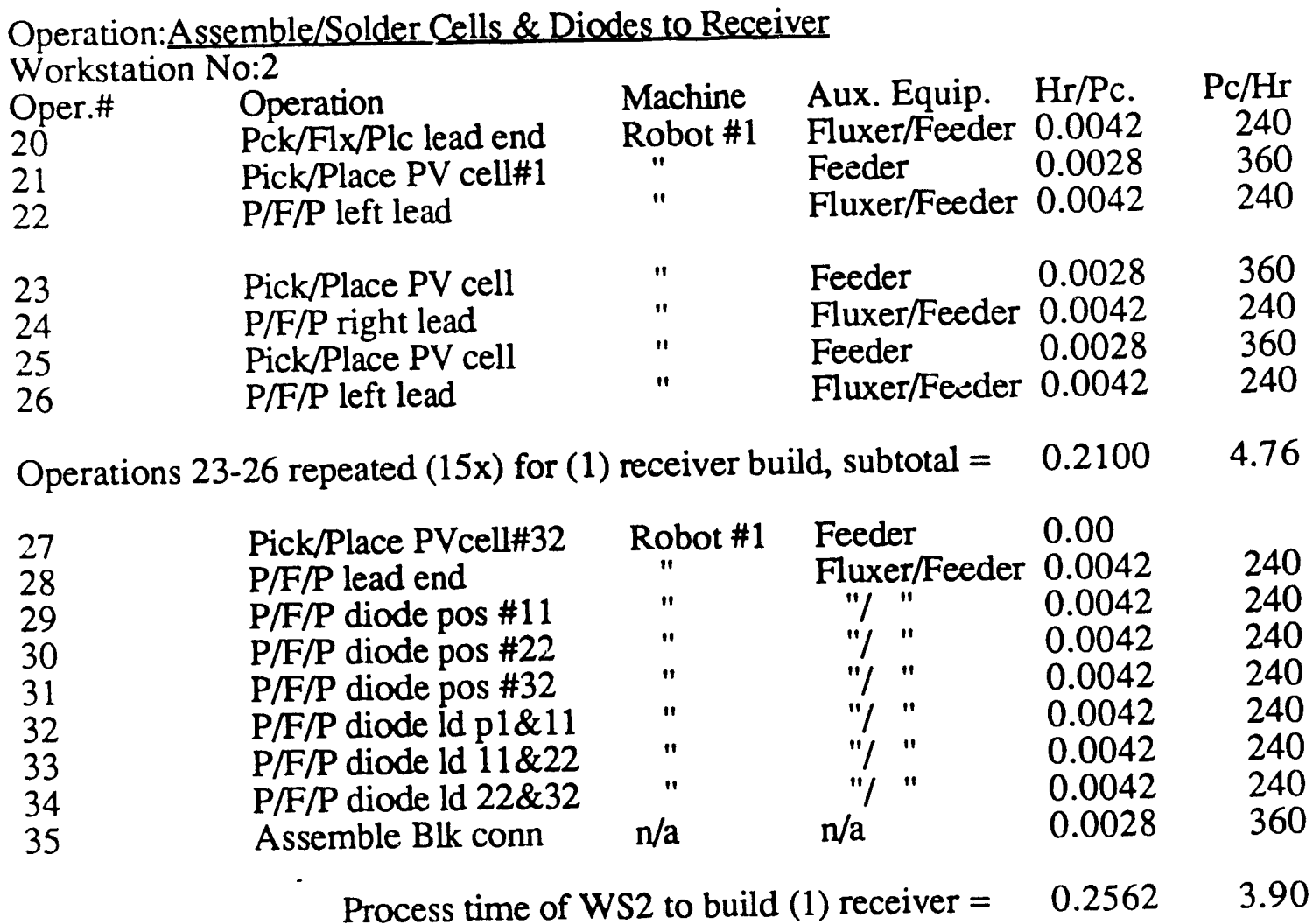

Equipment Cost:(design costs not included)

a) Robot- $\$ 20 \mathrm{k}$

b) Fluxer w/controller- $\$ 8 \mathrm{k}$

c) Feeders for cells, interconnects, diodes \& leads- $\$ 40 \mathrm{k}$

d) Indexing table- $\$ 25 \mathrm{k}$

e) Robot end effectors- $\$ 10 \mathrm{k}$ 
i) Tooling/fixturing- $\$ 10 \mathrm{k}$

g) Workstation controller- $\$ 3 \mathrm{k}$

Total WS2 equipment/tooling cost $=\$ 116 \mathrm{k}$

Labor:

a) (1) operator

Operation:Hot Bar Reflow Interconnect Lead to Cell

Workstation No:3

Oper.\#

40

41

Operation

Solder Rd connector

Hot bar R/L lead
Machine

$\mathrm{n} / \mathrm{a}$

Hot bar
Aux. Equip. $\mathrm{Hr} / \mathrm{Pc} . \quad \mathrm{Pc} / \mathrm{Hr}$

Solder iron $\quad 0.0000 \quad 000$

n/a

$0.0028 \quad 360$

Operation 41 repeated $(32 \mathrm{x})$ for $(1)$ receiver build, subtotal $=\quad 0.0896 \quad 11.16$

Solder Bk connector $\quad \mathrm{n} / \mathrm{a} \quad$ Solder iron $\quad 0.0000$

000

Process time of WS3 to build $(1)$ receiver $=\quad 0.0896 \quad 11.16$

Equipment Cost:

a) Hot bar on gantry robot- $\$ 50 \mathrm{k}$

b) Workstation controller- $\$ 3 \mathrm{k}$

Total WS3 equipment cost $=\$ 53 \mathrm{k}$

Labor:

a) (1) operator

Operation:Apply Silicone to Top of Receiver

Workstation No:4

Oper.\# Operation

50

Conformal coat Silic Spray coat n/a

Machine Aux. Equip. $\mathrm{Hr} / \mathrm{Pc} . \mathrm{Pc} / \mathrm{Hr}$

Process time of WS4 to build (1) receiver $=\quad 0.0833 \quad 12.00$

Equipment Cost:

a) Conformal Coating Machine- $\$ 100 \mathrm{k}$

b) Workstation controller- $\$ 3 \mathrm{k}$

Total WS4 equipment cost- $\$ 103 \mathrm{k}$

Labor:

a) (1) operator 


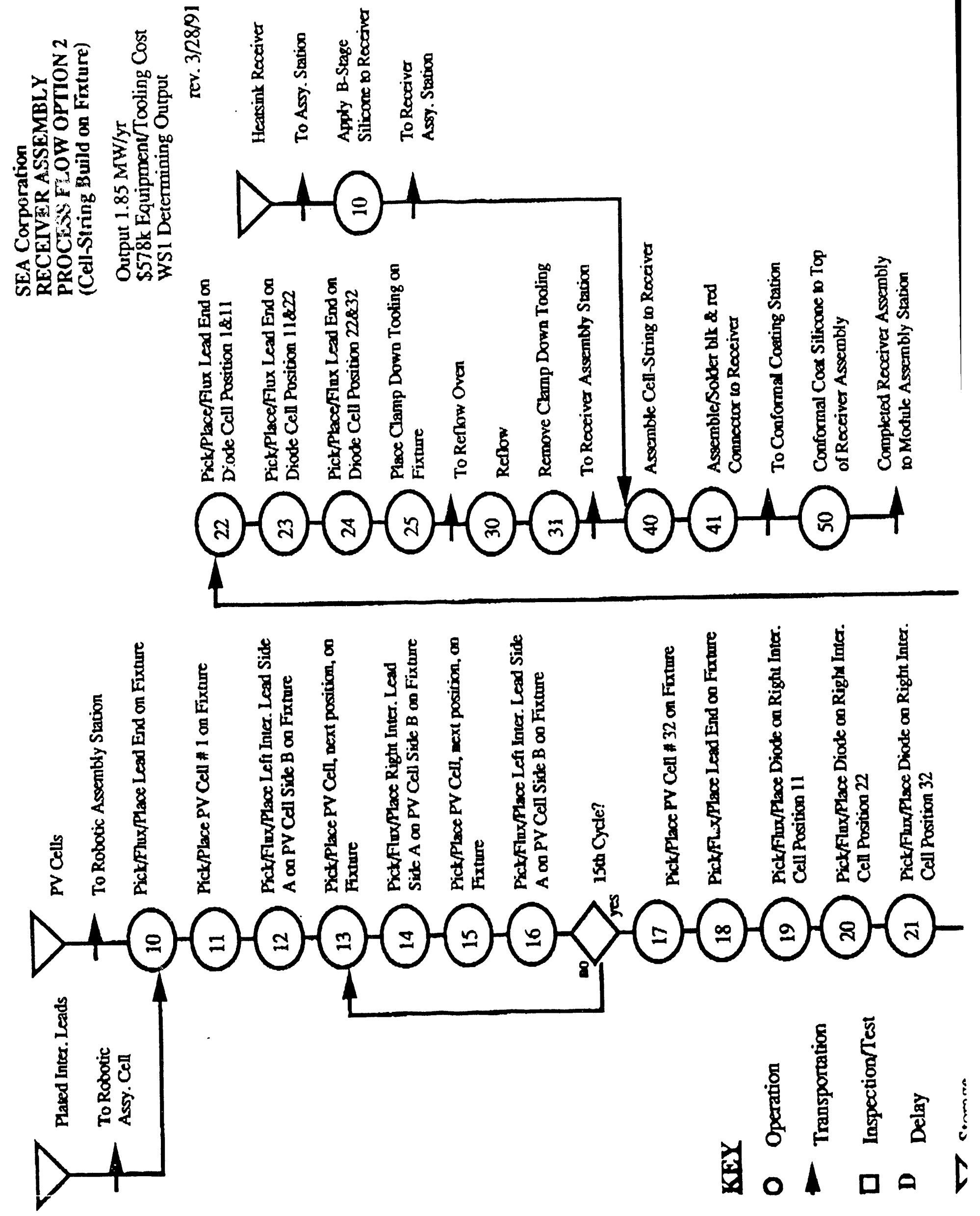

Page 17 


\section{Workstation Designs (Option2) \\ Cell String Build on Fixture}

Operation:Assemble/Solder Cells \& Diodes on Fixture

Workstation No:1

$\begin{array}{ll}\text { Oper.\# } & \text { Operation } \\ 10 & \text { Pck/Flx/Plc lead end } \\ 11 & \text { Pick/Place PV cell\#1 } \\ 12 & \text { P/F/P left lead } \\ 13 & \text { Pick/Place PV cell } \\ 14 & \text { P/F/P right lead } \\ 15 & \text { Pick/Place PV cell } \\ 16 & \text { P/F/P left lead }\end{array}$

$\begin{array}{lllr}\text { Machine } & \text { Aux. Equip. } & \mathrm{Hr} / \mathrm{Pc} . & \mathrm{Pc} / \mathrm{Hr} \\ \text { Robot \#1 } & \text { Fluxer/Feeder } & 0.0042 & 240 \\ " & \text { Feeder } & 0.0028 & 360 \\ " & \text { Fluxer/Feeder } & 0.0042 & 240 \\ & & & \\ " & \text { Feeder } & 0.0028 & 360 \\ " & \text { Fluxer/Feeder } & 0.0042 & 240 \\ " & \text { Feeder } & 0.0028 & 360 \\ & \text { Fluxer/Feeder } & 0.0042 & 240\end{array}$

4.76

360

240

240

240

240

240

240

240

180

Process time of WS1 to build $(1)$ receiver $=\quad 0.2590 \quad 3.86$

Equipment Cost:(design costs not included)
a) Robot- $\$ 20 \mathrm{k}$
b) Fluxer w/controller- $\$ 8 \mathrm{k}$
c) Feeders for cells, interconnects, diodes \& leads- $\$ 40 \mathrm{k}$
d) Indexing table- $\$ 25 \mathrm{k}$
e) Robot end effectors- $\$ 10 \mathrm{k}$
f) Solder Fixture- $\$ 10 \mathrm{k}$ each, (5) needed in production
g) Clamp down tooling- \$10k each,"
h) Workstation controller- $\$ 3 \mathrm{k}$

Total WS1 equipment/tooling cost $=\$ 206 \mathrm{k}$

Labor:
a) (1) operator

Operation:Reflow.Cell String in Oven

\section{Workstation No:2}

Oper.\#

30

31
Operation

Reflow

Remove Fixture
Machine IR Oven $\mathrm{n} / \mathrm{a}$ $\begin{array}{llr}\text { Aux. Equip. } & \mathrm{Hr} / \mathrm{Pc} . & \mathrm{Pc} / \mathrm{Hr} \\ \text { n/a } & 0.0833 & 12 \\ \text { Gloves } & 0.0167 & 60\end{array}$

Process time of WS2 to build (1) receiver $=\quad 0.1000 \quad 10.00$

Equipment Cost: 
a) IR Oven- $\$ 200 \mathrm{k}$

b) Workstation controller- $\$ 3 \mathrm{k}$

Total equipment cost $=\$ 203 \mathrm{~K}$

Labor:

a) (1) operator

Operation:Apply B-Stage Silicone to Receiver

Workstation No:3

Oper.\# Operation

10

Apply B-Stage

Machine

Aux. Equip. $\mathrm{Hr} / \mathrm{Pc} . \quad \mathrm{Pc} / \mathrm{Hr}$

Laminator $\mathrm{n} / \mathrm{a}$

$0.0167 \quad 60$

Process time of WS3 to build $(1)$ receiver $=0.0167 \quad 60.00$

Equipment Cost:

a) Laminator- $\$ 50 \mathrm{k}$

b) Workstation controller- $\$ 3 \mathrm{k}$

Total WS3 equipment $\operatorname{cost}=\$ 53 \mathrm{k}$

Labor:

a) (1) operator

Operation:Assemble Cell String to Receiver

Workstation No:4

Oper.\#

Operation

Assemble Cell String n/a

40

Ass/solder Bk\&Rd Con n/a

Aux. Equip. $\mathrm{Hr} / \mathrm{Pc} . \quad \mathrm{Pc} / \mathrm{Hr}$

Tooling $\quad 0.0125 \quad 80$

Solder Iron $\quad 0.0083 \quad 120$

Process time of WS4 to build $(1)$ receiver $=\quad 0.0208 \quad 48.08$

Equipment Cost:(does not include design cost)

a) Alignment tooling- $\$ 10 \mathrm{k}$

b) Workstation controller- $\$ 3 \mathrm{k}$

Total WS 4 tooling cost $=\$ 13 \mathrm{k}$

Labor:

a) (1) operator

Operation:Apply Silicone to Top of Receiver

Workstation No:5

Oper.\#

50
Operation

Conformal coat Silic

Process time of WS3 to build (1) receiver =
Machine Aux. Equip. $\mathrm{Hr} / \mathrm{Pc}$. $\mathrm{Pc} / \mathrm{Hr}$

$0.0833 \quad 12$

$0.0833 \quad 12.00$

Equipment Cost:

a) Conformal Coating Machine- $\$ 100 \mathrm{k}$

b) Workstation controller- $\$ 3 \mathrm{k}$

Total WS5 equipment cost $=\$ 103 \mathrm{k}$

Labor:

a) (1) operator 


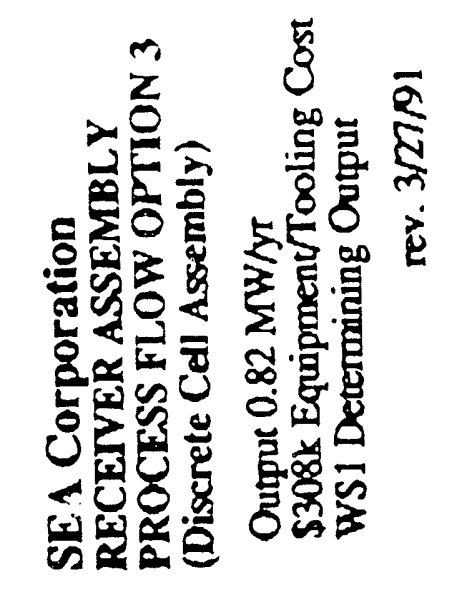

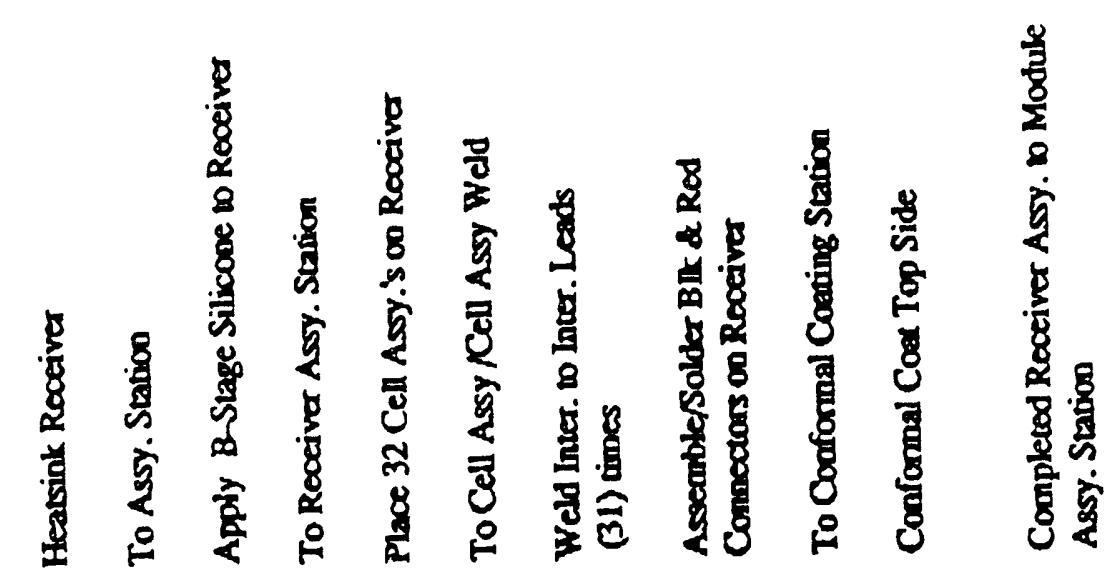

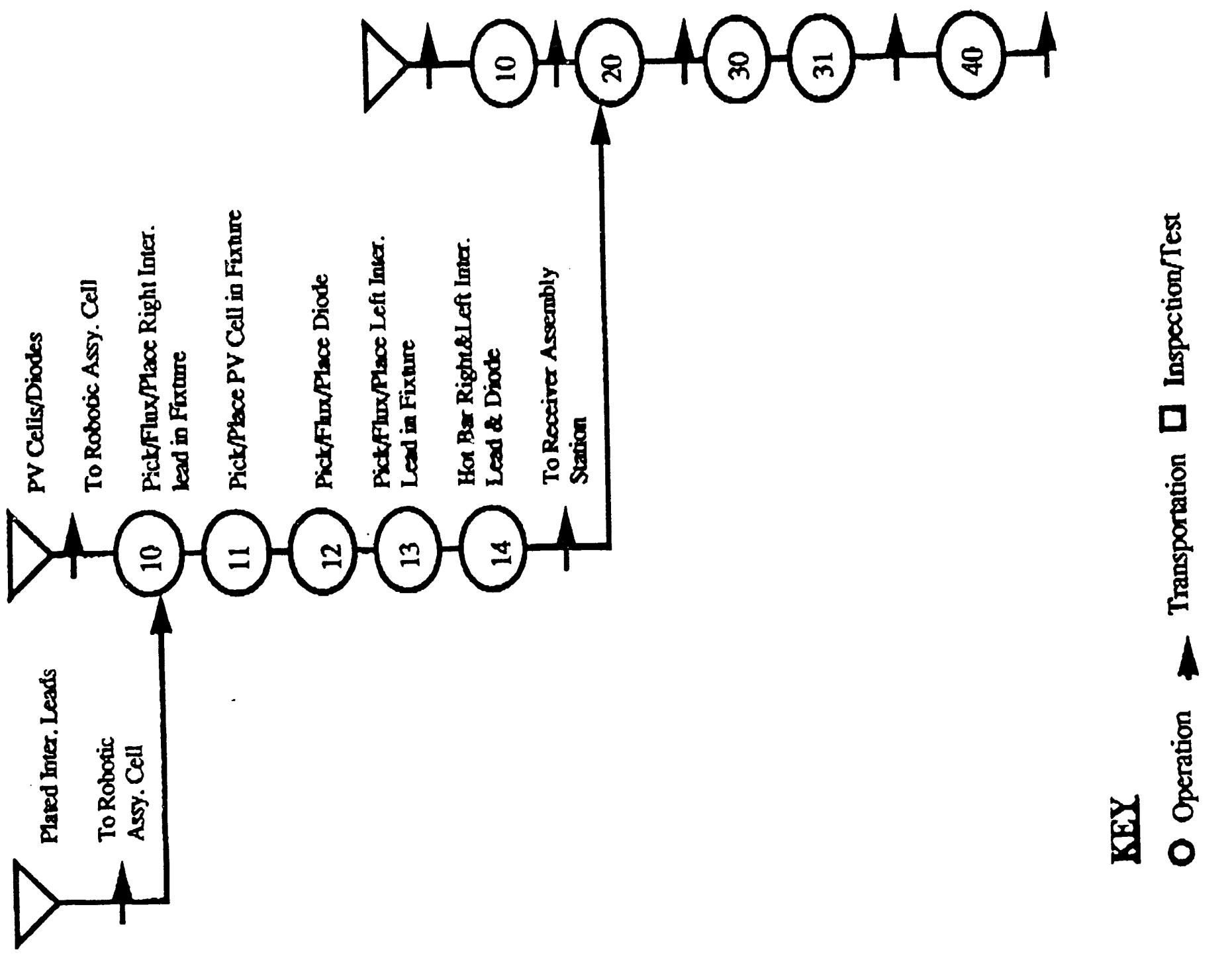




\section{Workstation Designs For Option 3 \\ Discrete Cell Assembly}

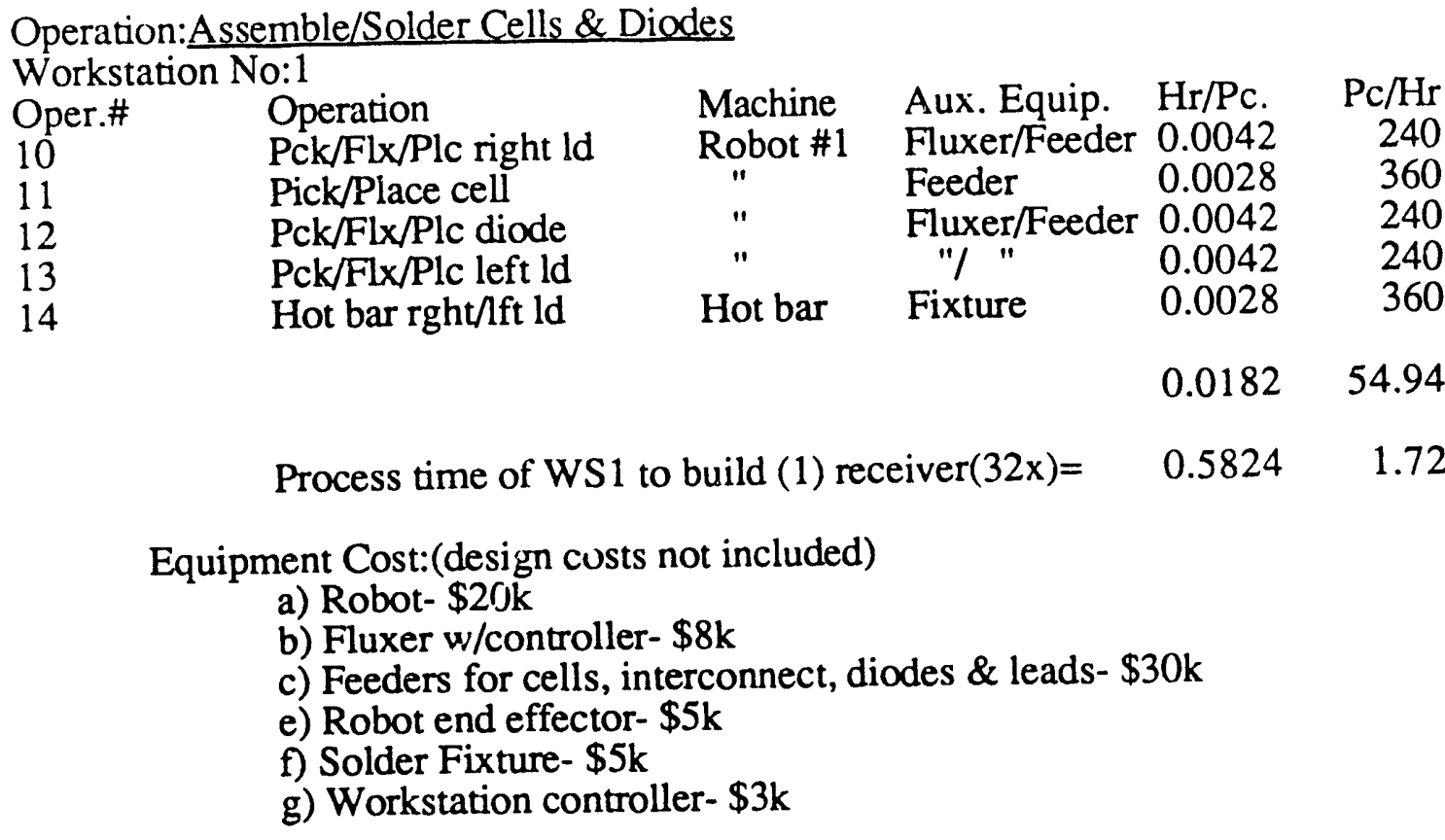

Total WS1 equipment/tooling cost $=\$ 71 \mathrm{k}$

Labor:

a) (1) operator

Operation:Apply B-Stage Silicone to Receiver

Workstation No:2

$\begin{array}{lllllr}\text { Oper.\# } & \text { Operation } & \text { Machine } & \text { Aux. Equip. } & \mathrm{Hr} / \mathrm{Pc} . & \mathrm{Pc} / \mathrm{Hr} \\ 10 & \text { Apply B-Stage } & \text { Laminator } & \mathrm{n} / \mathrm{a} & 0.0167 & 60\end{array}$

Process time of WS2 to build $(1)$ receiver $=0.0167 \quad 60.00$

Equipment Cost:

a) Laminator- $\$ 50 \mathrm{k}$

b) Workstation controller- $\$ 3 \mathrm{k}$

Total WS2 equipment $\operatorname{cost}=\$ 53 \mathrm{k}$

Labor:

a) (1) operator Operation:Assemble Cell Assemblies to Receiver

Workstation No:3

Oper.\#

20

Operation

Machine Aux. Equip. $\mathrm{Hr} / \mathrm{Pc}$

$\begin{array}{ll}\text { Robot \#1 End effector } & 0.0028 \\ \text { to build (1) receiver }(32 \mathrm{x})=0.0896\end{array}$

$\mathrm{Pc} / \mathrm{Hr}$

Place cell assy.

Process time of WS3 to build (1) receiver $(32 \mathrm{x})=0.0896 \quad 11.16$

Equipment Cost:

a) Robot- $\$ 20 \mathrm{k}$ 
b) End effector- $\$ 5 K$

c) Workstation controller- $\$ 3 \mathrm{k}$

Total WS 3 equipment/tooling cost $=\$ 28 \mathrm{k}$

Labor:

a) (1) operator

Operation: Weld Cell Assembly to Cell Assembly Interconnect leads

Workstation No:4

Oper.\# Operation

30

Weld lead to lead
Machine Aux. Equip. $\mathrm{Hr} / \mathrm{Pc} . \mathrm{Pc} / \mathrm{Hr}$

Ultrasonic $\mathrm{n} / \mathrm{a} \quad 0.0014 \quad 720$

Operation 30 repeated (31x) to build (1)receiver, subtotal= $\quad 0.0434 \quad 23.04$

31

Ass/solder Bk\&Rd con n/a

Solder iron $\quad 0.0000 \quad 000$

Process time of WS4 to build (1) receiver $=\quad 0.0434 \quad 23.04$

Equipment Cost:

a) Ultrasonic welder on gantry robot- $\$ 50 \mathrm{k}$

b) Workstation controller- $\$ 3 \mathrm{k}$

Total WS 4 equipment cost $=\$ 53 \mathrm{k}$

Labor:

a) (1) operator

Operation:Apply Silicone to Top of Receiver

Workstation No:5

Oper.\#

Operation

Machine Aux. Equip.

Spray coat $\mathrm{n} / \mathrm{a}$

$\mathrm{Hr} / \mathrm{Pc} . \quad \mathrm{Pc} / \mathrm{Hr}$

Conformal coat Silic

Process time of WS5 to build $(1)$ receiver $=\quad 0.0833 \quad 12.00$

Equipment Cost:

a) Conformal Coating Machine- $\$ 100 \mathrm{k}$

b)Workstation controller- $\$ 3 \mathrm{k}$

Total WS5 equipment cost $=\$ 103 \mathrm{k}$

Labor:

a) (1) operator 
APPENDIX C

\section{SEA PV SYSTEM DATA}

Concentration ratio

Module efficiency

Cell type

Cell efficiency

Heat sink material

Power output per mod

Aperture area

Assembly cost per module

Cells per mod

Lense extrusion rate

Current prod. capability

Lense material

lense efficiency

Production time
10:1

$15 \%$ (approximate)

$\mathrm{Si}-\mathrm{X}$, one sun

$16 \%$ (approximate)

0.032 " Al

100 watt, nominal

$10^{\prime \prime} \times 10^{\prime}(0.77 \mathrm{~m} 2)$

\$7.09 (@10,000 mod/yr), \$3.54(@100,000 mod/yr)

32

$34^{\prime \prime} / \mathrm{min}$.

$14 \mathrm{MW} / \mathrm{yr}$

acrylic expected

$90 \%$

$(50 \mathrm{wks} \times 8 \mathrm{hrs} / \mathrm{shift} \times 3$ shifts/day $\times 5$ days/wk $\times 0.8)=$ $4800 \mathrm{hr} / \mathrm{yr}$

0.48 hr/mod @1MW/yr

$54 \mathrm{sec} / \mathrm{cell} @ 1 \mathrm{MW} / \mathrm{yr}$ 


\title{
Photovoltaic Module Manufacturing Research and Development Capabilities of The Automation \& Robotics Research Institute(ARRI)
}

\author{
March 1991
}

\section{Introduction}

The Automation \& Robotics Research Institute (ARRI) is located in the RiverBend business park in Fort Worth. An integral part of The University of Texas at Arlington(UTA), ARRI was created to help strengthen the industrial base of the United States through the introduction of advanced manufacturing processes. After receiving $\$ 5$ million in pledges and 18.5 acres of land from some 30 corporate and private donors, ARRI began operations in 1987 in a new 48,000 square foot facility. By partnering with industry, and providing a state-of-the-art manufacturing research capability, the Institute now acts as a catalyst in assisting companies to reach higher levels of manufacturing efficiency.

ARRI is an applied research institute focusing on automated manufacturing, augmented by activities in software engineering, robotic controls and artificial intelligence for manufacturing. The Institute employs approximately 25 full-time professionals, 15 UTA faculty members and 10 UTA faculty associates. More than 50 graduate and undergraduate students in UTA engineering and business departments also work at ARRI.

ARRI's prime objective is to combine the resources of UTA, the Fort Worth/Dallas communities and relevant industries to facilitate the introduction of new manufacturing technologies into the American workplace. This is accomplished through mutual applied research and technology transfer. The result of ARRI's contribution to the manufacturing process is improved efficiency, lower product costs and highly trained employees.

The Automation \& Robotics Research Institute is dedicated to advancing our customers toward world class manufacturing. Since opening in 1988, we have worked with many manufacturing companies large and small to develop and apply automation technologies. We now have the staff and engineering tools that include: a process automation laboratory; many computer automated simulation and design systems, and a robotic workstation development system. From conceptual design through manufacturing system prototyping we focus our capabilities on the rapid and effective development of manufacturing solutions.

ARRI receives approximately $\$ 1$ million annually from the State of Texas to fund research activities. Private companies like American Airlines, Bell Helicopter, IBM, E-Systems, General Dynamics, General Motors, LTV, Lennox Industries, Texas Instruments, Southwestern Bell Telephone, Tandy Corporation and many others also fund the institute through their yearly membership dues and contracts.

\section{ARRI Capabilities}

ARRI is equipped with the tools and personnel needed to solve complex manufacturing problems. Both users and suppliers of automation equipment benefit from ARRI's unique capabilities. Thicse capabilities include: 


\section{HUMAN SKILLS}

Experienced, dedicated and highly motivated manufacturing professionals can rapidly prototype manufacturing systems using ARRI's unique modular manufacturing hardware and software.

ARRI engineers can quickly develop and analyze robotic workstation concepts and designs, as well as provide visually graphic CAD-based dynamic simulations. Working models of systems are no problem for ARRI's staff, who frequently demonstrate prototype systems for Institute customers in one of the many manufacturing laboratories.

ARRI's professional staff, along with faculty and students from UTA, has the ability to apply specific knowledge acquisition methodologies to acquire and document the important expertise and knowledge relevant to manufacturing applications.

\section{EQUIPMENT AND SOFTWARE RESOURCES}

A host of powerful, fast computing systems are incorporated into Institute projects, giving ARRI the capability of solving even the most complex of manufacturing problems.

ARRI has brought together a number of advanced software tools for use in its laboratories. Institute personnel are highly trained on these software programs, and frequently host seminars and continuing education courses to teach specific software techniques to customers.

The Institute has brought together millions of dollars worth of state-of-the-art automation equipment with the capability of iterally hundreds of functions. Just a few of those functions include:

- Precision assembly of many types of components by robots,

- Graphical simulation and design using Institute computer systems,

- Materials handling,

- Robotic vision, and

- Reverse engineering,

- Part/model fabrication.

- Automated inspection and surface finishing,

- Abrasive waterjet cutting of difficult-to-machine materials,

\section{MANUFACTURING SYSTEMS}

The Autornatically Reconfigurable Assembly Work Cell (ARAWC) is a modular highly flexible system for electronic and mechanical assembly. Cell and process control software is modular allowing for rapid high level data integration with $C A D$ functions and with computer integrated enterprise functions such as scheduling, material ordering, and process planning. ARAWC process equipment is mechanically modular. Robot tools and process stations are modular and transportable allowing for the physical reconfiguration of the cell. The ARAWC can be used both for prototype production testing and for assembly automation research. 
ARAWC applications are designed using event, control and graphical simulation systems to verify performance before construction. This combined simulation capability enabled a much more rapid implementation of the ARAWC by allowing the staff and faculty to correct problems in component interfaces, layout and programing before hardware was installed.

A business process modelling methodology has been developed to facilitate understanding small business operations. Unce complete, the methodology can be used to assist small companies in improving operations from the factory floor all the way to accounting systems.

\section{Photovoltaic Manufacturing_R\&D at_ARRI}

Through technology transfer activities, joint research and development projects with industry, and through consulting contracts, the ARRI staff have become broadly familiar with many module designs and the manufacturing practices and requirements of the PV industry. Our capabilities and experience in the automation of electronics assembly processes have proven to be very useful for PV module assembly automation development. Most of our efforts in PV manufacturing have been in the development of module assembly automation. Recently we have begun to investigate the use of robots and abrasive waterjet cutting to solve cell fabrication problems.

Automated assembly will be a requirement for achieving the full economic benefit of labor avoidance in large scale PV system production. The reduction of high manufacturing labor costs when producing photovoltaic modules through automation is critical to achieve affordable large scale solar power plants. When manual assembly methods are used, PV modules cost far too much because of the relatively large labor content, which may exceed 25 percent. When automation is used, labor content will be far less that of manuallyproduced modules. More importantly, automation of module assembly will be critical to achieving the quality and consistency needed to assure durability in the field.

For most PV manufacturers, ultirnate success depends upon achieving high rates of production. Automation is an assumption. It is assumed that it will be there when needed. For many PV manufacturers automation start-up is will be a major technical and financial risk. ARRI can reduce the risk.

\section{CONCURRENT ENGINEERING APPROACH}

There is a tendency to take a classical step by step approach to developing the PV module as a product. A concurrent engineering approach is suggested which can improve the design to market response time. Design for automation principles can be applied to improve manufacturing efficiency.

At ARRI the module as jembly automation approach is to design work with the PV design engineer to design the product and its manufacturing processes simultaneously. In this way many manufacturing problems may be identified early and solved by design. Solutions are then verified through analysis, simulation and/or prototype testing. Economic models developed by ARRI can be applied to develop decision making information based on business plans and production requirements. This approach can drastically reduce response time when production must be stepped or ramped up because systems can be developed quickly and effecively. 


\section{PROCESS DEVELOPMENT AND INTEGRATION}

PV module manufacturing is concerned primarily with assembly, interconnection, encapsulation, and fabrication processes. The selection and application of these processes should begin while the module design is being developed. Process reliability, robustness and controllability can be improved by designing module features that are compatible with selected processes.

Several PV manufacturing process applications have been developed in the ARRI Process and Manufacturing Laboratories. These are:

Robotic interconnect pretinning,

Automatic computer vision based gridline location,

Encapsulation insert molding,

Hot-Bar interconnect soldering,

Module-ready cell mounting package assembly,

Automatic precision optical rubber molding

Statistical design of experiments techniques are used for process parameterization and design. Process parameterization is the formal study of the relationship between controllable manufacturing process parameters and the observable characteristics of the process output. The objective of process parameterization is to determine, through industrial experimentation, the process parameter "settings" necessary to achieve the optimum process output. For example, through parametric experimentation it was discovered that the thickness of solder deposited in the pretinning process mentioned above is controlled largely by the rate at which the interconnect is withdrawn from the molten solder. Parametric experiments are a very useful tool in design of automated workstations. It is critical to establish that a process works reliably for a specific application, and that a particular set of equipment can achieve the desired result in terms of process quality. In the case of the pretinning process in the withdrawal rates requirements translate to robot motion performance specifications.

Statistical Process Control (SPC) is a decision making technology that uses statistics to evaluate the variation of the manufacturing process. The objective of SPC is to ensure that acceptable levels of product quality be achieved and maintained at a reasonable cost. This objective is accomplished by monitoring and controlling processes and product

conformance. Together process parameterization and SPC can yield powerful process control tools.

\section{PROTOTYPE MANUFACTURING SYSTEMS}

One of the best methods of reducing the technical risk of automation integration is through prototyping. Often there are specific processes that cannot be determined to be automatable by analytical means. A mock-up of the workstation concept that includes a prototype of the critical processes usually produces valuable design information. At ARRI processes are routinely prototyped and tested as part of a system design. The silicone encapsulation molding system mentioned above was developed first by testing critical mold release methods through prototype before the more costly "bench" mold was fabricated. Once a prototype has been built and tested, a production ready machine can be modelled, analyzed, simulated and designed rapidly and efficiently. 
Processes never before applied to PV manufacturing are often candidates for prototyping before production equipment is designed and built. An example is the new optical molding process conceived at ARRI to mold precision optical elements directly onto the top side of a crystalline silicon PV cell. The prototype is now being used to parameterize the precision molding process. This molding system is an example of a relatively expensive system that would be replicated several times for production. Throughput and quality improvements discovered in prototye testing can have huge payback potential.

As part of a research project funded by the Texas Higher Education Coordinating Board, a prototype robotic work cell has been built based using the ARAWC concept. It is capable of producing the photovoltaic cell assemblies for a concentrating collector automatically. Two robots pretin interconnects, then assemble interconnects, cells, and diodes, and then solder the assembly together.

\section{DESIGN OF MODULE MANUFACTURING AUTOMATION SYSTEMS}

A conceptual design for a complete work cell, shop, or factory to build any component or all of a PV module should begin as soon as the decision is made o develop a PV product. A process flow analysis gives an essential top down view of the overall processing requirements for a factory. As the processes are selected and tested and as the PV module design develops, the process flow can be developed in more detail. Individual equipment needs and workstation needs can be developed. As processes are parameterized and tested process time and equipment cost and space requirements can be developed. Material handling requirements can be defined.

ARRI's discrete event simulation capabilities can be used to evaluate the throughput capability of a particular design or scenario. Our CAD based graphic simulation capabilities can be used to develop detailed designs of robotic work cells. Tooling designs, cell layouts, process cycles can be simulated with remarkable precision. The designer can very rapidly adjust the configuration of the cell to test the effects of changing the number of robots, the sequence of assembly, the location of a fixture, and other design variables. The result is a better automation system design, in less time.

$A R R I$ is not in the business of building and selling factory equipment. We seek to provide the best solutions to PV manufacturing automation problems. A well conceived factory concept with automation and other processing work station requirements fully and accurately defined is the best basis for implementation. Both the PV manufacturer and the equipment and service suppliers will benefit. Both will have a better understanding of production requirements and both will be able to work more efficiently and at significantly reduced risk.

\section{A SHARED PRODUCTION FACILTY}

Using the ARAWC flexible assembly system, we currently have the capability to solder and assemble PV cell assemblies. We are also currently investigating the possibility of operating shared manufacturing facilities to more broadly address the mechanical assembly needs electronic product manufacturers.

The potential benefits of a shared manufacturing automation facility could be very important to PV manufacturers. Automation could be accessed immediately with no capital investment. Automation equipment suppliers could have an opportunity to have more applications developed that would use their equipment. The transition to high volume production could be accelerated, manual production could be largely bypassed. 


\section{Conclusion}

Our goal is to advance our customers toward world class manufacturing, we the goal of U.S. preeminence in $2 . \mathrm{mmercial}$ photovoltaics. To this end ARRI is positioned to support the development of manufacturing automation by teaming with PV manufacturers as products are developed and commercial markets expand. We strive to develop and deliver effective automation solutions quickly through the application of a unique set of skills and tools so that the PV manufacturers we work with can be the most competitive. 


\begin{tabular}{|c|c|c|c|}
\hline $\begin{array}{l}\text { Document Control } \\
\text { Page }\end{array}$ & $\begin{array}{l}\text { 16. NREL Roport No. } \\
\text { NREL/TP-214-4479 }\end{array}$ & $\begin{array}{l}\text { 2. NTIS Accession No. } \\
\text { DE92001151 }\end{array}$ & 3. Recipient's Accession No. \\
\hline \multirow{2}{*}{\multicolumn{3}{|c|}{$\begin{array}{l}\text { 4. Title and Subtitle } \\
\text { Cost Effective Manufacturing of the SEA 10X Concentrator Array }\end{array}$}} & $\begin{array}{l}\text { 5. Publication Date } \\
\text { November } 1991\end{array}$ \\
\hline & & & 6. \\
\hline \multicolumn{3}{|c|}{$\begin{array}{l}\text { 7. Author(s) } \\
\text { N. Kaminar, J. McEntee, D. Curchod }\end{array}$} & 8. Performing Organization Rept. No. \\
\hline \multirow{2}{*}{\multicolumn{3}{|c|}{$\begin{array}{l}\text { 9. Performing Organization Name and Address } \\
\text { Solar Engineering Application Corporation } \\
2010 \text { Fortune Drive, Suite } 102 \\
\text { San Jose, California } 95131\end{array}$}} & $\begin{array}{l}\text { 10. Project/Task/Work Unit No. } \\
\text { PV150101 }\end{array}$ \\
\hline & & & $\begin{array}{l}\text { 11. Contract (C) or Grant (G) No. } \\
\text { (C) XC-1-10057-21 } \\
\text { (G) }\end{array}$ \\
\hline \multirow{2}{*}{\multicolumn{3}{|c|}{$\begin{array}{l}\text { 12. Sponsoring Organization Name and Address } \\
\text { Nationai Renewable Energy Laboratory } \\
1617 \text { Cole Boulevard } \\
\text { Golden, Colorado } 80401-3393\end{array}$}} & $\begin{array}{l}\text { 13. Type of Report \& Poriod Covered } \\
\text { Technical Report }\end{array}$ \\
\hline & & & 14. \\
\hline \multicolumn{4}{|c|}{$\begin{array}{l}\text { 15. Supplementary Notes } \\
\text { NREL Technical Monitor: R. Mitchell }\end{array}$} \\
\hline \multicolumn{4}{|c|}{$\begin{array}{l}\text { This report describes a low-cost, mass-producible } 10 \mathrm{X} \text { concentrator system that has been claimed to produce } \\
\text { electricity at } \$ 0.04 / \mathrm{kWh} \text {. It details changes in manufacturing techniques that could produce a concentrator system } \\
\text { at a selling price of } \$ 0.71 / \mathrm{W} \text {. (A simple design and a minimum number of parts and manufacturing steps reduced } \\
\text { production costs.) Present production techniques, changes to improve these techniques, impediments to changes, } \\
\text { and solutions to the impediments are described. This } 10 \mathrm{X} \text { concentrator system uses available components and } \\
\text { manufacturing processes and one-sun solar cells in conjurction with inexpensive plastic lenses to generate about } \\
\text { eight times the amount of electricity normally produced by these cells. }\end{array}$} \\
\hline \multicolumn{4}{|c|}{$\begin{array}{l}\text { 17. Document Analysis } \\
\text { a. Descriptors } \\
\text { concentrators ; arrays ; photevoltai } \\
\text { b. Identifiers/Open-Ended Terms }\end{array}$} \\
\hline \multirow{2}{*}{\multicolumn{2}{|c|}{$\begin{array}{l}\text { 18. Availability Statement } \\
\text { National Technical Information Service } \\
\text { U.S. Department of Commerce } \\
\text { 5285 Port Royal Road } \\
\text { Springfield, VA } 22161\end{array}$}} & & $\begin{array}{l}\text { 19. No. of Pages } \\
103\end{array}$ \\
\hline & & & $\begin{array}{l}\text { 20. Price } \\
\text { A06 }\end{array}$ \\
\hline
\end{tabular}

Form No. 0069E (6-30-87) 

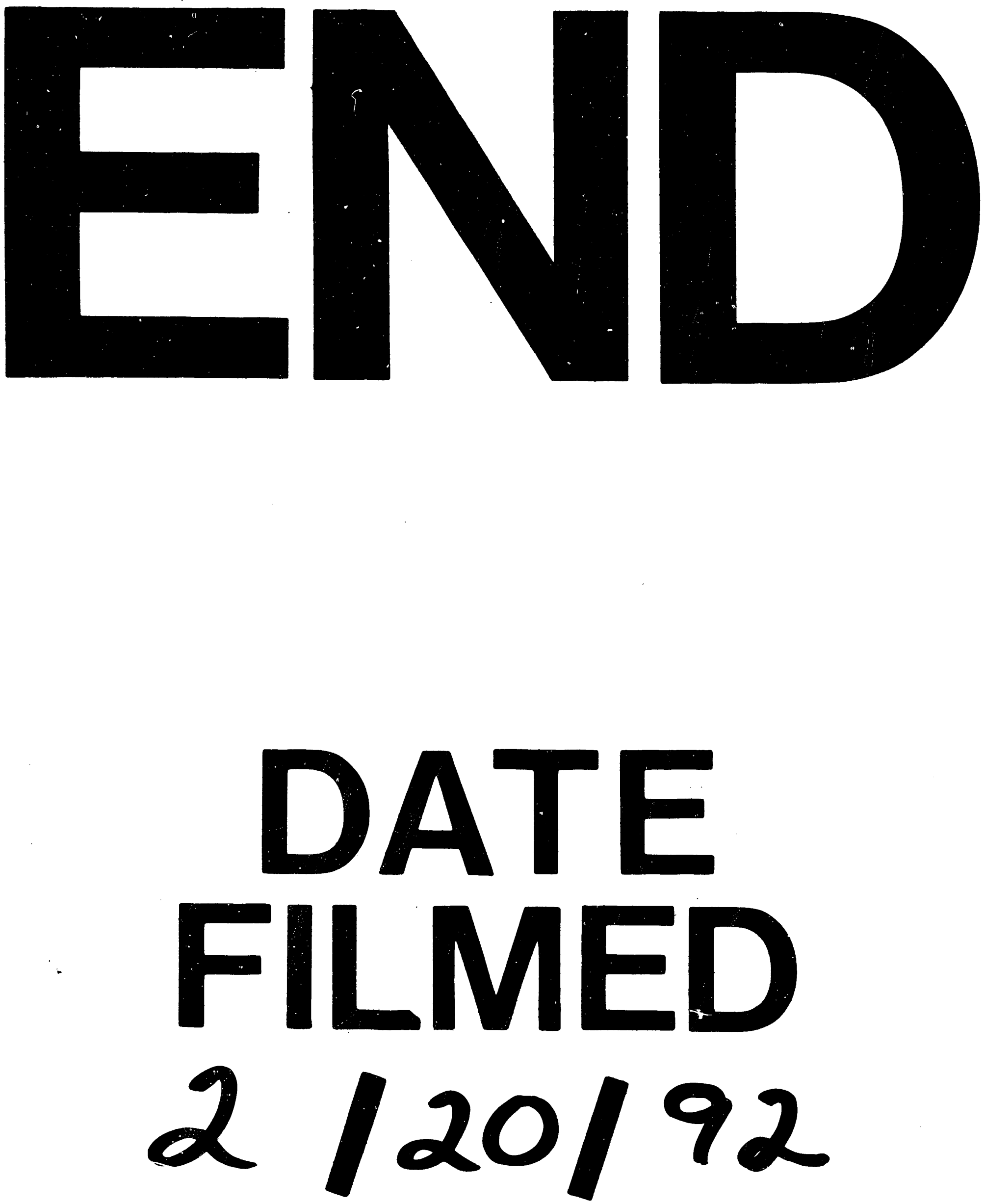

1 
